\title{
Methyl $\beta$-D-galactopyranoside esters as potential inhibitors for SARS-CoV-2 protease enzyme: synthesis, antimicrobial, PASS, molecular docking, molecular dynamics simulations and quantum computations
}

\author{
Md R. Amin ${ }^{1} \cdot$ Farhana Yasmin ${ }^{1} \cdot$ Sujan Dey ${ }^{2} \cdot$ Shafi Mahmud $^{3} \cdot$ Md A. Saleh ${ }^{3} \cdot$ Talha B. Emran $^{4} \cdot$ Imtiaj Hasan $^{5}$. \\ Sultana Rajia ${ }^{6} \cdot$ Yukiko Ogawa $^{7} \cdot$ Yuki Fujii $^{7} \cdot$ Masao Yamada $^{8} \cdot$ Yasuhiro Ozeki $^{8} \odot$ - Sarkar M. A. Kawsar ${ }^{1}$
}

Received: 5 October 2021 / Revised: 21 December 2021 / Accepted: 29 December 2021 / Published online: 17 January 2022

(c) The Author(s), under exclusive licence to Springer Science+Business Media, LLC, part of Springer Nature 2022

\begin{abstract}
Carbohydrate esters are significant in medicinal chemistry because of their efficacy for the synthesis of biologically active drugs. In the present study, methyl $\beta$-D-galactopyranoside (MGP) was treated with various acyl halides to produce 6-O-acyl MGP esters by direct acylation method with an excellent yield. To obtain newer products for antimicrobial assessment studies, the 6-O-MGP esters were further modified into 2,3,4-tri- $O$-acyl MGP esters containing a wide variety of functionalities in a single molecular framework. The chemical structures of the newly synthesized compounds were elucidated by analyzing their physicochemical, elemental, and spectroscopic data. In vitro antimicrobial testing against five bacteria and two fungi and the prediction of activity spectra for substances (PASS) revealed that these MGP estes have promising antifungal functionality compared to their antibacterial activities. The antimicrobial tests demonstrated that the compounds 3 and 10 were the most potent against Bacillus subtilis and Escherichia coli strains, with the minimum inhibitory concentration (MIC) values ranging from $0.352 \pm 0.02$ to $0.703 \pm 0.01 \mathrm{mg} / \mathrm{ml}$ and minimum bactericidal concentration (MBC) values ranging from $0.704 \pm 0.02$ to $1.408 \pm 0.04 \mathrm{mg} / \mathrm{ml}$. Density functional theory (DFT) at the B3LYP/3-21G level of theory was employed to enumerate, frontier orbital energy, enthalpy, free energy, electronic energy, MEP, dipole moment which evaluated the effect of certain groups (aliphatic and aromatic) on drug properties. They discovered that all esters were more thermodynamically stable than the parent molecule. Molecular docking is performed using AutoDock Vina to determine the binding affinities and interactions between the MGP esters and the SARS-CoV-2 main protease. The modified esters strongly interact with the prime Cys145, His41, MET165, GLY143, THR26, and ASN142 residues. The MGP esters' shape and ability to form multiple electrostatic and hydrogen bonds with the active site match other minor-groove binders' binding modes. The molecular dynamics simulation validates the molecular docking results. The pharmacokinetic characterization of the optimized inhibitor demonstrates that these MGP esters appear to be safer inhibitors and a combination of in silico ADMET (absorption, distribution, metabolism, excretion, and toxicity) prediction and drug-likeness had promising results due to their improved kinetic properties. Structure activity relationships (SAR) study including in vitro and silico results revealed that the acyl chain, palmitoyl $(\mathrm{C} 16)$ and 4-chlorobenzoyl $\left(4 . \mathrm{ClC}_{6} \mathrm{H}_{4} \mathrm{CO}-\right)$ in combination with sugar were found the most potential activates against human and fungal pathogens. After all, our comprehensive computational and statistical analysis shows that these selected MGP esters can be used as potential inhibitors against the SARS-CoV-2.
\end{abstract}

Keywords Methyl $\beta$-D-galactopyranoside $\cdot$ SARS-CoV-2 protease $\cdot$ Antimicrobial $\cdot$ Molecular docking $\cdot$ Molecular dynamics $\cdot$ Pharmacokinetic

This article belongs to the Topical Collection: Tribute to Professor Sen-itiroh Hakomori

Yasuhiro Ozeki

ozeki@yokohama-cu.ac.jp

Sarkar M. A. Kawsar

akawsarabe@yahoo.com

Extended author information available on the last page of the article

\begin{tabular}{|c|c|}
\hline \multicolumn{2}{|c|}{ Abbreviations } \\
\hline MGP & Methyl $\beta$-D-galactopyranoside \\
\hline PASS & Prediction of Activity Spectra for Substances \\
\hline DFT & Density Functional Theory \\
\hline $\mathrm{MIC}$ & Minimum Inhibitory Concentration \\
\hline $\mathrm{MBC}$ & Minimum Bactericidal Concentration \\
\hline
\end{tabular}




$\begin{array}{ll}\text { HOMO } & \text { Highest Occupied Molecular Orbital } \\ \text { LUMO } & \text { Lowest Unoccupied Molecular Orbital } \\ \text { LYP } & \text { Lee, Yang and Parr's } \\ \text { MEP } & \text { Molecular electrostatic potential } \\ \text { DOS } & \begin{array}{l}\text { Density of states } \\ \text { ADMET }\end{array} \\ & \begin{array}{l}\text { Absorption, Distribution, Metabolism, Excre- } \\ \text { tion, and Toxicity }\end{array} \\ \text { hERG } & \text { Human Ether-A-Go-Go-Related Gene } \\ \text { BBB } & \text { Blood-Brain Barrier } \\ \text { SAR } & \text { Structure Activity Relationships }\end{array}$

\section{Introduction}

The wondering and dynamics area for medicinal chemistry was explored by the carbohydrates compounds and their esters used and approved drugs against antibacterial, antifungal, antitumor, antiviral, anti-diabetic, anti-inflammatory, antineoplastic and antiprotozoal of human and phytopathogenic micro-organisms. Micro-organisms are responsible for a wide range of fatal diseases. Scientists worldwide are working to develop more effective and safe antimicrobial agents to treat diseases caused by pathogenic organisms. For these reasons, the best way to develop effective antimicrobial agents is to synthesize new chemicals and test their antimicrobial activity. Carbohydrates are important molecules in nature that play a variety of roles in biological processes. For a long time, carbohydrates have been a very attractive topic for scientists due to their immense importance in biological systems, including viral and bacterial infections, cell growth and proliferation, cell-cell communication as well as an immune response $[1,2]$. In addition, they are the source of the metabolic energy supply, and the fine-tuning of cell-cell interactions and other crucial processes [3, 4].

According to a literature review, many biologically active compounds have aromatic, heteroaromatic, and acyl substituents [5-12]. For example, benzene, substituted benzene, nitrogen, sulfur, and halogen-containing substituents are known to improve the biological activity of the parent compound [13-16]. It is also known that when an active nucleus is linked to another active nucleus, the resulting molecule may have greater biological activity potential [17, 18]. Moreover, selective acylation of carbohydrates and the evaluation of microbial activities [19, 20] reveal that combining two or more heteroaromatic nuclei and acyl groups enhances the biological activity manifold than its parent nucleus [21]. The recent outbreak of the novel coronavirus disease 2019 (COVID-19), occurring from a severe acute respiratory syndrome (SARS) like coronavirus started in Wuhan, China, is spreading rapidly in humans, which is now considered a global pandemic [22]. Though SARS-CoV and SARSCoV-2 agents belong to the beta-coronaviruses category, they are slightly different from each other. Recent research has shown that SARS-CoV-2 often shares $80 \%$ nucleotide identity and $89.10 \%$ nucleotide similarity with SARS-CoV. So, the main protease of SARS-CoV, 3CL ${ }^{\text {pro }}$, has been the target of several in silico investigations to develop potential inhibitors candidates. The $3 \mathrm{CL}^{\text {pro }}$ has a high sequence identity rate between $\mathrm{nCoV}$ and $\mathrm{nCoV} 2$; hence, their $3 \mathrm{CL}^{\text {pro }}$ are likely homologous and have similar structures and functions. Furthermore, SARS-CoV and SARS-CoV-2 agents have similar effects on cells and use the same protein machinery to multiply inside the host cell. Monosaccharide esters have been identified as a potential inhibitor of cancer cell protein [23]. Substitution of the hydroxyl $(-\mathrm{OH})$ group of the nucleoside and monosaccharide structure revealed some promising SARS-CoV-2 candidates [24-26] as well as antimicrobial agents [27, 28].

Therefore, in the present work, a series of MGP esters were designed to investigate their antimicrobial mode through their biological prediction, molecular docking interaction, pharmacokinetic and toxicity analysis. First, the antimicrobial evaluation was performed for all esters through the prediction of PASS properties. Then, a molecular docking simulation was performed against a receptor protein of SARS-CoV-2 main protease (PDB: 6Y84) to identify the binding mode, binding affinity, and non-bonding interaction of MGP esters with the receptor protein. To confirm the stability of the docked complexes, molecular dynamics was performed for 50 ns. Furthermore, pharmacokinetic prediction has been performed to compare their absorption, metabolism, and toxicity.

\section{Materials and methods}

Unless otherwise specified, all reagents used were commercially available Sigma-Aldrich (Germany) and were used exactly as received. An electrothermal melting point apparatus was used to determine melting points (mp). Evaporations were carried out on a Büchi rotary evaporator under reduced pressure. The solvents used were of analytical grade and were purified using standard procedures. Infrared spectral analyses were recorded using a Fourier-transform infrared (FTIR) spectrophotometer (IR Prestige-21, Shimadzu, Japan) at the Department of Chemistry, University of Chittagong. The proton nuclear magnetic resonance $\left({ }^{1} \mathrm{H}-\mathrm{NMR}\right)$ spectra were recorded at WMSRC, JU, Bangladesh, using a Brucker advance DPX $400 \mathrm{MHz}$ and tetramethylsilane as an internal standard. The mass spectra of the synthesized compounds were obtained using positive ionization liquid chromatography-electrospray ionization tandem mass spectrometry. Thin-layer chromatography (TLC) was performed on Kieselgel $\mathrm{GF}_{254}$ (Germany), and the chromatogram was visualized by spraying the plates with $1 \% \mathrm{H}_{2} \mathrm{SO}_{4}$, then heating the plates at $150-200{ }^{\circ} \mathrm{C}$ until coloration appeared. 
Column chromatography was performed using silica gel $\mathrm{G}_{60}$. The following software's were used in the present study: i) Gaussian 09, ii) AutoDock 4.2.6, iii) Swiss-Pdb 4.1.0, iv) Python 3.8.2, v) Discovery Studio 4.1, vi) PyMOL 2.3, vii) (http://www.pharmaexpert.ru/passonline/) to predict PASS properties viii) admetSAR server (http://lmmd.ecust.edu.cn/ admetsar2/about) and SwissADME free web tools (http:// www.swissadme.ch) were employed to calculate the pharmacokinetic properties.

\section{Synthesis}

Methyl 6- $O$-myristoyl- $\beta$-D-galactopyranoside (2).

A suspension of methyl $\beta$-D-galactopyranoside (1) $(100 \mathrm{mg}$, $0.515 \mathrm{mmol})$ was made with dry $N, N$-dimethylformamide (DMF) $(3 \mathrm{ml})$, and triethylamine $(0.15 \mathrm{ml})$ in a round bottle flask. It was then cooled to $-5^{\circ} \mathrm{C}$ in an ice bath, at which point myristoyl chloride $(0.29 \mathrm{ml}, 1.1$ molar eq.) was added. The reaction mixture was continuously stirred at the same temperature for $6 \mathrm{~h}$ and then the reaction mixture was standing overnight at room temperature with continuous stirring. The progress of the reaction was monitored by $\mathrm{TLC}\left(\mathrm{CH}_{3} \mathrm{OH}-\mathrm{CHCl}_{3}\right.$, 1:6), which indicated full conversion of the starting material into a single product $\left(R_{f}=0.52\right)$. The resulting syrup was passed through a silica gel column and eluted with $\mathrm{CH}_{3} \mathrm{OH}-\mathrm{CHCl}_{3}$ (1:6) provided the myristoyl derivative (2) (180 $\mathrm{mg}, 86.45 \%)$ as a crystalline solid. Recrystallization from chloroform-hexane gave the methyl 6- $O$-myristoyl- $\beta$-D-galactopyranoside (2) as needless, m.p. $135-140{ }^{\circ} \mathrm{C}$. The compound was sufficiently pure for use in the next stage without further purification and identification.

FTIR $(\mathrm{KBr})\left(\nu_{\max }\right): 1710(\mathrm{C}=\mathrm{O}), 3414 \sim 3511 \mathrm{~cm}^{-1}$ (br) (-OH). ${ }^{1} \mathrm{H}-\mathrm{NMR}\left(\mathrm{CDCl}_{3}, 400 \mathrm{MHz}\right)(\delta \mathrm{ppm}): \delta_{\mathrm{H}} 4.86$ $(1 \mathrm{H}, \mathrm{d}, \mathrm{J}=8.0 \mathrm{~Hz}, \mathrm{H}-1), 4.77(1 \mathrm{H}, \mathrm{dd}, \mathrm{J}=11.1$ and $6.5 \mathrm{~Hz}$, $\mathrm{H}-6 \mathrm{a}), 4.70(1 \mathrm{H}, \mathrm{dd}, \mathrm{J}=11.1$ and $6.7 \mathrm{~Hz}, \mathrm{H}-6 \mathrm{~b}), 4.35(1 \mathrm{H}$, $\mathrm{d}, \mathrm{J}=3.5 \mathrm{~Hz}, \mathrm{H}-4), 4.18(1 \mathrm{H}, \mathrm{dd}, \mathrm{J}=3.0$ and $10.5 \mathrm{~Hz}, \mathrm{H}-3)$, $3.89(1 \mathrm{H}, \mathrm{dd}, \mathrm{J}=8.0$ and $10.5 \mathrm{~Hz}, \mathrm{H}-2), 3.61(1 \mathrm{H}, \mathrm{m}, \mathrm{H}-5)$, $3.56\left(3 \mathrm{H}, \mathrm{s}, 1-\mathrm{OCH}_{3}\right), 2.35\left\{2 \mathrm{H}, \mathrm{m}, \mathrm{CH}_{3}\left(\mathrm{CH}_{2}\right)_{11} \mathrm{CH}_{2} \mathrm{CO}-\right\}$, $1.64\left\{2 \mathrm{H}, \mathrm{m}, \mathrm{CH}_{3}\left(\mathrm{CH}_{2}\right)_{10} \mathrm{CH}_{2} \mathrm{CH}_{2} \mathrm{CO}-\right\}, 1.27\{20 \mathrm{H}, \mathrm{m}$, $\left.\mathrm{CH}_{3}\left(\mathrm{CH}_{2}\right)_{10} \mathrm{CH}_{2} \mathrm{CH}_{2} \mathrm{CO}-\right\}, 0.89\left\{3 \mathrm{H}, \mathrm{m}, \mathrm{CH}_{3}\left(\mathrm{CH}_{2}\right)_{12} \mathrm{CO}-\right\}$. LC-MS $[\mathrm{M}+1]^{+}$405.54. Anal Calcd. for $\mathrm{C}_{21} \mathrm{H}_{40} \mathrm{O}_{7}$ : $\mathrm{C}, 62.34, \mathrm{H}, 9.96$; found: $\mathrm{C}, 62.35, \mathrm{H}, 9.97 \% .{ }^{13} \mathrm{C}-\mathrm{NMR}$ $\left(100 \mathrm{MHz}, \mathrm{CDCl}_{3}\right): \delta_{\mathrm{C}} 178.13\left\{\mathrm{CH}_{3}\left(\mathrm{CH}_{2}\right)_{12} \mathrm{CO}-\right\}, 104.10$ (C-1), 77.22 (C-2), 77.02 (C-4), 75.25 (C-3), 69.15 (C-5), 62.05 (C-6), $57.06\left(1-\mathrm{OCH}_{3}\right), 34.19,33.84,31.91$ (2), 29.64, 29.51 (2), 29.44, 24.92, 24.90, 22.68 (2) $\left\{\mathrm{CH}_{3}\left(\mathrm{CH}_{2}\right)_{12} \mathrm{CO}-\right\}$, $14.10\left\{\mathrm{CH}_{3}\left(\mathrm{CH}_{2}\right)_{12} \mathrm{CO}-\right\}$.

Methyl 2,3,4-tri- $O$-acetyl-6- $O$-myristoyl- $\beta$-Dgalactopyranoside (3).

A solution of myristoyl derivative (2) $(300 \mathrm{mg}$, $0.74 \mathrm{mmol})$ in dry $\mathrm{N}, \mathrm{N}$-dimethylformamide $(3 \mathrm{ml})$ and triethylamine $(0.15 \mathrm{ml})$ was cooled to $0{ }^{\circ} \mathrm{C}$ and acetyl chloride $(0.26 \mathrm{ml}, 5.0$ molar eq.) was added. The mixture was stirred at $0{ }^{\circ} \mathrm{C}$ for $6 \mathrm{~h}$ and then kept standing overnight at room temperature. TLC examination $\left(\mathrm{CH}_{3} \mathrm{OH}-\mathrm{CHCl}_{3}\right.$, 1:5) showed complete conversion of reactant into a single product $\left(R_{f}=0.54\right)$. The excess reagent was destroyed by adding a few pieces of ice and the reaction mixture was evaporated off. The resulting syrup was purified by column chromatography (with $\mathrm{CH}_{3} \mathrm{OH}-\mathrm{CHCl}_{3}, 1: 5$, as eluent) to afford the acetyl derivative (3) $(283.5 \mathrm{mg}, 72.50 \%)$ as a crystalline solid, m.p. $144-145{ }^{\circ} \mathrm{C}$. Similar reaction and purification methods were employed to synthesize a compound (4) $\left(252.5 \mathrm{mg}, 55.38 \%\right.$, m.p. $\left.153-155^{\circ} \mathrm{C}\right)$, compound (5) $\left(673 \mathrm{mg}, 96.65 \%\right.$, m.p. $\left.133-134{ }^{\circ} \mathrm{C}\right)$, compound (6) $\left(491.5 \mathrm{mg}, 82.58 \%\right.$, m.p. $\left.149-150{ }^{\circ} \mathrm{C}\right)$, compound (7) (466 mg, $92.57 \%$, m.p. $166-167^{\circ} \mathrm{C}$ ), compound (8) (187 mg, $69.66 \%$, m.p. $128-129^{\circ} \mathrm{C}$ ), compound (9) (406 mg, $75.78 \%$, m.p. $151-152{ }^{\circ} \mathrm{C}$ ), and compound (10) (463 mg, $91.85 \%$, m.p. $\left.193-195^{\circ} \mathrm{C}\right)$.

FTIR $(\mathrm{KBr})\left(\nu_{\max }\right): 1709,1706,1700 \mathrm{~cm}^{-1}(\mathrm{C}=\mathrm{O})$. ${ }^{1} \mathrm{H}-\mathrm{NMR}\left(\mathrm{CDCl}_{3}, 400 \mathrm{MHz}\right)(\delta \mathrm{ppm}): \delta_{\mathrm{H}} 4.94(1 \mathrm{H}$, $\mathrm{d}, \mathrm{J}=8.0 \mathrm{~Hz}, \mathrm{H}-1), 4.81(1 \mathrm{H}, \mathrm{dd}, \mathrm{J}=8.0$ and $10.4 \mathrm{~Hz}$, $\mathrm{H}-2), 4.74(1 \mathrm{H}, \mathrm{dd}, \mathrm{J}=3.3$ and $10.7 \mathrm{~Hz}, \mathrm{H}-3), 4.68(1 \mathrm{H}$, $\mathrm{d}, \mathrm{J}=3.5 \mathrm{~Hz}, \mathrm{H}-4), 4.11(1 \mathrm{H}, \mathrm{dd}, \mathrm{J}=11.2$ and $6.6 \mathrm{~Hz}$, $\mathrm{H}-6 \mathrm{a}), 3.94(1 \mathrm{H}, \mathrm{dd}, \mathrm{J}=11.2$ and $6.8 \mathrm{~Hz}, \mathrm{H}-6 \mathrm{~b}), 3.88(1 \mathrm{H}$, $\mathrm{m}, \mathrm{H}-5), 3.45\left(3 \mathrm{H}, \mathrm{s}, 1-\mathrm{OCH}_{3}\right), 2.21,2.14,2.11(3 \times 3 \mathrm{H}$, $\left.3 \times \mathrm{s}, 3 \times \mathrm{CH}_{3} \mathrm{CO}-\right), 2.36\left\{2 \mathrm{H}, \mathrm{m}, \mathrm{CH}_{3}\left(\mathrm{CH}_{2}\right)_{11} \mathrm{CH}_{2} \mathrm{CO}-\right\}$, $1.68\left\{2 \mathrm{H}, \mathrm{m}, \mathrm{CH}_{3}\left(\mathrm{CH}_{2}\right)_{10} \mathrm{CH}_{2} \mathrm{CH}_{2} \mathrm{CO}-\right\}, 1.25\{20 \mathrm{H}, \mathrm{m}$, $\left.\mathrm{CH}_{3}\left(\mathrm{CH}_{2}\right)_{10} \mathrm{CH}_{2} \mathrm{CH}_{2} \mathrm{CO}-\right\}, 0.94\left\{3 \mathrm{H}, \mathrm{m}, \mathrm{CH}_{3}\left(\mathrm{CH}_{2}\right)_{12} \mathrm{CO}-\right\}$. LC-MS $[\mathrm{M}+1]^{+}$531.65. Anal Calcd. for $\mathrm{C}_{27} \mathrm{H}_{46} \mathrm{O}_{10}$ : C, 61.11, H, 8.73; found: $\mathrm{C}, 61.10, \mathrm{H}, 8.75 \%$.

Methyl 2,3,4-tri- $O$-butyryl-6- $O$-myristoyl- $\beta$-Dgalactopyranoside (4).

FTIR $(\mathrm{KBr})\left(\nu_{\max }\right): 1708 \mathrm{~cm}^{-1}(\mathrm{C}=\mathrm{O}) .{ }^{1} \mathrm{H}-\mathrm{NMR}\left(\mathrm{CDCl}_{3}\right.$, $400 \mathrm{MHz})(\delta \mathrm{ppm}): \delta_{\mathrm{H}} 5.41(1 \mathrm{H}, \mathrm{d}, \mathrm{J}=8.2 \mathrm{~Hz}, \mathrm{H}-1), 5.21$ $(1 \mathrm{H}, \mathrm{dd}, \mathrm{J}=8.1$ and $10.5 \mathrm{~Hz}, \mathrm{H}-2), 5.13(1 \mathrm{H}, \mathrm{dd}, \mathrm{J}=3.2$ and $10.6 \mathrm{~Hz}, \mathrm{H}-3), 4.46(1 \mathrm{H}, \mathrm{d}, \mathrm{J}=3.5 \mathrm{~Hz}, \mathrm{H}-4), 4.22(1 \mathrm{H}$, $\mathrm{dd}, \mathrm{J}=11.1$ and $6.8 \mathrm{~Hz}, \mathrm{H}-6 \mathrm{a}), 4.16(1 \mathrm{H}, \mathrm{dd}, \mathrm{J}=11.1$ and $6.8 \mathrm{~Hz}, \mathrm{H}-6 \mathrm{~b}), 3.92(1 \mathrm{H}, \mathrm{m}, \mathrm{H}-5), 3.45\left(3 \mathrm{H}, \mathrm{s}, 1-\mathrm{OCH}_{3}\right)$, $2.36\left\{6 \mathrm{H}, \mathrm{m}, 3 \times \mathrm{CH}_{3} \mathrm{CH}_{2} \mathrm{CH}_{2} \mathrm{CO}-\right\}, 2.35\{2 \mathrm{H}, \mathrm{m}$, $\left.\mathrm{CH}_{3}\left(\mathrm{CH}_{2}\right)_{11} \mathrm{CH}_{2} \mathrm{CO}-\right\}, 1.68\left(6 \mathrm{H}, \mathrm{m}, 3 \times \mathrm{CH}_{3} \mathrm{CH}_{2} \mathrm{CH}_{2} \mathrm{CO}-\right)$, $1.66\left\{2 \mathrm{H}, \mathrm{m}, \mathrm{CH}_{3}\left(\mathrm{CH}_{2}\right)_{10} \mathrm{CH}_{2} \mathrm{CH}_{2} \mathrm{CO}-\right\}, 1.28\{20 \mathrm{H}, \mathrm{m}$, $\left.\mathrm{CH}_{3}\left(\mathrm{CH}_{2}\right)_{10} \mathrm{CH}_{2} \mathrm{CH}_{2} \mathrm{CO}-\right\}, 0.98\left\{9 \mathrm{H}, \mathrm{m}, 3 \times \mathrm{CH}_{3}\left(\mathrm{CH}_{2}\right)_{2} \mathrm{CO}-\right\}$, $0.96\left\{3 \mathrm{H}, \mathrm{m}, \mathrm{CH}_{3}\left(\mathrm{CH}_{2}\right)_{12} \mathrm{CO}-\right\}$. LC-MS [M+1] ${ }^{+} 615.81$. Anal Calcd. for $\mathrm{C}_{33} \mathrm{H}_{58} \mathrm{O}_{10}$ : C, 64.46, H, 9.50; found: C, 64.47, $\mathrm{H}, 9.52 \%$.

Methyl 6- $O$-myristoyl-2,3,4-tri- $O$-palmitoyl- $\beta$-Dgalactopyranoside (5).

FTIR $(\mathrm{KBr})\left(\nu_{\max }\right): 1707 \mathrm{~cm}^{-1}(\mathrm{C}=\mathrm{O}) .{ }^{1} \mathrm{H}-\mathrm{NMR}\left(\mathrm{CDCl}_{3}\right.$, $400 \mathrm{MHz})(\delta \mathrm{ppm}): \delta_{\mathrm{H}} 5.38(1 \mathrm{H}, \mathrm{d}, \mathrm{J}=8.3 \mathrm{~Hz}, \mathrm{H}-1), 5.16$ $(1 \mathrm{H}, \mathrm{dd}, \mathrm{J}=8.0$ and $10.5 \mathrm{~Hz}, \mathrm{H}-2), 5.03(1 \mathrm{H}, \mathrm{dd}, \mathrm{J}=3.1$ and $10.6 \mathrm{~Hz}, \mathrm{H}-3), 4.75(1 \mathrm{H}, \mathrm{d}, \mathrm{J}=3.6 \mathrm{~Hz}, \mathrm{H}-4), 4.39(1 \mathrm{H}, \mathrm{dd}$, $\mathrm{J}=11.2$ and $6.7 \mathrm{~Hz}, \mathrm{H}-6 \mathrm{a}), 4.14(1 \mathrm{H}, \mathrm{dd}, \mathrm{J}=11.1$ and $6.8 \mathrm{~Hz}$, H-6b), 3.99 (1H, m, H-5), 3.47 (3H, s, 1-OCH $\left.{ }_{3}\right), 2.34\{2 \mathrm{H}, \mathrm{m}$, 
$\left.\mathrm{CH}_{3}\left(\mathrm{CH}_{2}\right)_{11} \mathrm{CH}_{2} \mathrm{CO}-\right\}, 2.31\left\{6 \mathrm{H}, \mathrm{m}, 3 \times \mathrm{CH}_{3}\left(\mathrm{CH}_{2}\right)_{13} \mathrm{CH}_{2} \mathrm{CO}-\right\}$, $1.64\left\{2 \mathrm{H}, \quad \mathrm{m}, \quad \mathrm{CH}_{3}\left(\mathrm{CH}_{2}\right){ }_{10} \mathrm{CH}_{2} \mathrm{CH}_{2} \mathrm{CO}-\right\}, 1.26$ $\left\{20 \mathrm{H}, \mathrm{m}, \mathrm{CH}_{3}\left(\mathrm{CH}_{2}\right)_{10} \mathrm{CH}_{2} \mathrm{CH}_{2} \mathrm{CO}-\right\}, 1.24\{78 \mathrm{H}, \mathrm{m}$, $\left.3 \times \mathrm{CH}_{3}\left(\mathrm{CH}_{2}\right)_{13} \mathrm{CH}_{2} \mathrm{CO}-\right\}, 0.94\left\{3 \mathrm{H}, \mathrm{m}, \mathrm{CH}_{3}\left(\mathrm{CH}_{2}\right)_{12} \mathrm{CO}-\right\}$, $0.91\left\{9 \mathrm{H}, \mathrm{m}, 3 \times \mathrm{CH}_{3}\left(\mathrm{CH}_{2}\right)_{14} \mathrm{CO}\right\}$. LC-MS [M+1] ${ }^{+} 1120.76$. Anal Calcd. for $\mathrm{C}_{69} \mathrm{H}_{130} \mathrm{O}_{10}$ : C, 74.0, H, 11.69; found: $\mathrm{C}$, $74.02, \mathrm{H}, 11.68 \%$.

Methyl 6- $O$-myristoyl-2,3,4-tri- $O$-stearoyl- $\beta$-Dgalactopyranoside (6).

FTIR $(\mathrm{KBr})\left(\nu_{\max }\right): 1703 \mathrm{~cm}^{-1}(-\mathrm{CO}) .{ }^{1} \mathrm{H}-\mathrm{NMR}\left(\mathrm{CDCl}_{3}\right.$, $400 \mathrm{MHz})(\delta \mathrm{ppm}): \delta_{\mathrm{H}} 5.30(1 \mathrm{H}, \mathrm{d}, \mathrm{J}=8.1 \mathrm{~Hz}, \mathrm{H}-1), 5.15$ $(1 \mathrm{H}, \mathrm{dd}, \mathrm{J}=8.2$ and $10.6 \mathrm{~Hz}, \mathrm{H}-2), 5.01(1 \mathrm{H}, \mathrm{dd}, \mathrm{J}=3.2$ and $10.6 \mathrm{~Hz}, \mathrm{H}-3), 4.85(1 \mathrm{H}, \mathrm{d}, \mathrm{J}=3.7 \mathrm{~Hz}, \mathrm{H}-4), 4.40(1 \mathrm{H}, \mathrm{dd}$, $\mathrm{J}=11.2$ and $6.6 \mathrm{~Hz}, \mathrm{H}-6 \mathrm{a}), 4.11(1 \mathrm{H}, \mathrm{dd}, \mathrm{J}=11.2$ and $6.8 \mathrm{~Hz}$, $\mathrm{H}-6 \mathrm{~b}), 3.51(1 \mathrm{H}, \mathrm{m}, \mathrm{H}-5), 3.45\left(3 \mathrm{H}, \mathrm{s}, 1-\mathrm{OCH}_{3}\right), 2.31\{2 \mathrm{H}, \mathrm{m}$, $\left.\mathrm{CH}_{3}\left(\mathrm{CH}_{2}\right)_{11} \mathrm{CH}_{2} \mathrm{CO}-\right\}, 2.27\left\{2 \mathrm{H}, \mathrm{m}, \mathrm{CH}_{3}\left(\mathrm{CH}_{2}\right)_{15} \mathrm{CH}_{2} \mathrm{CO}-\right\}$, $1.62\left\{2 \mathrm{H}, \quad \mathrm{m}, \mathrm{CH}_{3}\left(\mathrm{CH}_{2}\right)_{10} \mathrm{CH}_{2} \mathrm{CH}_{2} \mathrm{CO}-\right\}, 1.32$ $\left\{20 \mathrm{H}, \mathrm{m}, \mathrm{CH}_{3}\left(\mathrm{CH}_{2}\right)_{10} \mathrm{CH}_{2} \mathrm{CH}_{2} \mathrm{CO}-\right\}, 1.29\{30 \mathrm{H}, \mathrm{m}$, $\left.\mathrm{CH}_{3}\left(\mathrm{CH}_{2}\right)_{15} \mathrm{CH}_{2} \mathrm{CO}-\right\}, 0.93\left\{3 \mathrm{H}, \mathrm{m}, \mathrm{CH}_{3}\left(\mathrm{CH}_{2}\right)_{12} \mathrm{CO}-\right\}, 0.90$ $\left\{3 \mathrm{H}, \mathrm{m}, \mathrm{CH}_{3}\left(\mathrm{CH}_{2}\right)_{16} \mathrm{CO}-\right\}$. LC-MS [M+1] ${ }^{+}$1204.92. Anal Calcd. for $\mathrm{C}_{75} \mathrm{H}_{142} \mathrm{O}_{10}$ : C, 74.82, H, 11.88; found: C, 74.83, $\mathrm{H}, 11.90 \%$.

Methyl 6- $O$-myristoyl-2,3,4-tri- $O$-trityl- $\beta$-Dgalactopyranoside (7).

FTIR $(\mathrm{KBr})\left(\nu_{\max }\right): 1699 \mathrm{~cm}^{-1}(\mathrm{C}=\mathrm{O}) \cdot{ }^{1} \mathrm{H}-\mathrm{NMR}$ $\left(\mathrm{CDCl}_{3}, 400 \mathrm{MHz}\right)(\delta \mathrm{ppm}): \delta_{\mathrm{H}} 7.67(18 \mathrm{H}, \mathrm{m}, 3 \times \mathrm{Ar}-\mathrm{H})$, $7.45(27 \mathrm{H}, \mathrm{m}, 3 \times \mathrm{Ar}-\mathrm{H}), 5.22(1 \mathrm{H}, \mathrm{d}, \mathrm{J}=8.0 \mathrm{~Hz}, \mathrm{H}-1)$, $5.05(1 \mathrm{H}, \mathrm{dd}, \mathrm{J}=8.1$ and $10.6 \mathrm{~Hz}, \mathrm{H}-2), 4.75(1 \mathrm{H}, \mathrm{dd}$, $\mathrm{J}=3.0$ and $10.6 \mathrm{~Hz}, \mathrm{H}-3), 4.55(1 \mathrm{H}, \mathrm{d}, \mathrm{J}=3.6 \mathrm{~Hz}, \mathrm{H}-4)$, $4.30(1 \mathrm{H}, \mathrm{dd}, \mathrm{J}=11.1$ and $6.6 \mathrm{~Hz}, \mathrm{H}-6 \mathrm{a}), 4.10(1 \mathrm{H}, \mathrm{dd}$, $\mathrm{J}=11.0$ and $6.7 \mathrm{~Hz}, \mathrm{H}-6 \mathrm{~b}), 3.91(1 \mathrm{H}, \mathrm{m}, \mathrm{H}-5), 3.56$ $\left(3 \mathrm{H}, \mathrm{s}, 1-\mathrm{OCH}_{3}\right), 2.32\left\{2 \mathrm{H}, \mathrm{m}, \mathrm{CH}_{3}\left(\mathrm{CH}_{2}\right)_{11} \mathrm{CH}_{2} \mathrm{CO}-\right\}$, $1.61\left\{2 \mathrm{H}, \mathrm{m}, \mathrm{CH}_{3}\left(\mathrm{CH}_{2}\right)_{10} \mathrm{CH}_{2} \mathrm{CH}_{2} \mathrm{CO}-\right\}, 1.24\{20 \mathrm{H}, \mathrm{m}$, $\left.\mathrm{CH}_{3}\left(\mathrm{CH}_{2}\right)_{10} \mathrm{CH}_{2} \mathrm{CH}_{2} \mathrm{CO}-\right\}, 0.91\left\{3 \mathrm{H}, \mathrm{m}, \mathrm{CH}_{3}\left(\mathrm{CH}_{2}\right)_{12} \mathrm{CO}-\right\}$. LC-MS $[\mathrm{M}+1]^{+}$1132.48. Anal Calcd. for $\mathrm{C}_{78} \mathrm{H}_{82} \mathrm{O}_{7}: \mathrm{C}$, 82.79, H, 7.30; found: C, 82.78, H, 7.31\%.

Methyl 2,3,4-tri- $O$-cinnamoyl-6- $O$-myristoyl- $\beta$-Dgalactopyranoside (8).

FTIR $(\mathrm{KBr})\left(\nu_{\max }\right): 1702(-\mathrm{CO}) \mathrm{cm}^{-}{ }^{1} .{ }^{1} \mathrm{H}-\mathrm{NMR}\left(\mathrm{CDCl}_{3}\right.$, $400 \mathrm{MHz})(\delta \mathrm{ppm}): \delta_{\mathrm{H}} 7.757 .52,7.37(3 \times 1 \mathrm{H}, 3 \times \mathrm{d}$, $\mathrm{J}=16.0 \mathrm{~Hz}, 3 \times \mathrm{PhCH}=\mathrm{CHCO}-), 7.54(6 \mathrm{H}, \mathrm{m}, \mathrm{Ar}-\mathrm{H})$, $7.28(9 \mathrm{H}, \mathrm{m}, \mathrm{Ar}-\mathrm{H}), 6.55,6.16,6.07(3 \times 1 \mathrm{H}, 3 \times \mathrm{d}$, $\mathrm{J}=16.1 \mathrm{~Hz}, 3 \times \mathrm{PhCH}=\mathrm{CHCO}-), 5.48(1 \mathrm{H}, \mathrm{d}, \mathrm{J}=8.2 \mathrm{~Hz}$, $\mathrm{H}-1), 5.34(1 \mathrm{H}, \mathrm{dd}, \mathrm{J}=8.2$ and $10.6 \mathrm{~Hz}, \mathrm{H}-2), 5.05(1 \mathrm{H}$, $\mathrm{dd}, \mathrm{J}=3.2$ and $10.6 \mathrm{~Hz}, \mathrm{H}-3), 4.66(1 \mathrm{H}, \mathrm{d}, \mathrm{J}=3.7 \mathrm{~Hz}$, $\mathrm{H}-4), 4.40(1 \mathrm{H}, \mathrm{dd}, \mathrm{J}=11.2$ and $6.6 \mathrm{~Hz}, \mathrm{H}-6 \mathrm{a}), 4.01(1 \mathrm{H}$, $\mathrm{dd}, \mathrm{J}=11.2$ and $6.8 \mathrm{~Hz}, \mathrm{H}-6 \mathrm{~b}), 3.52(1 \mathrm{H}, \mathrm{m}, \mathrm{H}-5), 3.50$ $\left(3 \mathrm{H}, \mathrm{s}, 1-\mathrm{OCH}_{3}\right), 2.32\left\{2 \mathrm{H}, \mathrm{m}, \mathrm{CH}_{3}\left(\mathrm{CH}_{2}\right)_{11} \mathrm{CH}_{2} \mathrm{CO}-\right\}$, $1.63\left\{2 \mathrm{H}, \mathrm{m}, \mathrm{CH}_{3}\left(\mathrm{CH}_{2}\right)_{10} \mathrm{CH}_{2} \mathrm{CH}_{2} \mathrm{CO}-\right\}, 1.25\{20 \mathrm{H}, \mathrm{m}$, $\left.\mathrm{CH}_{3}\left(\mathrm{CH}_{2}\right)_{10} \mathrm{CH}_{2} \mathrm{CH}_{2} \mathrm{CO}-\right\}, 0.88\left\{3 \mathrm{H}, \mathrm{m}, \mathrm{CH}_{3}\left(\mathrm{CH}_{2}\right)_{12} \mathrm{CO}-\right\}$. LC-MS $[\mathrm{M}+1]^{+}$795.97. Anal Calcd. for $\mathrm{C}_{48} \mathrm{H}_{58} \mathrm{O}_{10}$ : C, 72.52, H, 7.35; found: C, 72.53, H, 7.37\%.
Methyl 6- $O$-myristoyl-2,3,4-tri- $O$-( $p$-toluenesulfonyl)- $\beta$-Dgalactopyranoside (9).

FTIR $(\mathrm{KBr})\left(\nu_{\max }\right): 1705 \mathrm{~cm}^{-1}(\mathrm{C}=\mathrm{O}) .{ }^{1} \mathrm{H}-\mathrm{NMR}\left(\mathrm{CDCl}_{3}\right.$, $400 \mathrm{MHz})(\delta \mathrm{ppm}): \delta_{\mathrm{H}} 8.03(3 \times 2 \mathrm{H}, \mathrm{m}, \mathrm{Ar}-\mathrm{H}), 7.94(3 \times 2 \mathrm{H}, \mathrm{m}$, $\mathrm{Ar}-\mathrm{H}), 5.23(1 \mathrm{H}, \mathrm{d}, \mathrm{J}=8.2 \mathrm{~Hz}, \mathrm{H}-1), 5.08(1 \mathrm{H}, \mathrm{dd}, \mathrm{J}=8.0$ and $10.5 \mathrm{~Hz}, \mathrm{H}-2), 4.77(1 \mathrm{H}, \mathrm{dd}, \mathrm{J}=3.1$ and $10.6 \mathrm{~Hz}, \mathrm{H}-3), 4.53(1 \mathrm{H}$, d, J=3.7 Hz, H-4), $4.27(1 \mathrm{H}, \mathrm{dd}, \mathrm{J}=11.0$ and $6.5 \mathrm{~Hz}, \mathrm{H}-6 \mathrm{a})$, $4.11(1 \mathrm{H}, \mathrm{dd}, \mathrm{J}=11.1$ and $6.8 \mathrm{~Hz}, \mathrm{H}-6 \mathrm{~b}), 3.98(1 \mathrm{H}, \mathrm{m}, \mathrm{H}-5)$, $3.46\left(3 \mathrm{H}, \mathrm{s}, 1-\mathrm{OCH}_{3}\right), 2.37\left\{2 \mathrm{H}, \mathrm{m}, \mathrm{CH}_{3}\left(\mathrm{CH}_{2}\right)_{11} \mathrm{CH}_{2} \mathrm{CO}-\right\}$, $1.63\left\{2 \mathrm{H}, \mathrm{m}, \mathrm{CH}_{3}\left(\mathrm{CH}_{2}\right)_{10} \mathrm{CH}_{2} \mathrm{CH}_{2} \mathrm{CO}-\right\}, 1.27\{20 \mathrm{H}, \mathrm{m}$, $\left.\mathrm{CH}_{3}\left(\mathrm{CH}_{2}\right)_{10} \mathrm{CH}_{2} \mathrm{CH}_{2} \mathrm{CO}-\right\}, 0.98\left\{3 \mathrm{H}, \mathrm{m}, \mathrm{CH}_{3}\left(\mathrm{CH}_{2}\right)_{12} \mathrm{CO}\right\}$. LC-MS $[\mathrm{M}+1]^{+}$868.10. Anal Calcd. for $\mathrm{C}_{42} \mathrm{H}_{58} \mathrm{O}_{13} \mathrm{~S}_{3}$ : C, 58.17, H, 6.74; found: C, 58.19, H, 6.76\%.

Methyl 2,3,4-tri- $O$-(3-chlorobenzoyl)-6- $O$-myristoyl- $\beta$ D-galactopyranoside (10).

FTIR $(\mathrm{KBr})\left(\nu_{\max }\right): 1709 \mathrm{~cm}^{-1}(\mathrm{C}=\mathrm{O}) .{ }^{1} \mathrm{H}-\mathrm{NMR}\left(\mathrm{CDCl}_{3}\right.$, $400 \mathrm{MHz}): \delta_{\mathrm{H}} 8.05(3 \mathrm{H}, \mathrm{m}, \mathrm{Ar}-\mathrm{H}), 7.96(3 \mathrm{H}, \mathrm{m}, \mathrm{Ar}-\mathrm{H})$, $7.55(3 \mathrm{H}, \mathrm{m}, \mathrm{Ar}-\mathrm{H}), 7.38(3 \mathrm{H}, \mathrm{m}, \mathrm{Ar}-\mathrm{H}), 5.63(1 \mathrm{H}, \mathrm{d}$, $\mathrm{J}=8.1 \mathrm{~Hz}, \mathrm{H}-1), 5.21(1 \mathrm{H}, \mathrm{dd}, \mathrm{J}=8.2$ and $10.6 \mathrm{~Hz}, \mathrm{H}-2)$, $5.01(1 \mathrm{H}, \mathrm{dd}, \mathrm{J}=3.1$ and $10.6 \mathrm{~Hz}, \mathrm{H}-3), 4.65(1 \mathrm{H}, \mathrm{d}$, $\mathrm{J}=3.7 \mathrm{~Hz}, \mathrm{H}-4), 4.40(1 \mathrm{H}, \mathrm{dd}, \mathrm{J}=11.1$ and $6.6 \mathrm{~Hz}, \mathrm{H}-6 \mathrm{a})$, $4.20(1 \mathrm{H}, \mathrm{dd}, \mathrm{J}=11.2$ and $6.8 \mathrm{~Hz}, \mathrm{H}-6 \mathrm{~b}), 4.00(1 \mathrm{H}, \mathrm{m}, \mathrm{H}-5)$, $3.46\left(3 \mathrm{H}, \mathrm{s}, 1-\mathrm{OCH}_{3}\right), 2.35\left\{2 \mathrm{H}, \mathrm{m}, \mathrm{CH}_{3}\left(\mathrm{CH}_{2}\right)_{11} \mathrm{CH}_{2} \mathrm{CO}-\right\}$, $1.65\left\{2 \mathrm{H}, \mathrm{m}, \mathrm{CH}_{3}\left(\mathrm{CH}_{2}\right)_{10} \mathrm{CH}_{2} \mathrm{CH}_{2} \mathrm{CO}-\right\}, 1.24\{20 \mathrm{H}, \mathrm{m}$, $\left.\mathrm{CH}_{3}\left(\mathrm{CH}_{2}\right)_{10} \mathrm{CH}_{2} \mathrm{CH}_{2} \mathrm{CO}-\right\}, 0.86\left\{3 \mathrm{H}, \mathrm{m}, \mathrm{CH}_{3}\left(\mathrm{CH}_{2}\right)_{12} \mathrm{CO}-\right\}$. LC-MS $[\mathrm{M}+1]^{+}$821.19. Anal Calcd. for $\mathrm{C}_{42} \mathrm{H}_{49} \mathrm{O}_{10} \mathrm{Cl}_{3}$ : C, 61.50, H, 6.02; found: C, 61.52, H, 6.03\%.

\section{Antimicrobial screening}

The fifteen modified thymidine derivatives (2-10) were subjected to antibacterial screening using five bacterial strains: two Gram-positive strains, namely, Bacillus subtilis ATCC 6633 and Staphylococcus aureus ATCC 6538, and three Gram-negative strains, namely, Escherichia coli ATCC 8739, Salmonella abony NCTC 6017 and Pseudomonas aeruginosa ATCC 9027. All the compounds were dissolved in dimethylformamide (DMSO) to obtain a $2 \%-3 \%$ solution $(\mathrm{w} / \mathrm{v})$. Additionally, antifungal activities of the compounds were studied against two fungi strains, namely, Aspergillus niger ATCC 16,404 and Aspergillus flavus ATCC 204,304. These test micro-organisms (bacteria and fungi) were obtained from the Department of Microbiology, University of Chittagong, Bangladesh. Disks soaked in DMSO were used as the negative control.

\section{Screening of antibacterial activity}

The antibacterial spectra of the test derivatives were obtained in vitro by the disk diffusion method [29]. This method used paper disks of $4 \mathrm{~mm}$ diameter and a glass Petri-plate of $90 \mathrm{~mm}$ 
diameter throughout the experiment. Sterile 5\% (w/v) dimethyl sulfoxide (DMSO) solution prepared the synthesized compounds' desired concentration and standard antibiotics. The paper disks were soaked in test chemicals for antibacterial testing at a $20 \mathrm{mg} / \mathrm{ml}$ concentration. The bacterial suspensions were swabbed with Müeller-Hinton agar media (MHA) before being placed on sterile soaked disks. The plates were incubated at $370{ }^{\circ} \mathrm{C}$ for $24 \mathrm{~h}$ to allow test organisms to grow. Bangladesh Export Import Company (BEXIMCO) Ltd. azithromycin was used as a positive control, while DMSO was used as a negative control. The experiments were carried out in triplicate.

\section{Minimum inhibitory concentration and minimum bactericidal concentration}

Following the Clinical and Laboratory Standards Institute, a 96-well U-bottomed microtiter plate was used to determine the MIC [30]. MIC was determined as the concentration of the last well (with the lowest concentration of the compound) where no bacterial growth was observed. Next, the contents of the wells were seeded on Müeller-Hinton agar plates to determine the $\mathrm{MBC}$, which is the lowest concentration that kills bacteria. The broth microdilution method was used to calculate the MIC and MBC [11].

\section{Screening of mycelial growth}

The in vitro antifungal activity of the test derivatives was investigated by the "poisons food" technique [31], in which potato dextrose agar (PDA) was used as the culture medium. The test compounds were dissolved in DMSO to obtain a $1 \%\left(\mathrm{w} \mathrm{v}^{-1}\right)$ solution. A sterilized pipette was used to transfer $0.1 \mathrm{~mL}$ of this solution to a sterile petri dish, after which $20 \mathrm{~mL}$ of the medium was poured into the petri dish and allowed to solidify. Each petri dish was inoculated with a 5-mm mycelium block of each fungus, which was inverted to maximize contact between the mycelium and the culture medium. The mycelium block was created by squeezing the growing area of a 5-day-old culture of the test fungus growing on PDA with a corkscrew. The inoculated plates were further incubated at $25 \pm 2{ }^{\circ} \mathrm{C}$. The experiment was conducted in triplicates. The radial mycelial growth of the fungus was determined by taking the average of three measurements (in $\mathrm{mm}$ ). The antifungal agent Nystatin was used as a standard to compare the results. The percentage inhibition of fungi mycelial growth was calculated using the equation below.

$\mathrm{I}=\frac{C-T}{C} \times 100$

where, $\mathrm{I}=$ Percentage of inhibition.
$\mathrm{C}=$ diameter of the fungal colony in control (DMSO).

$\mathrm{T}=$ diameter of the fungal colony in treatment.

Positive control was maintained with Nystatin, and negative control was also maintained without using any chemicals.

\section{Geometry optimization}

Quantum mechanical methods are widely used in computational chemistry to calculate thermal, molecular orbital, and molecular electrostatic properties [32]. Geometry optimization and further modification of all synthesized esters are carried out using Gaussian 09 program [33]. DFT with Beck's (B) [34] three-parameter hybrid model, Lee, Yang, and Parr's (LYP) [35] correlation functional under 3-21G basis set has been employed to optimize and predict their thermal and molecular orbital properties. The dipole moment, enthalpy, free energy, entropy, heat capacity, total energy, and polarizability were calculated for each compound. At the same level of theory, the frontier molecular orbital features highest occupied molecular orbital (HOMO) and lowest unoccupied molecular orbital (HOMO) were counted. For each of the MGP esters, HOMO-LUMO energy gap, hardness $(\eta)$, and softness $(S)$ were calculated from the energies of frontier HOMO and LUMO as reported considering Parr and Pearson interpretation of DFT and Koopmans theorem [36] on the correlation of ionization potential (I) and electron affinities (E) with HOMO and LUMO energy $(\varepsilon)$. The following equations are used to calculate hardness $(\eta)$, softness $(S)$.

$$
\begin{aligned}
& \text { Gap }(\Delta \varepsilon)=\varepsilon \text { LUMO }-\varepsilon \text { HOMO } \\
& \eta=\frac{[\varepsilon L U M O-\varepsilon \text { HOMO }]}{2} \\
& \mathrm{~S}=\frac{1}{\eta}
\end{aligned}
$$

\section{PASS prediction}

The online web application PASS (http://www.pharmaexpert. ru/passonline/) has been employed to calculate the antimicrobial activity spectrum of the selected MGP esters [37]. Firstly, the MGP esters structures were drawn and then changed into their smiles formats by using SwissADME free online applications (http://www.swissadme.ch), which were renowned for determining antimicrobial spectrum using the PASS web tool. This server is planned to surmise above 4000 types of antimicrobial function together with drug and non-drug 
activity, which helps suggest the best potential objects with $90 \%$ validity. PASS outcomes are revealed by $\mathrm{Pa}$ (probability for active molecule) and Pi (probability for inactive molecule). Having potentialities, the $\mathrm{Pa}$ and $\mathrm{Pi}$ scores vary in the range of 0.00 to 1.00 and usually, $\mathrm{Pa}+\mathrm{Pi} \neq 1$, as these potentialities are predicted freely. The biological actions with $\mathrm{Pa}>\mathrm{Pi}$ are only thought of as probable for a selected drug molecule. PASS calculation outcomes were explained and used flexibly, viz. (i) when Pa greater than 0.7 , the probability of identifying the activity is analytically high, (ii) if $0.5<\mathrm{Pa}<0.7$, the probability of identifying the activity is analytically low, again, the molecule is perhaps not so alike to well conversant pharmaceutically used drugs and (iii) if $\mathrm{Pa}<0.5$, the potentiality to identify the activity analytically is less. As a result, the prediction of the spectrum of antimicrobial activity of a probable drug molecule is expressed as its intrinsic parameter.

\section{Protein collection and molecular docking simulation}

The three-dimensional structure of SARS-CoV-2 $\mathrm{M}^{\text {pro }}$ (PDB: 6Y84) (Fig. 1) was collected in pdb format from the protein data bank [38]. First, all hetero atoms and water molecules were taken away using PyMol (version 1.3) software packages [39]. Next, swiss-Pdb viewer software (version 4.1.0) was employed for energy minimization of the protein [40] Then optimized drugs were subjected for molecular docking study against SARS-CoV-2 $\mathrm{M}^{\text {pro }}$ protein (6Y84). In fine, molecular docking simulation was rendered by PyRx software (version 0.8) [41], considering the protein as a macromolecule and the drug as a ligand. Finally, AutoDockVina was employed for docking analysis, and AutoDock Tools of the MGL (molecular graphics laboratory) software package was used to convert pdb into a pdbqt format to input protein and ligands. The grid box size in AutoDockVina was kept at 41.2147, 69.0754, and 63.7031 $\mathrm{for} \mathrm{X,} \mathrm{Y,} \mathrm{Z}$ directions, respectively. After completing docking, both the macromolecule and ligand structures were saved in. pdbqt format needed by Accelrys Discovery Studio (version 4.1) to explore and visualize the docking result and search the non-bonding interactions between ligands and amino acid residues of receptor protein [42]. PDBsum online server was also used to check the validation of the protein (PDB: 6Y84) with Ramachandran (Fig. 2a) and Lig-plot (Fig. 2b), which revealed that $89.60 \%$ residues in the allowed region and no residues were missed.

\section{Molecular dynamics simulation}

The docked complexes were molecular dynamics simulated in YASARA dynamics using the AMBER14 force field [43, 44]. Initially, the docked complexes were cleaned and optimized, and the hydrogen bond network was oriented. The TIP3P water solvation model created the cubic simulation cell with periodic boundary conditions [45]. The physiological conditions of the cell were set as $310 \mathrm{~K}, \mathrm{pH} 7.4$, and $0.9 \% \mathrm{NaCl}$. The initial energy minimizations were done with the steepest gradient approaches (5000 cycles) by simulated
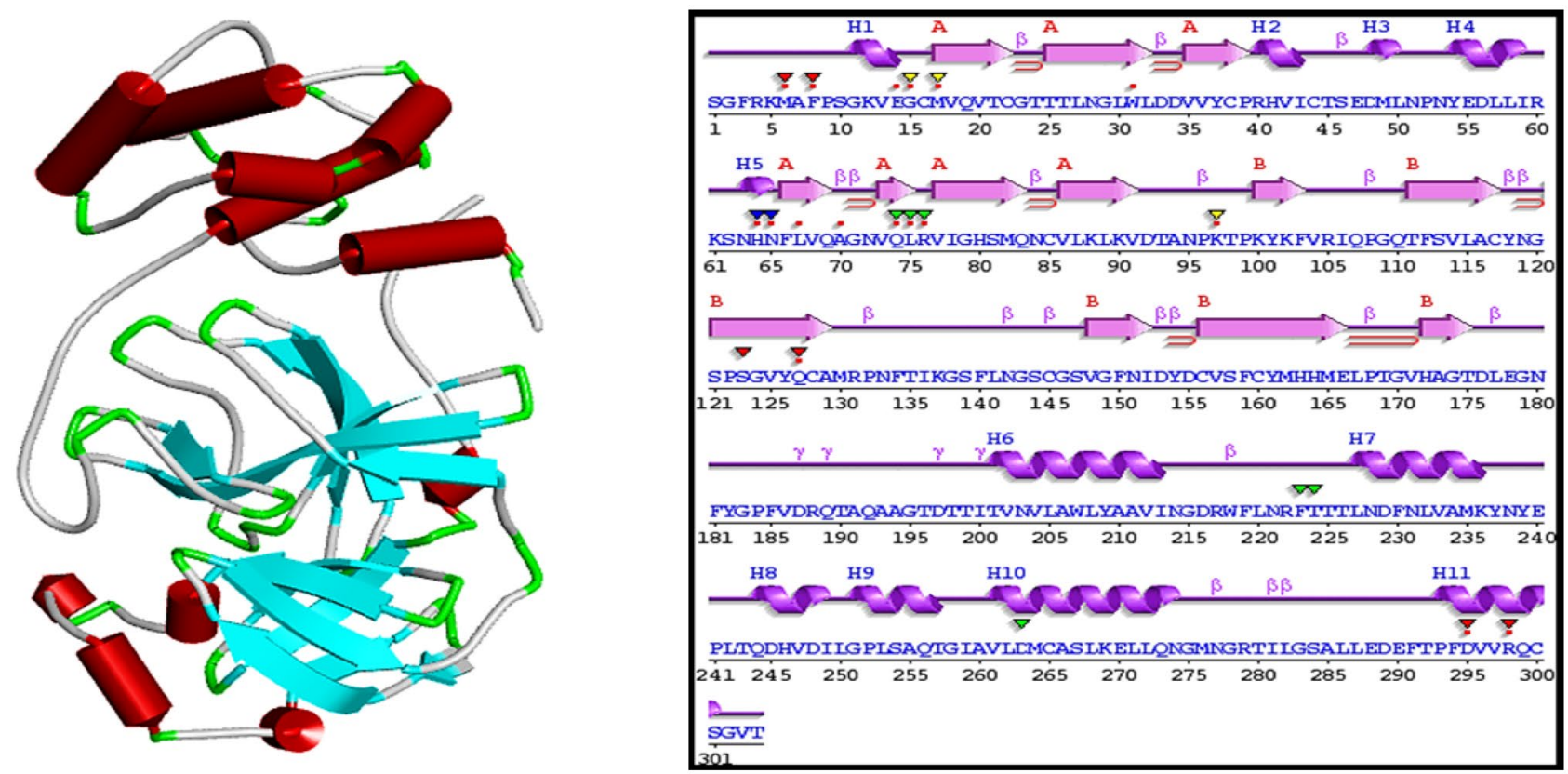

Fig. 1 Crystal structure and multiple sequence alignment of closest homologs of SARS-CoV-2 main protease (PDB: 6Y84) 

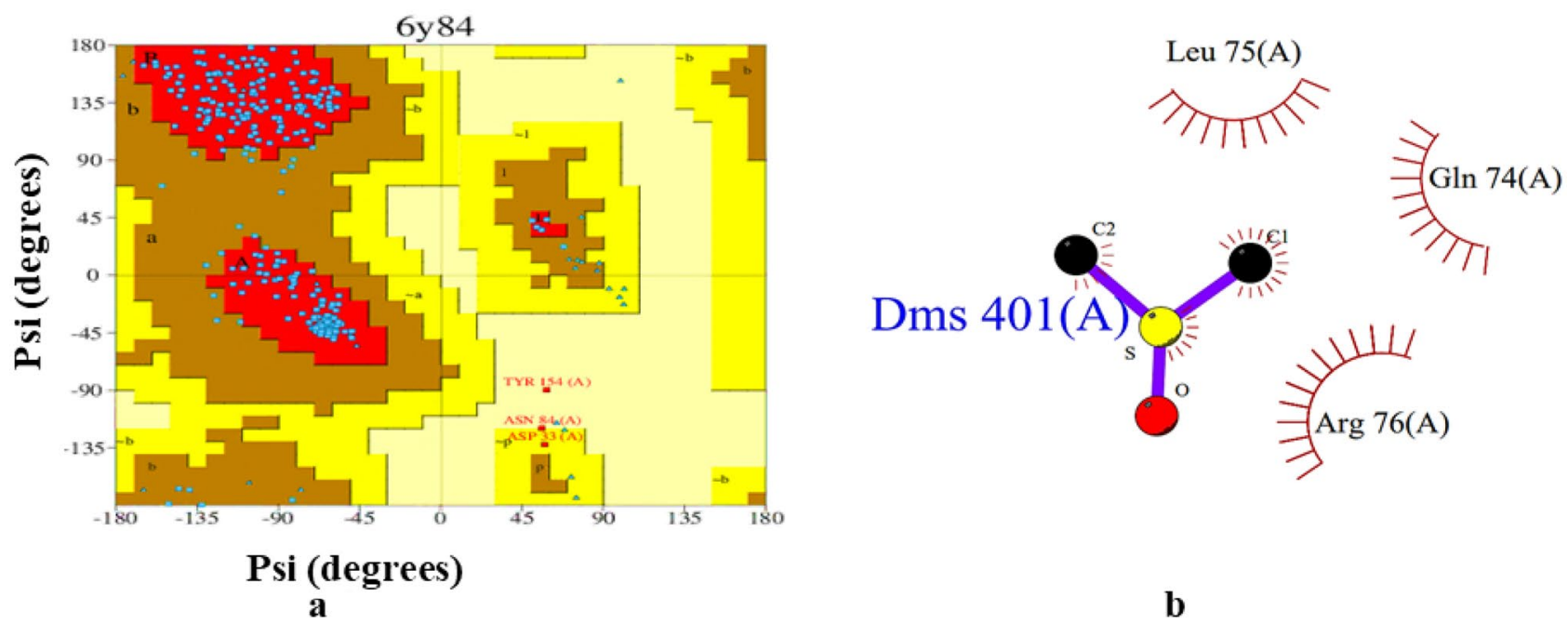

Fig. 2 (a) Ramachandran plot for the SARS-CoV-2 main protease (PDB: 6Y84); (b) LigPlot image of the SARS-CoV-2 main protease (PDB: $6 \mathrm{Y} 84$ ) complex in 2D view predicted by PDBsum

annealing methods. The time step of the simulation systems was set as 2.0 fs. The Particle Mesh Ewalds calculated the long-range electrostatic interactions by a cut-off radius of $8.0 \AA$ [46-48]. The time step of the simulation cell was set as $2.0 \mathrm{fs}$ [49]. The simulation trajectories were saved after every 100 ps. By following constant pressure and Berendsen thermostat, the simulation was run for $50 \mathrm{~ns}$. Simulation trajectories were used to calculate the root mean square deviations and root mean square fluctuations, solvent-accessible surface area, and radius of gyrations [50-52].

\section{Pharmacokinetic prediction}

The online server pkCSM, admetSAR (http://lmmd.ecust. edu.cn/admetsar2/about) and swiss-absorption, distribution, metabolism, excretion (ADME) (http://www.swissadme.ch) was employed to investigate the pharmacokinetic parameters and toxicity of the MGP esters. We have utilized the online database to assess the pharmacokinetics parameters related to the parent drug's drug absorption, metabolism, and toxicity and its designed esters [53]. These online tools use structure similarity search methods to predict the latest and most comprehensive manually curated data for diverse chemicals associated with known ADME/T profiles. Generally, drug-likeness is evaluated using Lipinski's rule of five [54]. Although it is difficult to verify all of these compounds and determine whether or not this program included organicbased drugs, well-known Pt-based cisplatin and carboplatin, as well as metal-based drugs approved by the FDA and in clinical trials, were used as test candidates to validate our carbohydrate esters. Furthermore, to identify potential drug candidates, we calculate in silico parameters that allow for the inclusion of pharmacokinetic features such as absorption in the human intestine, percolation of the blood-brain barrier, and the central nervous system (CNS), metabolism, which indicates the chemical biotransformation of a potential drug by the body, total clearance of drugs, and toxicity.

\section{Results and discussion}

\section{Characterization}

The main objective of the research work reported in this paper was to carry out selective myristoylation (Scheme 1) of methyl $\beta$-D-galactopyranoside (1) with myristoyl chloride using the direct acylation method. A series of derivatives of the resulting myristoylation products were prepared employing a wide variety of acylating agents. The products thus obtained from this were derivatized with several differently substituted acyl chlorides. The main acylation products and their derivatives were established by analyzing their FTIR, ${ }^{1} \mathrm{H}-\mathrm{NMR}$, mass spectra, and physical \& elemental analysis Tables 2 and 3. In continuation of carbohydrate research in our Laboratory of Carbohydrate and Nucleoside Chemistry, we intended to prepare a series of methyl $\beta$-D-galactopyranoside derivatives for use test MGP esters for antibacterial, antifungal evaluation, and computational studies.

Our next effort was to react methyl $\beta$-D-galactopyranoside (1) with a unimolecular amount of myristoyl chloride as an acylating agent in dry DMF and $\mathrm{Et}_{3} \mathrm{~N}$ at freezing temperature, followed by removal of solvent and silica gel column chromatographic purification, furnished the myristoyl 
Scheme 1 Reagents and conditions: (a) dry DMF, $\mathrm{Et}_{3} \mathrm{~N}, 0{ }^{\circ} \mathrm{C}$, $6 \mathrm{~h}$; DMAP, (b) $\mathrm{R}-\mathrm{Cl}=$ several acyl halides, $0{ }^{\circ} \mathrm{C}$ to $\mathrm{rt}$, stirrer for $6 \mathrm{~h}$. (3-10)

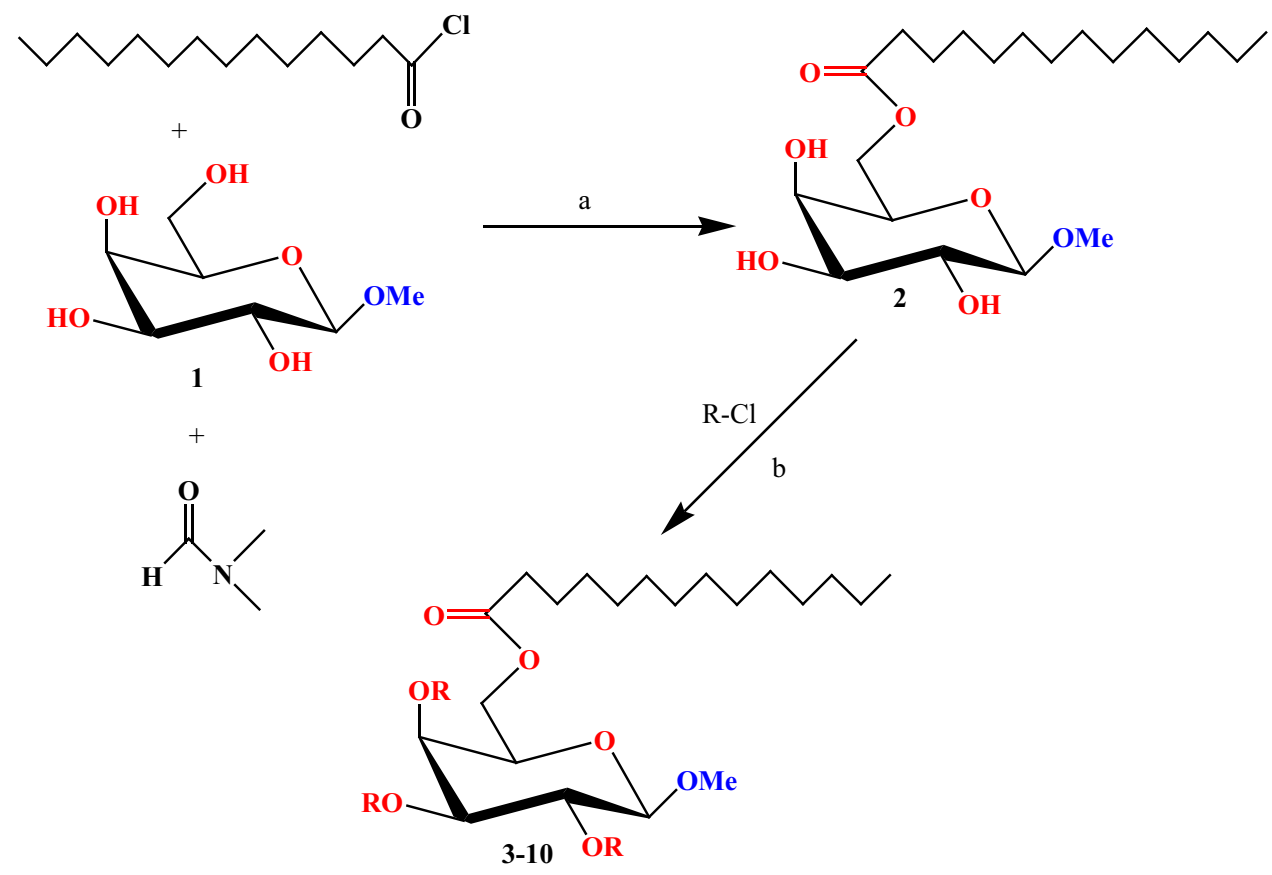

derivative (2) in $86.45 \%$ yield as a crystalline solid, m.p. $135-140{ }^{\circ} \mathrm{C}$. The structure of the myristoyl derivative (2) was established by analyzing its FTIR, ${ }^{1} \mathrm{H}-\mathrm{NMR}$ spectra, and elemental data. The FTIR spectrum (Fig. 3A) exhibited absorption bands at $1710 \mathrm{~cm}-{ }^{1}$ for $\mathrm{C}=\mathrm{O}$ stretching and $3414 \sim 3511 \mathrm{~cm}^{-}{ }^{1}$ (br) for $-\mathrm{OH}$ broad stretching. In its ${ }^{1} \mathrm{H}-$ NMR spectrum (Fig. 3B), the characteristic two-proton multiplets at $\delta 2.38\left\{\mathrm{CH}_{3}\left(\mathrm{CH}_{2}\right)_{11} \mathrm{CH}_{2} \mathrm{CO}-\right\}$ and $\delta 1.64\left\{\mathrm{CH}_{3}(\mathrm{C}\right.$ $\left.\mathrm{H}_{2}\right)_{10} \mathrm{CH}_{2} \mathrm{CH}_{2} \mathrm{CO}$ - $\}$, twenty-proton multiplet at $\delta 1.28\left\{\mathrm{CH}_{3}\right.$ $\left.\left(\mathrm{CH}_{2}\right)_{10} \mathrm{CH}_{2} \mathrm{CH}_{2} \mathrm{CO}-\right\}$ and three-proton multiplet at $\delta 0.94$ $\left\{\mathrm{CH}_{3}\left(\mathrm{CH}_{2}\right)_{12} \mathrm{CO}-\right\}$ were due to myristoyl group in the molecule. The downfield shift of C-6 to $\delta 4.85$ (as dd, $\mathrm{J}=11.1$ and $6.5 \mathrm{~Hz}, 6 \mathrm{a}$ ) and 4.72 (as dd, $\mathrm{J}=11.1$ and $6.7 \mathrm{~Hz}, 6 \mathrm{~b}$ ) from its usual value ( 4.00 ppm) [19] indicated the attachment of the myristoyl group at position 6 . The formation of 6-O-myristoyl derivative (2) might be due to the higher reactivity of the precursor molecule's sterically less hindered primary hydroxyl group (1). Mass spectrum of compound (2) had a molecular ion peak at $m / z[\mathrm{M}+1]^{+} 405.54$ corresponding to molecular formula, $\mathrm{C}_{21} \mathrm{H}_{40} \mathrm{O}_{7}$. By complete analysis of the FTIR, ${ }^{1} \mathrm{H}$-NMR spectra, and other properties, the structure of this compound was assigned as methyl 6-O-myristoyl- $\beta$-D-galactopyranoside (2).

In the COSY spectrum of compound 2, the starting point could well be the signal from H-6a proton which is the most downfield and therefore readily assigned. Thus the signal from H-6a at the bottom left of the diagonal has a cross-peak labelled as H-6a, H-5 connecting it to the signal from H-5. Thus, H-6a proton around 84.85 is coupled to the hydrogen whose signal appears around $\delta 3.88$ (i.e. H-5 proton). Similarly, the signal from $\mathrm{H}-5$ is further connected by a cross-peak to the signal from $3 \mathrm{H}, \mathrm{CH}_{3}\left(\mathrm{CH}_{2}\right)_{12} \mathrm{CO}$ - to show the coupling between $\mathrm{H}-5$ and $3 \mathrm{H}, \mathrm{CH}_{3}\left(\mathrm{CH}_{2}\right)_{12} \mathrm{CO}$-. The Downfield shift of $\mathrm{H}-1, \mathrm{H}-3, \mathrm{H}-4, \mathrm{H}-6 \mathrm{a}$ and $\mathrm{H}-6 \mathrm{~b}$ as compared to precursor compound 2 (Table 1) clearly demonstrated the attachment of myristoyl groups at C-6 positions. Signal assignments by analyzing the COSY, HSQC and HMBC spectral experiments (Fig. 4) along with ${ }^{13} \mathrm{C}$ NMR spectrum confirmed the structure as methyl 6- $O$-myristoyl- $\beta$-D-galactopyranoside (2).

The 6-O-myristoyl derivative (2) structure was further supported by its conversion to and identification of the acetyl derivative (3). Thus, compound 2 with an excess of acetyl chloride, followed by the usual aqueous work-up procedure, provided the acetyl derivative (3). The FTIR spectrum of this compound showed the absorption peaks at 1709, 1706, and $1700 \mathrm{~cm}^{-1}$ due to carbonyl (-CO) stretching. Three three-proton singlets demonstrated the introduction of three acetyl groups in the molecule at $\delta 2.21,2.14$, and 2.11 in its ${ }^{1} \mathrm{H}-\mathrm{NMR}$ spectrum. Molecular ion peak at $\mathrm{m} / z[\mathrm{M}+1]^{+}$ 531.65 corresponding to molecular formula, $\mathrm{C}_{27} \mathrm{H}_{46} \mathrm{O}_{10}$, and the structure of the triacetylate was ascertained as methyl 2,3,4-tri- $O$-acetyl-6- $O$-myristoyl- $\beta$-D-galactopyranoside (3) (Tables 2, 3 and Fig. 5).

Further support for the structure accorded to compound (2) was obtained by preparation of its butyryl derivative (4), palmitoyl derivative (5), and stearoyl derivative (6). Thus, treatment of compound (2) with butyryl chloride, palmitoyl chloride, and stearoyl chloride in dry 
A
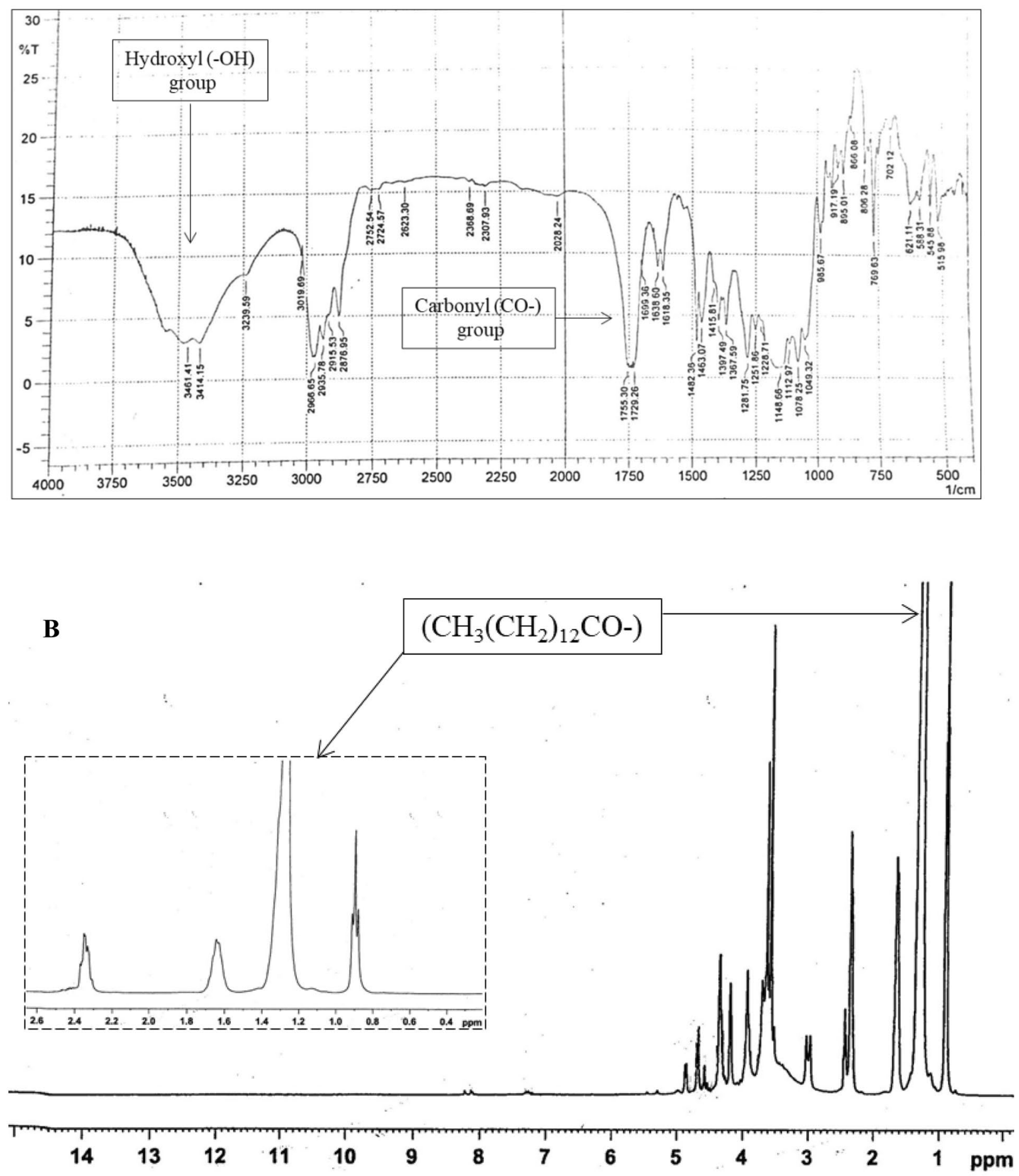

Fig. 3 (A) FTIR and (B) ${ }^{1}$ H-NMR spectra of the methyl 6- $O$-myristoyl- $\beta$-D-galactopyranoside (2)

$\mathrm{N}, \mathrm{N}$-dimethylformamide and triethylamine, followed by conventional work-up and chromatographic purification, afforded the butyryl derivative (4), palmitoyl derivative (5), and stearoyl derivative (6) in good yield. We were able to propose a structure of the compounds $4-6$ by analysis of complete spectroscopic data.

Thus, treatment of compound 2 with trityl chloride provided the trityl derivative (7) as needles. In its ${ }^{1} \mathrm{H}-\mathrm{NMR}$ 
Table $1{ }^{1} \mathrm{H}$-NMR and ${ }^{13} \mathrm{C}$-NMR shift values of compound $2 .{ }^{1} \mathrm{H}$ and ${ }^{13} \mathrm{C}$ assignments were obtained from HSQC and HMBC experiments were performed on Bruker DPX-400 spectrometer $\left(\mathrm{CDCl}_{3}, 400 \mathrm{MHz}\right)$

\begin{tabular}{llrl}
\hline Position & $\delta_{\mathrm{H}}(\mathrm{ppm})(\mathrm{J} \mathrm{Hz})$ & $\begin{array}{c}(\mathrm{HSQC}) \\
\delta_{\mathrm{C}}(\mathrm{ppm})\end{array}$ & $\mathrm{HMBC}$ \\
\hline 1 & $4.86(\mathrm{~d}, \mathrm{~J}=8.0)$ & 104.10 & $\mathrm{H}: 2, \mathrm{OCH}_{3}$ \\
2 & $3.89(\mathrm{dd}, \mathrm{J}=8.0$ and & 77.22 & $\mathrm{H}: 1,3$ \\
& $10.5)$ & & \\
3 & $4.18(\mathrm{dd}, \mathrm{J}=3.0$ and & 75.25 & $\mathrm{H}: 2,4$ \\
& $10.5)$ & & \\
4 & $4.35(\mathrm{~d}, \mathrm{~J}=3.5)$ & 77.02 & $\mathrm{H}: 3,5$ \\
5 & $3.61(\mathrm{~m})$ & 69.15 & $\mathrm{H}: 4,6 \mathrm{a}, 6 \mathrm{~b}$ \\
$6 \mathrm{a}, 6 \mathrm{~b}$ & $4.77(\mathrm{dd}, \mathrm{J}=11.1$ and & 62.05 & $\mathrm{H}: 5, \mathrm{CO}$ \\
& $6.5) ; 4.70(\mathrm{dd}, \mathrm{J}=11.1$ & & \\
$\mathrm{OCH}_{3}$ & and 6.7$)$ & & \\
6-COCH & & 57.06 & $\mathrm{H}: 1$ \\
\hline
\end{tabular}

spectrum, two characteristic peaks; eighteen-proton multiplet at $\delta 7.67(3 \times \mathrm{Ar}-\mathrm{H}))$ and a twenty-seven-proton multiplet at $\delta 7.45(3 \times \mathrm{Ar}-\mathrm{H})$ were due to the three trityl groups in the molecule. The rest of the protons resonated in their anticipated positions, leading us to propose a structure of this compound as methyl 6-O-myristoyl-2,3,4tri- $O$-trityl- $\beta$-D-galactopyranoside (7). Cinnamoylation of 2 with an excess of cinnamoyl chloride in dry $\mathrm{DMF} / \mathrm{Et}_{3} \mathrm{~N}$, isolated compound (8) in crystalline solid. In the ${ }^{1} \mathrm{H}-\mathrm{NMR}$ spectrum, three one-proton doublets at $\delta$ 77.757.52, $7.37(3 \times 1 \mathrm{H}, 3 \times \mathrm{d}, \mathrm{J}=16.0 \mathrm{~Hz}, 3 \times \mathrm{PhCH}=\mathrm{CHCO}-)$ and also three one-proton doublets at $\delta 6.55,6.16,6.07(3 \times 1 \mathrm{H}$, $3 \times \mathrm{d}, \mathrm{J}=16.1 \mathrm{~Hz}, 3 \times \mathrm{PhCH}=\mathrm{CHCO}-$ ) due to the presence of three cinnamoyl groups in the molecule. In addition, a six-proton multiplet at $\delta 7.54$ (as $\mathrm{m}, \mathrm{Ar}-\mathrm{H})$ and a nineproton multiplet at $\delta 7.28$ (as, $\mathrm{m}, \mathrm{Ar}-\mathrm{H}$ ) due to the three aromatic rings protons. The rest of the FTIR, ${ }^{1} \mathrm{H}-\mathrm{NMR}$, mass spectrum, and other properties was in accord with the structure of this compound assigned as methyl2,3,4-tri$O$-cinnamoyl-6- $O$-myristoyl- $\beta$-D-galactopyranoside (8).

Finally, we used $p$-toluenesulfonyl chloride and 3 -chlorobenzoyl chloride for derivatizing compound 2 by direct acylation method. After the usual work-up and purification procedure, we obtained the $p$-toluenesulfonyl derivative (9) and 3-chlorobenzoyl derivative (10) in excellent yields. By complete analysis of their FTIR, ${ }^{1} \mathrm{H}-\mathrm{NMR}$, mass spectrum, and by analogy with similar derivatives described earlier, the structures of these compounds were confidently assigned as methyl 6- $O$-myristoyl-2,3,4-tri- $O$-( $p$-toluenesulfonyl $)-\beta$ D-galactopyranoside (9) and methyl 2,3,4-tri- $O$-(3chlorobenzoyl)-6- $O$-myristoyl- $\beta$-D-galactopyranoside (10).

\section{Antibacterial inhibitory activity}

The results of the antibacterial activity of the test MGP esters (1-10) were measured in terms of zone of inhibition
$\mathbf{A}$

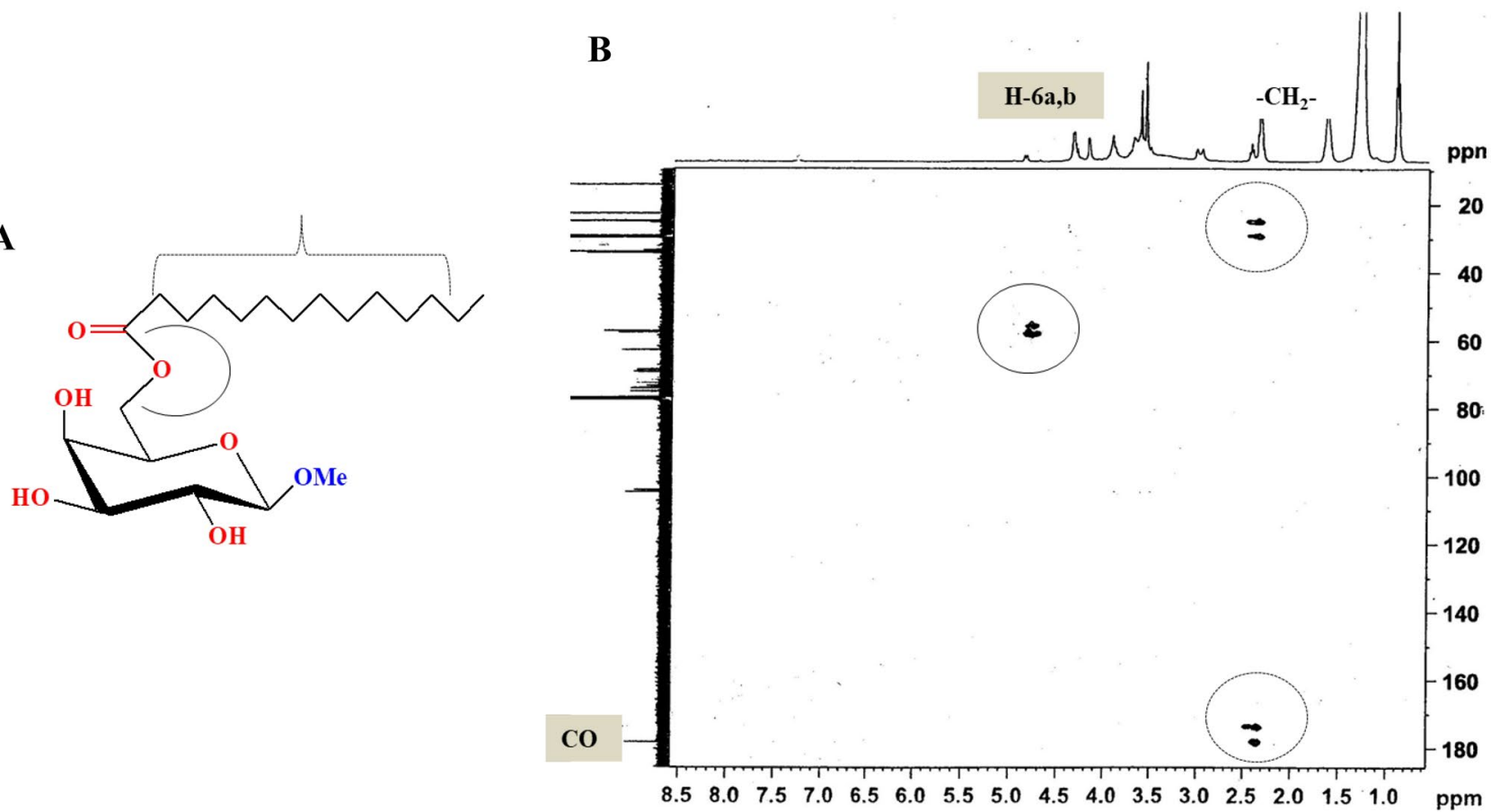

Fig. 4 The HMBC correlations of (A) comppound 2 and (B) $\mathrm{CO}$ with $\mathrm{H}-6 \mathrm{a}, \mathrm{b}$ and $\mathrm{CH}_{2}$ protons 


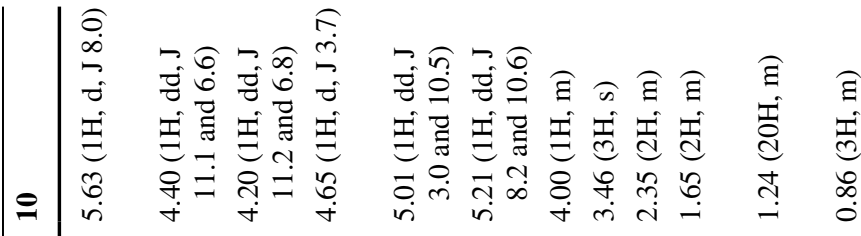

z

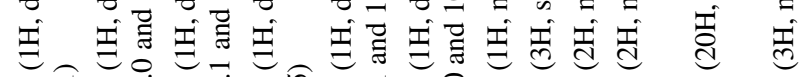

तुळ

ฮิ

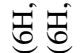

कृ

ت

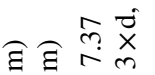

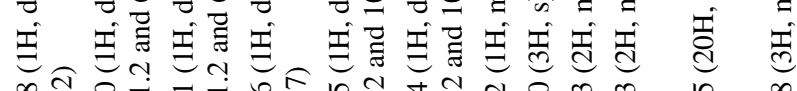

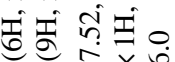

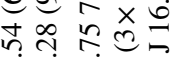

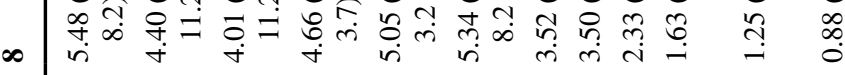

$r i$

ฮิ

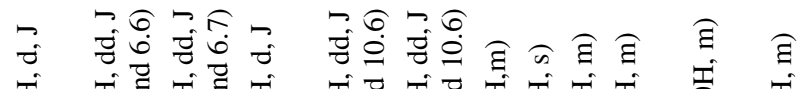

赵芒

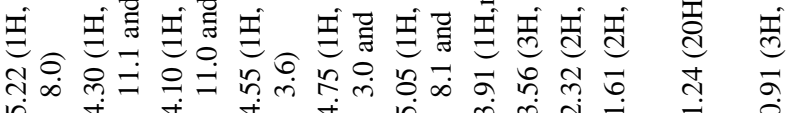

许.

-

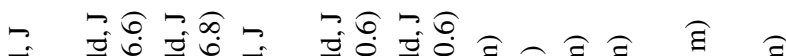

๕ิ ఏ

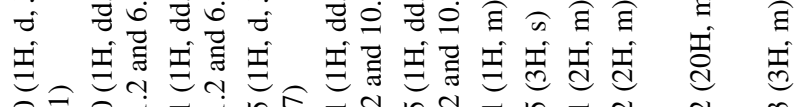

○

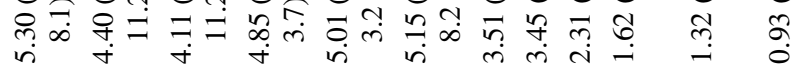

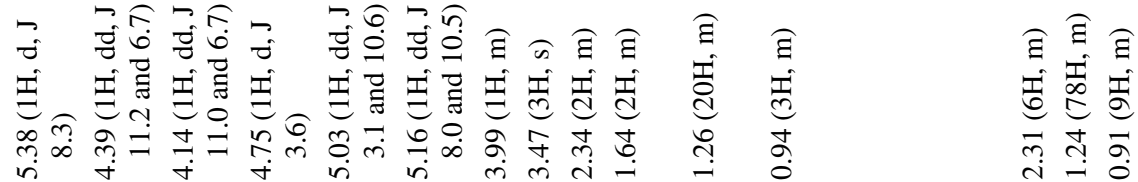

in

z

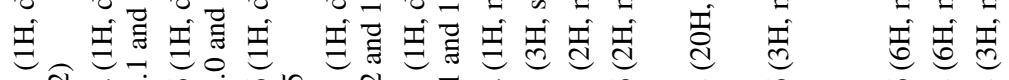

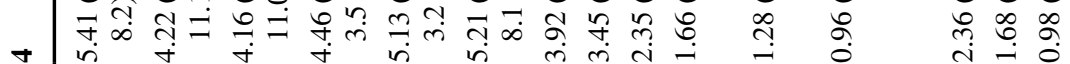

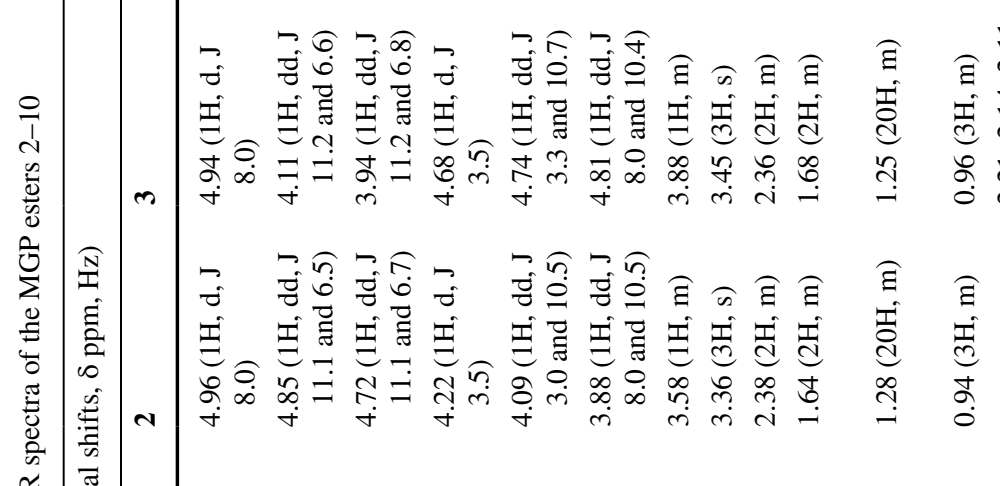

$\exists \underset{\hat{n}}{\dot{x}}$

ì

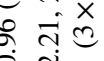

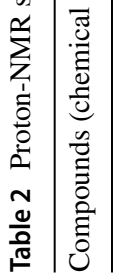

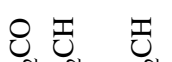
记 范

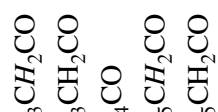

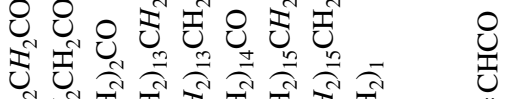

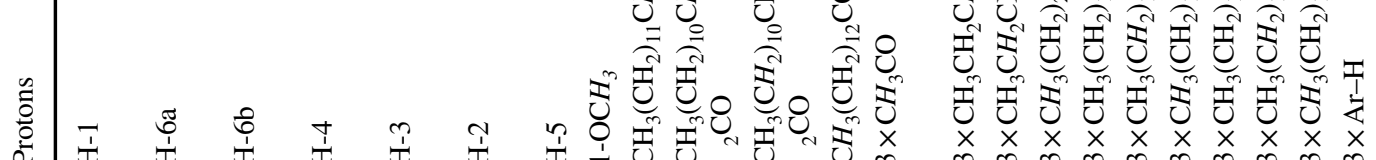
$\underset{m}{x} \underset{m}{x} \underset{m}{x} \underset{m}{x} \underset{m}{x} \underset{m}{x} \underset{m}{x} \underset{m}{x} \underset{m}{x} \underset{m}{x}$ 


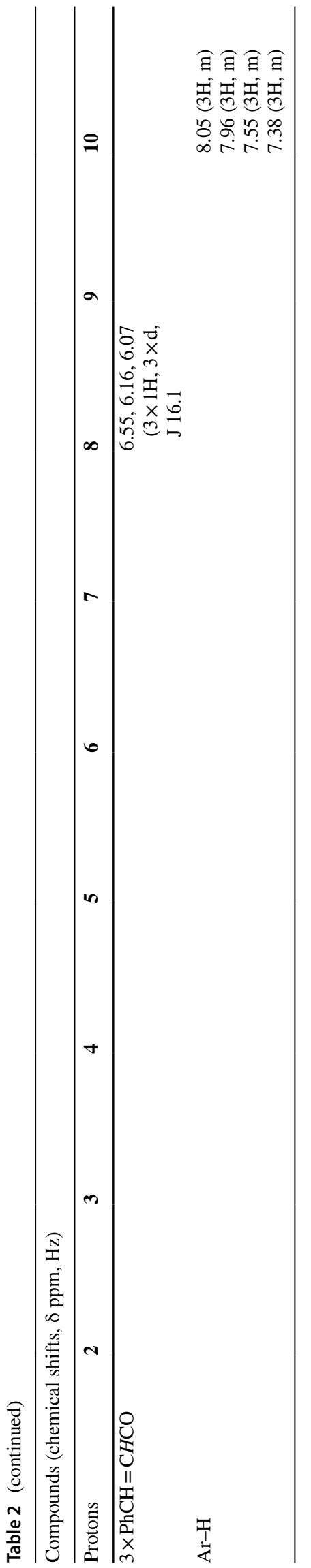

and are presented in Table 4, Figs. 6, 7. The compounds showed promising inhibitory activity against a number of both Gram-positive and Gram-negative bacteria. The inhibition data (Table 4) indicated that compound 4 showed the highest activity $(39 \pm 0.4 \mathrm{~mm})$; compounds 2 $(29 \pm 0.4 \mathrm{~mm}), 3(21 \pm 0.3 \mathrm{~mm}), 8(25 \pm 0.3 \mathrm{~mm})$, and 10 $(34 \pm 0.4 \mathrm{~mm})$ were also exhibited an excellent inhibition activity against Bacillus subtilis than the standard antibiotic azithromycin $(19 \pm 0.3 \mathrm{~mm})$. On the other hand, compound $10(26 \pm 0.3 \mathrm{~mm})$ showed more activity than standard drug on Staphylococcus aureus. However, compounds $3(20 \pm 0.3 \mathrm{~mm}), 4(22 \pm 0.3 \mathrm{~mm}), 6(20 \pm 0.3 \mathrm{~mm})$, $7(18 \pm 0.3 \mathrm{~mm})$, and $10(33 \pm 0.4 \mathrm{~mm})$ showed the highest inhibition zone against Escherichia coli. In addition, compound 10 showed good inhibition against both Salmonella abony and Pseudomonas aeruginosa organisms. We also observed that compound 10 was very active against both the Gram-positive and Gram-negative organisms. The results also observed that the MGP ester 10 was very effective against all tested organisms compared to azithromycin, which led us to carry out the MIC and MBC tests for this compound. The results are presented in Fig. 8A and B. The MIC values of the MGP ester 10 was found to be ranging from $0.352 \pm 0.02$ to $0.703 \pm 0.01 \mathrm{mg} / \mathrm{ml}$, and $\mathrm{MBC}$ values were found ranging from $0.704 \pm 0.02$ to $1.408 \pm 0.04 \mathrm{mg} /$ $\mathrm{ml}$. The MIC and MBC indicate the usefulness of these compounds as antimicrobial drugs, but some other experiments must be carried out before these can be used as effective drugs. So this compound may be targeted for future studies for their usage as broad-spectrum antibiotics.

\section{Antifungal activity}

The test compounds' antifungal activity was tested against two phytopathogenic fungi and compared with antifungal antibiotic Nystatin. The inhibition of fungal mycelial growth results is given in Table 5, Figs. 9, and 10. The tested compounds displayed marked toxicities toward several fungal phytopathogens. The antifungal screening data (Table 4) suggests that the test chemicals $3(75.56 \pm 1.1 \%)$, $4(84.44 \pm 1.2 \%), 5(74.11 \pm 1.1 \%), 6(82.22 \pm 1.2 \%)$, and $10(92.22 \pm 1.2 \%)$, showed marked toxicities toward Aspergillus niger, even higher than the standard antibiotic, Nystatin $(66.4 \pm 1.0 \%)$. On the other hand, compounds 6 $(86.67 \pm 1.2 \%), 8(75.56 \pm 1.1 \%), 9(72.22 \pm 1.1 \%)$, and 10 $(87.78 \pm 1.2 \%)$ showed excellent inhibition against Aspergillus flavus, being higher than or comparable to Nystatin $(63.1 \pm 1.0 \%)$. However, the inhibition of the MGP ester 7 $(64.45 \pm 1.0 \%)$ inhibition of mycelial growth against Aspergillus niger was reasonably high, though not as high as the standard antibiotic, Nystatin. These results are very much in accordance with our previous study [19]. 
Table 3 Infrared, mass and physicochemical properties of the MGP esters 2-10

\begin{tabular}{|c|c|c|c|c|c|c|c|}
\hline \multirow[t]{2}{*}{ Compound no } & \multirow[t]{2}{*}{ Mol. formula } & \multirow[t]{2}{*}{ FTIR $\left(\mathrm{KBr}, \nu_{\max }\right) \mathrm{cm}^{-1}$} & \multirow[t]{2}{*}{$\mathrm{LC}-\mathrm{MS}[\mathrm{M}+1]^{+}$} & \multirow[t]{2}{*}{ mp. $\left({ }^{\circ} \mathrm{C}\right)$} & \multirow[t]{2}{*}{ Yield (\%) } & \multicolumn{2}{|c|}{ Found (calculated) } \\
\hline & & & & & & $\% \mathrm{C}$ & $\% \mathrm{H}$ \\
\hline 2 & $\mathrm{C}_{21} \mathrm{H}_{40} \mathrm{O}_{7}$ & $\begin{array}{l}1710(\mathrm{C}=\mathrm{O}), 3414 \sim 3511(\mathrm{br}) \\
\quad(-\mathrm{OH})\end{array}$ & 405.54 & $139-140$ & 86.45 & $62.35(62.34)$ & $9.97(9.96)$ \\
\hline 3 & $\mathrm{C}_{27} \mathrm{H}_{46} \mathrm{O}_{10}$ & $1709,1706,1700(\mathrm{C}=\mathrm{O})$ & 531.65 & $144-145$ & 72.50 & $61.09(61.11)$ & $8.75(8.73)$ \\
\hline 4 & $\mathrm{C}_{33} \mathrm{H}_{58} \mathrm{O}_{10}$ & $1708(\mathrm{C}=\mathrm{O})$ & 615.81 & $154-155$ & 55.38 & $64.44(64.46)$ & $9.52(9.50)$ \\
\hline 5 & $\mathrm{C}_{69} \mathrm{H}_{130} \mathrm{O}_{10}$ & $1707(\mathrm{C}=\mathrm{O})$ & 1120.76 & $133-134$ & 96.65 & $74.02(74.0)$ & $11.68(11.69)$ \\
\hline 6 & $\mathrm{C}_{75} \mathrm{H}_{142} \mathrm{O}_{10}$ & $1703(-\mathrm{CO})$ & 1204.92 & $149-150$ & 82.58 & $74.83(74.82)$ & $11.90(11.88)$ \\
\hline 7 & $\mathrm{C}_{78} \mathrm{H}_{82} \mathrm{O}_{7}$ & $1699(\mathrm{C}=\mathrm{O})$ & 1132.48 & $166-167$ & 92.57 & $82.78(82.79)$ & $7.33(7.30)$ \\
\hline 8 & $\mathrm{C}_{48} \mathrm{H}_{58} \mathrm{O}_{10}$ & $1702(-\mathrm{CO})$ & 795.97 & $128-129$ & 69.66 & $72.53(72.52)$ & $7.37(7.35)$ \\
\hline 9 & $\mathrm{C}_{42} \mathrm{H}_{58} \mathrm{O}_{13} \mathrm{~S}_{3}$ & $1705(\mathrm{C}=\mathrm{O}), 1324\left(\mathrm{SO}_{2}\right)$ & 868.10 & $151-152$ & 75.78 & $58.19(58.17)$ & $6.76(6.74)$ \\
\hline 10 & $\mathrm{C}_{42} \mathrm{H}_{49} \mathrm{O}_{10} \mathrm{Cl}_{3}$ & $1709(\mathrm{C}=\mathrm{O})$ & 821.19 & 194-195 & 91.85 & $61.53(61.50)$ & $6.03(6.02)$ \\
\hline
\end{tabular}

\section{SAR study}

This study attempted to explain the SAR of the tested MGP esters, while compound 10 is the most active chemical against all the tested bacterial pathogens. It was evident from the results that incorporation of different acyl groups, especially in the C-5 position and later on C-2, C-3 and C-4 position of methyl- $\beta$-D-galactopyranoside, increase the activity of the tested chemicals against bacteria and fungus. The bacterial membrane consists of almost $40 \%$ phospholipids and $60 \%$ proteins. In Gram-negative bacteria, the outer membrane contains phospholipid, i.e., hydrophobic hydrocarbon chain. Our synthesized compound 10 had been acylated hydrophobic hydrocarbon chain at the C-5 position. Therefore, it was hypothesized that compound 10 interact with the bacterial membrane through hydrophobic attraction. Then the poisonous activity provided by the 3 -chlorobenzoyl benzoyl group attached at C-2, C-3, and C-4 position of methyl- $\beta$ D-galactopyranoside (Fig. 11) and ultimately the fate of a bacterial cell is death.

In Gram-positive bacteria, the synthesized compound 10 penetrates the membrane through the thick peptidoglycan layer (Fig. 11). We believe there might be an interaction between sugar moieties of compound 10 and peptidoglycan of the bacterial cell wall (like dissolve like concept). The rest of the mechanism is almost the same as Gram-negative bacteria, as explained previously. We assume that this kind of mechanism may also be applicable for tested compounds 3 and 4 etc.

Because it is directly related to membrane permeation, material hydrophobicity is an important parameter to such bioactivity as toxicity or membrane integrity alteration. Hunt [55] also proposed that the potency of aliphatic alcohols is directly related to their lipid solubility via the hydrophobic interaction of alcohol alkyl chains with lipid regions in the membrane. It is assumed that the hydrophobic interaction might occur between the acyl chains of methyl- $\beta$-Dgalactopyranoside accumulated in the lipid-like nature of the bacteria membranes. Due to their hydrophobic interaction, bacteria lose their membrane permeability, ultimately causing the bacteria's death.

\section{Antimicrobial spectra analysis: PASS}

We have also predicted the antimicrobial spectrum applying web server PASS of all the MGP esters 2-10. The PASS results are yclept as $\mathrm{Pa}$ and $\mathrm{Pi}$, which are displayed in Table 6. It was manifest from predication Table 6 for MGP esters $2-10$ showed $0.36<\mathrm{Pa}<0.55$ for antibacterial, $0.38<\mathrm{Pa}<0.70$ for antifungal, $0.26<\mathrm{Pa}<0.54$ for antioxidant and $0.29<\mathrm{Pa}<0.76$ for anti-carcinogenic. These results revealed that these molecules were more efficient against fungal pathogens than bacterial pathogens. Attachment of additional aliphatic acyl chains (C2 to C18) increased antifungal activity ( $\mathrm{Pa} 1 / 40.704)$ of MGP (1, $\mathrm{Pa} 1 / 40.628)$, whereas insertion of cinnamoyl, Cl- and Ph-substituted aromatic groups also improved reasonably. The same scenario was observed for an antioxidant activity where acyl chain esters revealed improves values than the halo-benzoyl esters. However, ester 8 , which has the cinnamoyl group, exhibited the highest antioxidant activity ( $\mathrm{Pa} 1 / 40.647)$. We also tried to predict the anti-carcinogenic parameter of these esters.

Moreover, PASS determination exhibited $0.29<\mathrm{Pa}<0.76$ for anti-carcinogenic, which revealed that the MGP esters were more potential as anti-carcinogenic agents than previous antimicrobial parameters. Interestingly, the antibacterial, antifungal, antioxidant, and anti-carcinogenic properties of MGP esters with saturated acyl chains (2-6) were found more promising than the halo-benzoyl esters (7-10). 
Fig. 5 Structure of designed MGP esters (2-10)
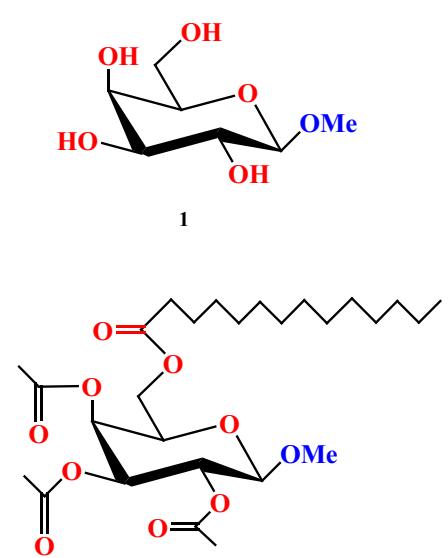<smiles>CCCCCCCCCCCCC(=O)OCC1O[C@H](OC)[C@@H](O)[C@H](O)[C@H]1O</smiles>

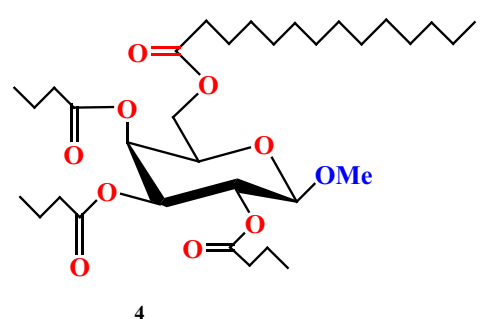

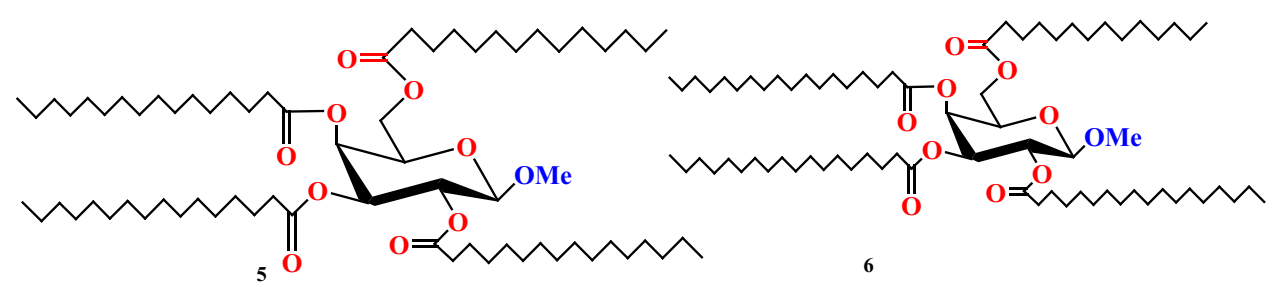

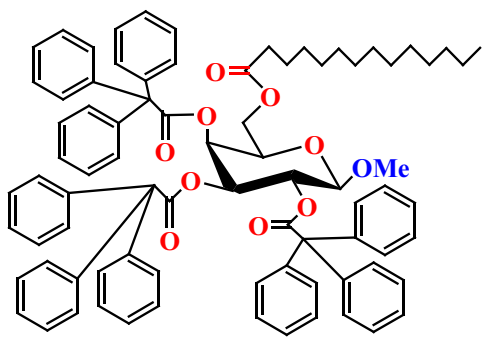

7

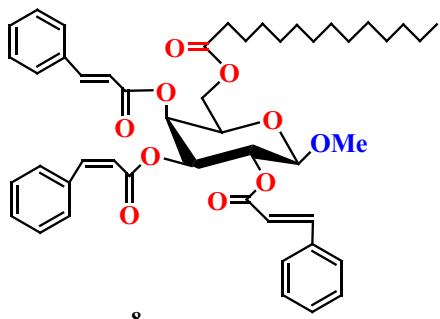

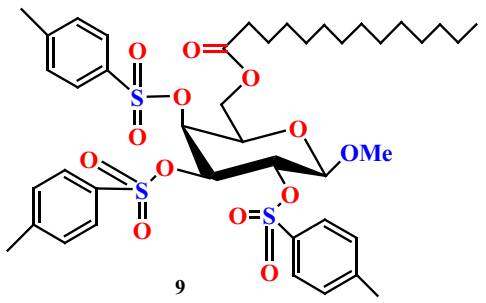

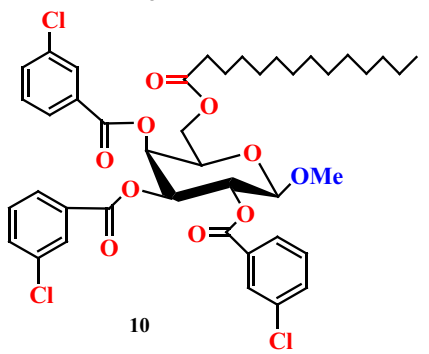

\section{Thermodynamic assessment}

A simple change in the chemical structure significantly impacts structural properties, including thermal and molecular orbital properties. The free energy and enthalpy values can be used to calculate the spontaneity of a reaction and the stability of a product [56]. Highly negative values have a better chance of achieving thermal stability. In drug design, hydrogen bond formation and non-bonded interactions are also influenced by dipole moment. Free energy $(G)$ is a significant criterion to represent the interaction of binding partners, where a negative value is favorable for spontaneous binding and interaction. In the present study, all the MGP esters possess a greater negative value for $E, H$, and $G$ than the parent MGP, and hence, indicated that the attachment of the ester group could improve interaction and binding of these molecules with different microbial enzymes. Comparatively higher dipole moment can improve the binding property [57] of a ligand. MGP ester (7) found the highest free energy, which showed the highest enthalpy and highest electronic energy. As shown in Table 7, some of the MGP esters have improved dipole moment that enhances a molecule's polar nature and promotes the binding affinity, hydrogen 
Table 4 Zone of inhibition observed against Gram-positive and Gram-negative bacteria by the tested MGP esters

\begin{tabular}{llllll}
\hline \multicolumn{5}{l}{ Diameter of inhibition zone $(\mathrm{mm})$} \\
\hline Compounds & B. subtilis $(+v e)$ & S. aureus $(+v e)$ & $\begin{array}{l}\text { E. coli } \\
(-v e)\end{array}$ & $\begin{array}{l}\text { S. abony } \\
(-v e)\end{array}$ & $\begin{array}{l}\text { P. aeruginosa } \\
(-v e)\end{array}$ \\
$\mathbf{1}$ & $\mathrm{NI}$ & $\mathrm{NI}$ & $\mathrm{NI}$ & $\mathrm{NI}$ & $\mathrm{NI}$ \\
$\mathbf{2}$ & $29 \pm 0.4^{*}$ & $\mathrm{NI}$ & $14 \pm 0.3$ & $\mathrm{NI}$ & $\mathrm{NI}$ \\
$\mathbf{3}$ & $21 \pm 0.3^{*}$ & $\mathrm{NI}$ & $20 \pm 0.3^{*}$ & $\mathrm{NI}$ & $\mathrm{NI}$ \\
$\mathbf{4}$ & $39 \pm 0.4^{*}$ & $\mathrm{NI}$ & $22 \pm 0.3^{*}$ & $\mathrm{NI}$ & $\mathrm{NI}$ \\
$\mathbf{5}$ & $\mathrm{NI}$ & $10 \pm 0.1$ & $9 \pm 0.1$ & $13 \pm 0.2$ & $9 \pm 0.3$ \\
$\mathbf{6}$ & $\mathrm{NI}$ & $\mathrm{NI}$ & $20 \pm 0.3^{*}$ & $\mathrm{NI}$ & $\mathrm{NI}$ \\
$\mathbf{7}$ & $\mathrm{NI}$ & $\mathrm{NI}$ & $18 \pm 0.3^{*}$ & $\mathrm{NI}$ & $\mathrm{NI}$ \\
$\mathbf{8}$ & $25 \pm 0.3^{*}$ & $\mathrm{NI}$ & $\mathrm{NI}$ & $\mathrm{NI}$ & $22 \pm 0.3^{*}$ \\
$\mathbf{9}$ & $15 \pm 0.3$ & $15 \pm 0.3$ & $14 \pm 0.3$ & $\mathrm{NI}$ & $\mathrm{NI}$ \\
$\mathbf{1 0}$ & $34 \pm 0.4^{*}$ & $26 \pm 0.3^{*}$ & $33 \pm 0.4^{*}$ & $24 \pm 0.3^{*}$ & $25 \pm 0.4^{*}$ \\
Azithromycin & $19 \pm 0.3^{* *}$ & $18 \pm 0.3^{* *}$ & $17 \pm 0.3^{* *}$ & $19 \pm 0.3^{* *}$ & $17 \pm 0.3^{* *}$ \\
\hline
\end{tabular}

The data are presented as mean $\pm \mathrm{SD}$, and the values are represented for triplicate experiments. Statistically significant inhibition $(\mathrm{p}<0.05)$ is marked with an asterisk $(*)$ for test compounds and a double asterisk $(* *)$ for the reference antibiotic azithromycin

NINo inhibition bonding, and non-bonding interaction with the receptor protein.

The dipole moment of MGP esters (7-10) was higher than the MGP, resulting in their better binding affinity and interactions with the amino acid residues of the receptor protein. The highest dipole moment is (17.5358 Debye) found for ester (9), whereas MGP showed the lower score (4.7712 Debye). Halogenated and aromatic esters had better scores for all parameters, as evidenced by esters (7 and 9-10) (tri-phenyl, $p$-toluenesulfonyl, and 3-chlorobenzoyl) had the highest free energy of the therapeutics under investigation and showed markedly improved dipole moment. Finally, this discussion proves that modification of hydroxyl $(-\mathrm{OH})$ groups of MGP significantly increases its thermodynamic properties, indicating the synthesized esters' inherent stability.

\section{Frontier molecular orbitals analysis}

The most important orbitals in a molecule are the frontier molecular orbitals (FMOs), used to study chemical reactivity and kinetic stability. The HOMO and the LUMO are the FMOs (LUMO). The transition from the ground to the first excited state is referred to as electronic absorption, and it is primarily described by one electron excitation from HOMO to LUMO [58]. Kinetic stability increases as the HOMO-LUMO gap widens. A small HOMO-LUMO gap is important for low chemical stability. Adding electrons to a high-lying LUMO and removing electrons from a low-lying HOMO is energetically favorable in any potential reaction. As a result, removing electrons from ground state HOMO to excited state LUMO requires more energy. The HOMO and LUMO energies, HOMO-LUMO gap $(\Delta)$,

\section{A}

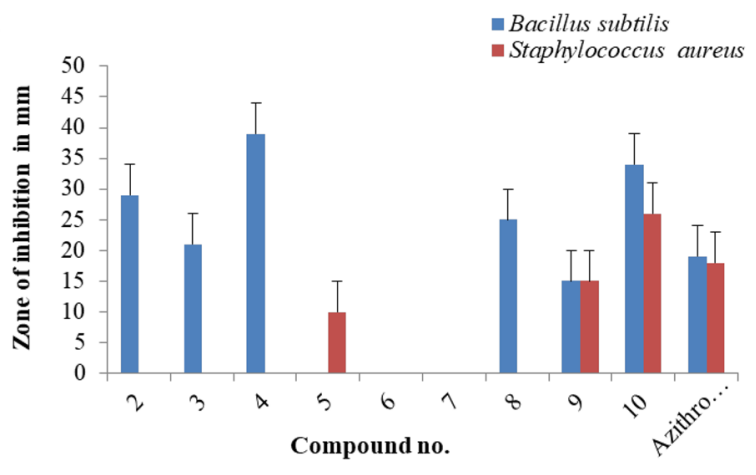

B

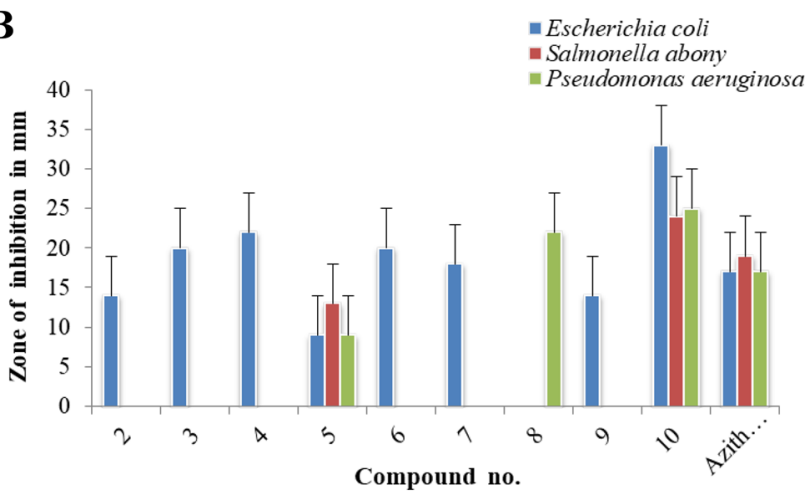

Fig. 6 Inhibition zones against (A) Gram-positive and (B) Gram-negative bacteria for compounds (2-10), [Azith=standard antibiotic] 
A

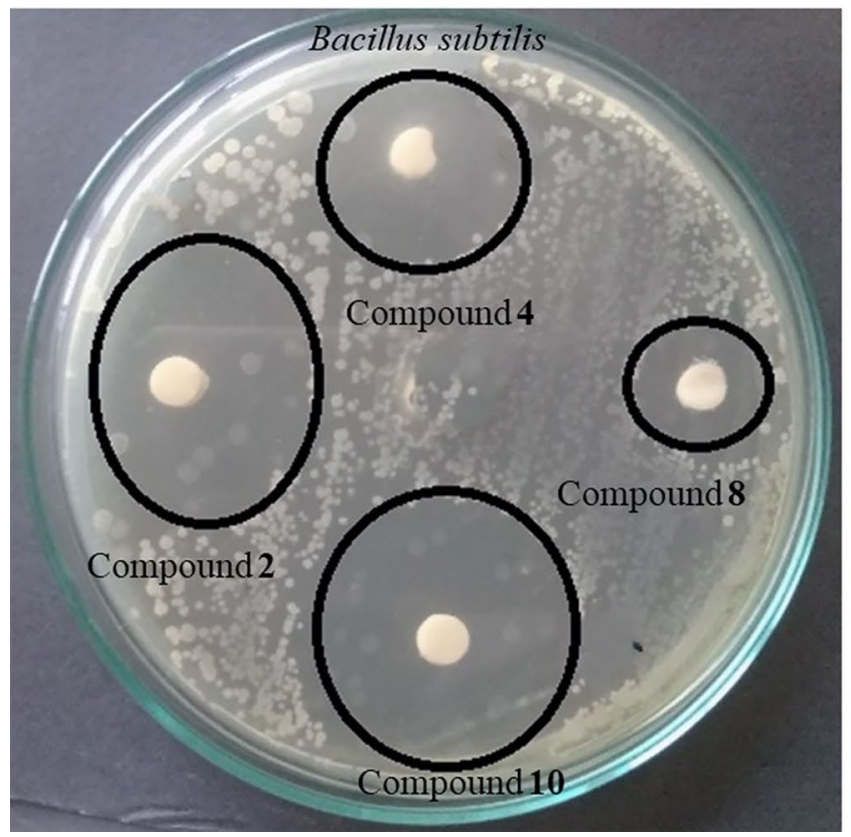

B

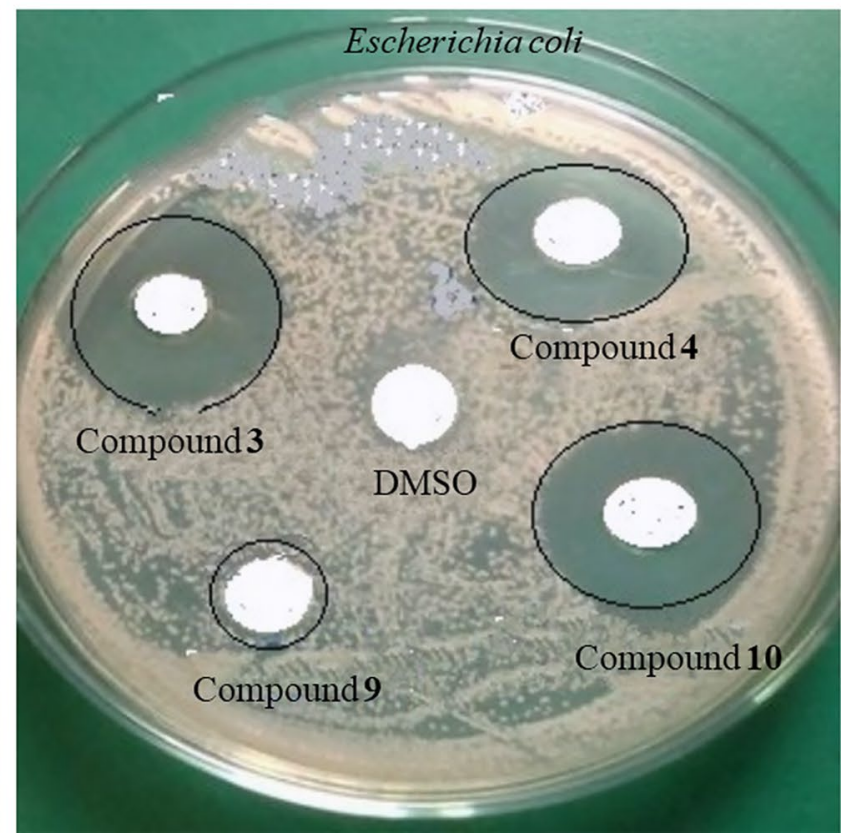

Fig. 7 Inhibition zones were observed against A) Bacillus subtilis by compounds 2, 4, 8, and 10; B) Escherichia coli by compounds 3, 4, 9, and 10. DMSO was treated as a negative control

hardness $(\eta)$, softness $(S)$, and chemical potential $(\mu)$ index of all esters are presented in Table 8.

We discovered that as the number of ester groups and chain length (2-10) increased, the hardness of these compounds decreased while their softness improved. All of these characteristics may indicate increased chemical activity and polarizability in drug-related chemical and biochemical functionalities. For example, in Fig. 12 the LUMO plot of the ester (2) showed that the electron was localized only at the modified acylating group regions. In contrast, the HOMO plot showed that the electron was localized on the pyranose ring's upper part.
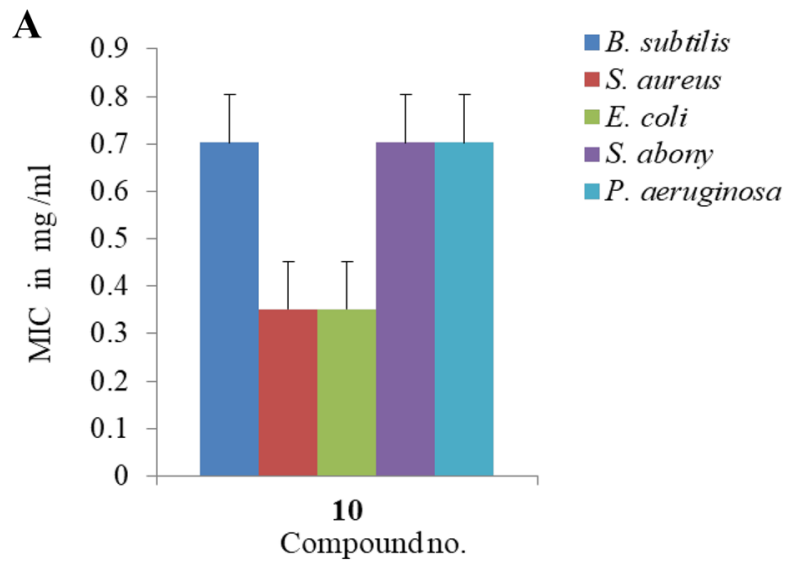

\section{MEP analysis}

In computer-aided drug design, atomic charges are employed to investigate the connectivity between drug structure and biological activity. The molecular electrostatic potential (MEP) is globally used as a reactivity map displaying the most suitable region for the electrophilic and nucleophilic attack of charged point-like reagents on organic molecules [59]. It helps to interpret the biological recognition process and hydrogen bonding interaction [60]. MEP counter map gives a simple way to predict how different geometry could interact. The MEP of title ester is obtained based on the

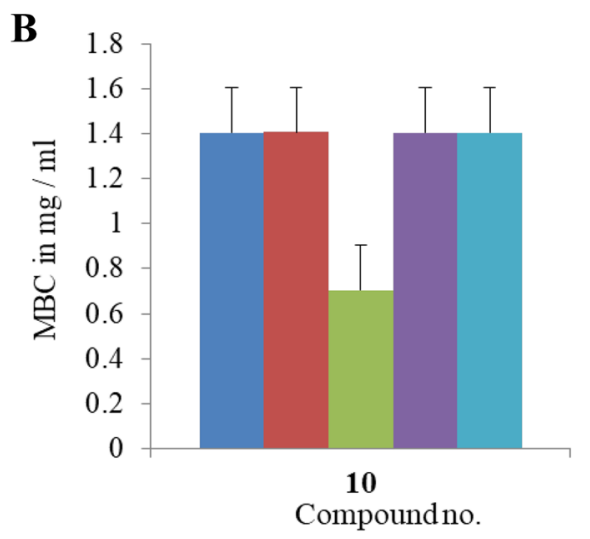

B. subtilis
S. aureus
E. coli
S. abony
P. aeruginosa

Fig. 8 A) MIC and B) MBC values of the compound 10 against five bacteria 
Table 5 Antifungal activities of the synthesized MGP esters in (\%) of inhibition

\begin{tabular}{lll}
\hline \multirow{2}{*}{$\begin{array}{l}\text { Compound } \\
\text { no }\end{array}$} & \multicolumn{2}{l}{ Percentage $(\%)$ of inhibition } \\
\cline { 2 - 3 } & Aspergillus niger & Aspergillus. flavus \\
\hline $\mathbf{2}$ & $67.44 \pm 1.0$ & $\mathrm{NI}$ \\
$\mathbf{3}$ & $75.56 \pm 1.1^{*}$ & $\mathrm{NI}$ \\
$\mathbf{4}$ & $84.44 \pm 1.2^{*}$ & $\mathrm{NI}$ \\
$\mathbf{5}$ & $74.11 \pm 1.1^{*}$ & $\mathrm{NI}$ \\
$\mathbf{6}$ & $82.22 \pm 1.2^{*}$ & $86.67 \pm 1.2^{*}$ \\
$\mathbf{7}$ & $64.45 \pm 1.0$ & $\mathrm{NI}$ \\
$\mathbf{8}$ & $66.67 \pm 1.0$ & $75.56 \pm 1.1^{*}$ \\
$\mathbf{9}$ & $\mathrm{NI}$ & $72.22 \pm 1.1^{*}$ \\
$\mathbf{1 0}$ & $92.22 \pm 1.2^{*}$ & $87.78 \pm 1.2^{*}$ \\
Nystatin & $66.40 \pm 1.0^{* *}$ & $63.10 \pm 1.0^{* *}$ \\
\hline
\end{tabular}

The data are presented as mean \pm SD and the values are represented for triplicate experiments. Statistically significant inhibition $(\mathrm{p}<0.05)$ is marked with an asterisk $(*)$ for test compounds and a double asterisk $(* *)$ for the reference antibiotic azithromycin

NINo inhibition

B3LYP with basis set 3-21G optimized result and shown in Fig. 13.

The importance of MEP lies in the fact that it simultaneously shows a molecular size, shape as well as positive, negative, and neutral electrostatic potential regions in terms of color grading and is very useful in research of molecular structure with physicochemical properties relationship [61]. MEP was calculated to forecast the reactive sites for electrophilic and nucleophilic attack of the optimized structure of MGP (1) and its esters (2, 3, 4, and 8). The different values of electrostatic potential represent by different colors. Potential increases in the order red $<$ orange $<$ yellow $<$ green $<$ blue. Red color displays the maximum negative area, which shows a favorable site for an electrophilic attack, blue indicates the maximum positive area favorable for a nucleophilic attack, and the green represents zero potential areas.

\section{Molecular docking and interaction analysis}

Molecular docking is an important computational technique in structural biology and computer-aided drug design. The primary goal of molecular docking is to identify potential binding geometries of a putative ligand with a known three-dimensional structure with a target protein. Using the AutoDock Vina software, a series of MGP esters were studied in silico to highlight their possible binding energy and interaction modes with the active site of SARS-CoV-2 $\mathrm{M}^{\text {pro }}$ (Tables 9 and 10). The estimated binding energies of the binding site of the 6 Y84 protein structure are summarized in Tables 8 and 9 for all the studied compounds. According to the outcomes obtained from docking screening, six esters (2-4 and 8-10) with the strongest binding energies were selected to describe the binding mode of the MGP inhibitors. Comparatively, the aromatic esters were displayed a better binding score than the aliphatic esters. The interactions between the inhibitor and bordering residues of SARS-CoV-2 $\mathrm{M}^{\text {pro }}$ are illustrated in the $2 \mathrm{D}$ schematics, which they were obtained by importing docking results into the Discovery Studio Visualizer (Figs. 14 and 15) shows the amino acids participated in the pattern of interactions between the ligand and enzyme with an important contribution to the total energy of interaction. Most of these interactions include hydrophobic contacts, Van der Waals interactions, hydrogen bonds, electrostatic, carbonyl, and one specific atom-aromatic ring and provide insight into understanding molecular recognition. Figure 14 depicted the docked conformation of the most active molecules (3 and 10) based on docking studies.
Fig. 9 Antifungal activities of compounds (2-10)

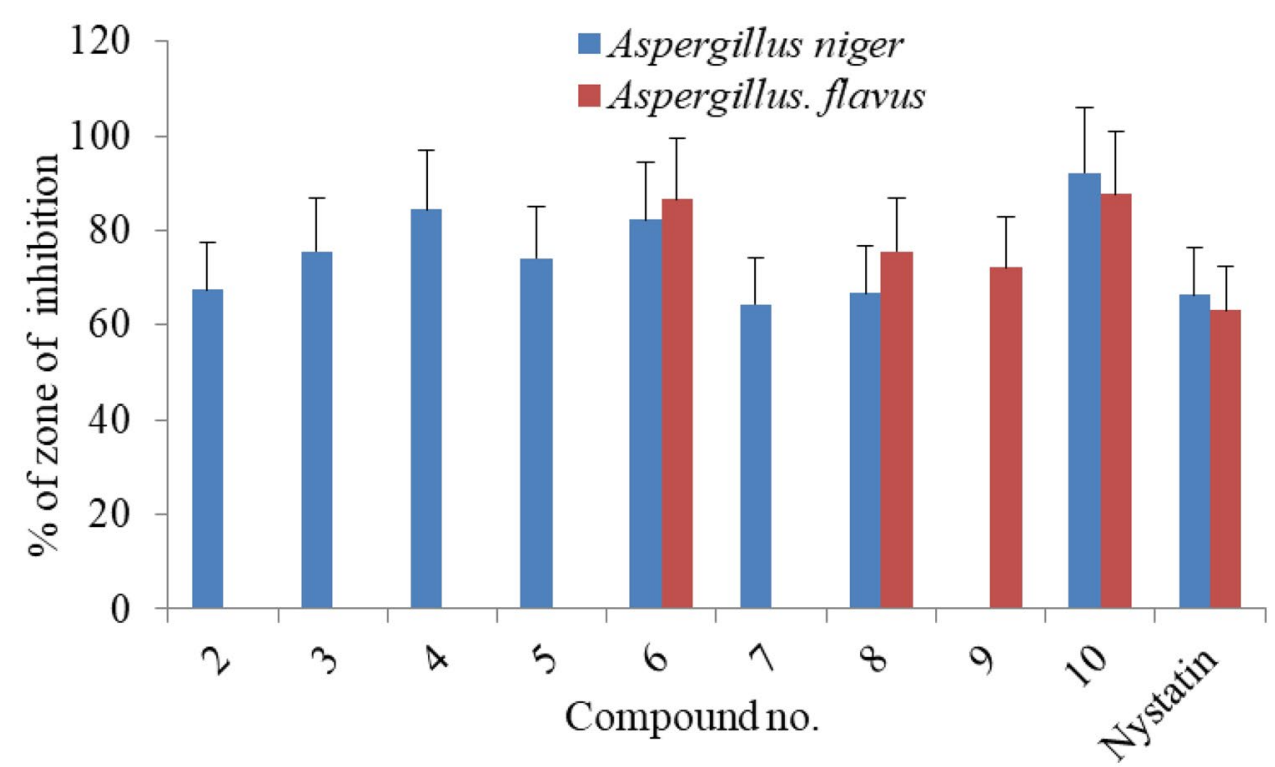


Fig. 10 Inhibition of fungal growth observed by compound 10 against A) Aspergillus niger and $\mathbf{B})$ Aspergillus flavus
A

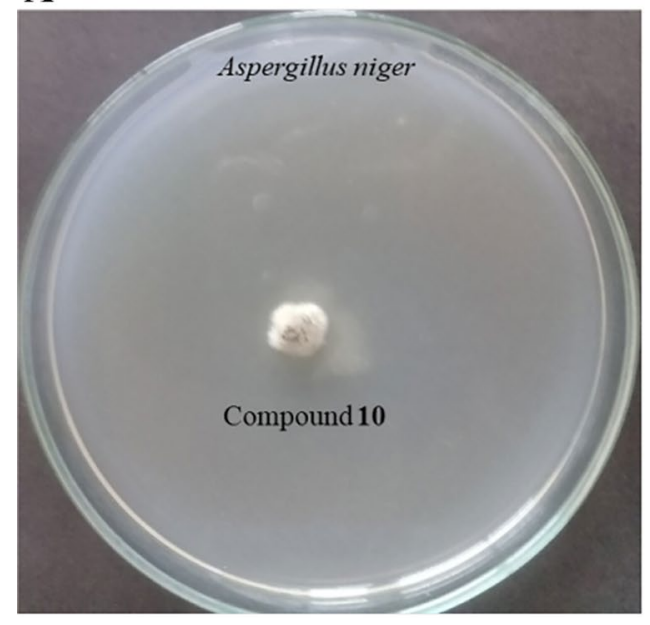

B

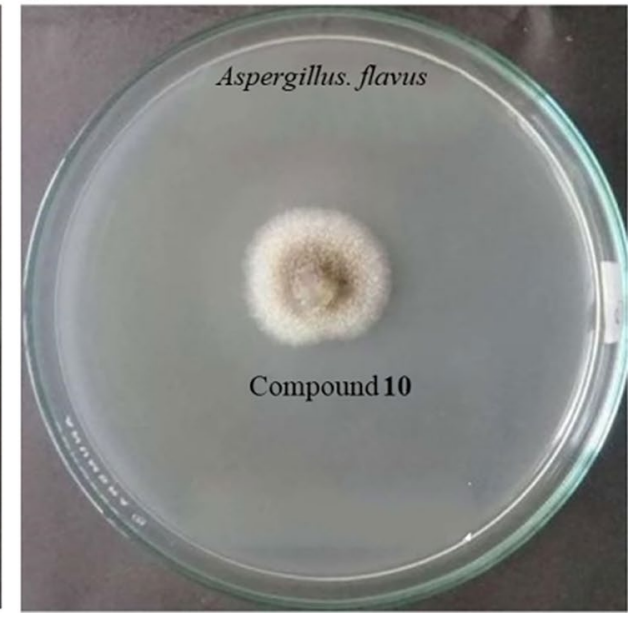

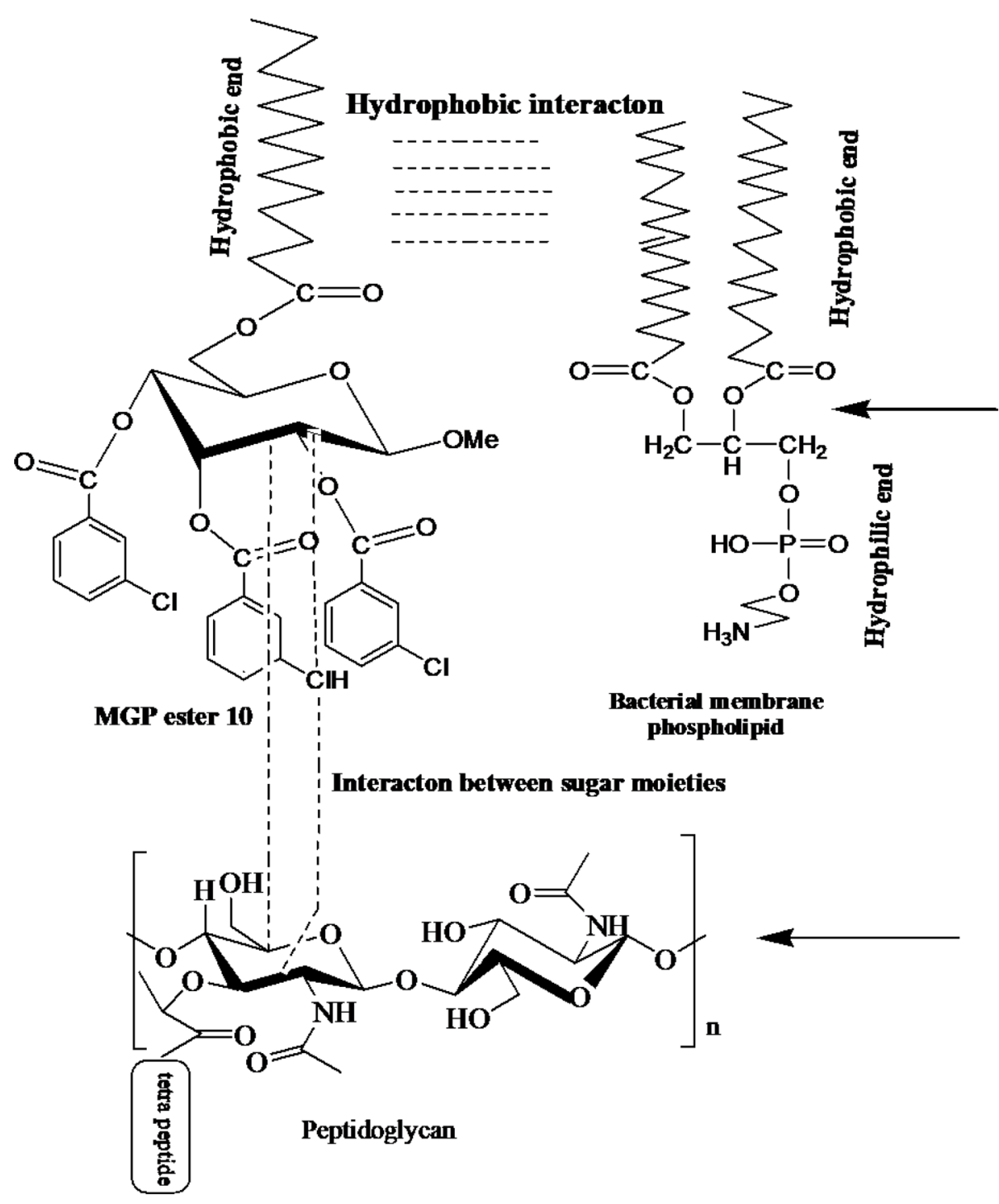

Gram-negative bacteria

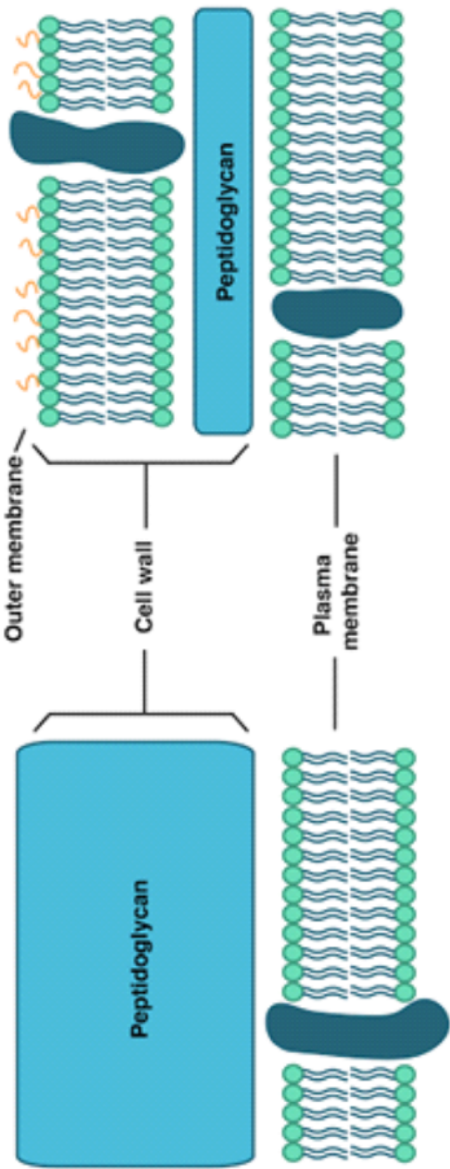

Gram-positive bacteria

Fig. 11 SAR study of the MGP ester 10 against bacterial pathogens 
Table 6 Prediction of antimicrobial activity of the MGP esters using PASS

\begin{tabular}{|c|c|c|c|c|c|c|c|c|}
\hline \multicolumn{9}{|c|}{ Biological Activity } \\
\hline \multirow[t]{2}{*}{ Compounds } & \multicolumn{2}{|c|}{ Antibacterial } & \multicolumn{2}{|c|}{ Antifungal } & \multicolumn{2}{|c|}{ Antioxidant } & \multicolumn{2}{|c|}{ Anti-carcinogenic } \\
\hline & $\mathrm{Pa}$ & $\mathrm{Pi}$ & $\mathrm{Pa}$ & $\mathrm{Pi}$ & $\mathrm{Pa}$ & $\mathrm{Pi}$ & $\mathrm{Pa}$ & $\mathrm{Pi}$ \\
\hline 1 & 0.541 & 0.013 & 0.628 & 0.016 & 0.403 & 0.041 & 0.731 & 0.008 \\
\hline 2 & 0.528 & 0.014 & 0.669 & 0.012 & 0.530 & 0.005 & 0.769 & 0.006 \\
\hline 3 & 0.558 & 0.012 & 0.675 & 0.011 & 0.461 & 0.008 & 0.675 & 0.010 \\
\hline 4 & 0.551 & 0.012 & 0.673 & 0.011 & 0.463 & 0.008 & 0.614 & 0.012 \\
\hline 5 & 0.551 & 0.012 & 0.673 & 0.011 & 0.463 & 0.008 & 0.614 & 0.012 \\
\hline 6 & 0.551 & 0.012 & 0.673 & 0.011 & 0.463 & 0.008 & 0.614 & 0.012 \\
\hline 7 & 0.387 & 0.017 & 0.603 & 0.018 & 0.348 & 0.017 & 0.454 & 0.024 \\
\hline 8 & 0.538 & 0.013 & 0.704 & 0.009 & 0.542 & 0.005 & 0.764 & 0.006 \\
\hline 9 & 0.362 & 0.040 & 0.388 & 0.052 & 0.263 & 0.032 & 0.299 & 0.058 \\
\hline 10 & 0.453 & 0.021 & 0.652 & 0.013 & 0.337 & 0.018 & 0.499 & 0.019 \\
\hline
\end{tabular}

Table 7 Molecular formula, molecular weight, electronic energy $(E)$, enthalpy $(H)$, Gibb's free energy $(G)$ in Hartree and dipole moment ( $\mu$, Debye) of MGP esters

\begin{tabular}{lllllll}
\hline Compounds & $\mathrm{MF}$ & $\mathrm{MW}$ & \multicolumn{1}{l}{$\mathrm{H}$} & \multicolumn{1}{l}{$G$} & $\mu$ \\
\hline $\mathbf{1}$ & $\mathrm{C}_{7} \mathrm{H}_{14} \mathrm{O}_{6}$ & 194.18 & -722.2093 & -722.2084 & -722.2608 & 4.7712 \\
$\mathbf{2}$ & $\mathrm{C}_{21} \mathrm{H}_{40} \mathrm{O}_{7}$ & 404.54 & -1342.8611 & -1342.8602 & -1342.9634 & 3.1549 \\
$\mathbf{3}$ & $\mathrm{C}_{27} \mathrm{H}_{46} \mathrm{O}_{10}$ & 530.65 & -1798.2291 & -1798.2281 & -1798.3510 & 4.1724 \\
$\mathbf{4}$ & $\mathrm{C}_{33} \mathrm{H}_{58} \mathrm{O}_{10}$ & 614.81 & -2032.6637 & -2032.6627 & -2032.8045 & 2.0463 \\
$\mathbf{5}$ & $\mathrm{C}_{69} \mathrm{H}_{130} \mathrm{O}_{10}$ & 1119.76 & -3441.0244 & -3441.0234 & -3441.2673 & 2.7996 \\
$\mathbf{6}$ & $\mathrm{C}_{75} \mathrm{H}_{142} \mathrm{O}_{10}$ & 1203.92 & -4109.6415 & -4109.6404 & -4109.8433 & 3.6310 \\
$\mathbf{7}$ & $\mathrm{C}_{78} \mathrm{H}_{82} \mathrm{O}_{7}$ & 1131.48 & -3891.2733 & -3891.2722 & -3891.3894 & 5.0938 \\
$\mathbf{8}$ & $\mathrm{C}_{48} \mathrm{H}_{58} \mathrm{O}_{10}$ & 794.97 & -2600.9142 & -2600.9132 & -2600.0807 & 7.4419 \\
$\mathbf{9}$ & $\mathrm{C}_{42} \mathrm{H}_{58} \mathrm{O}_{13} \mathrm{~S}_{3}$ & 867.10 & -3784.1678 & -3784.1665 & -3784.3561 & 17.5358 \\
$\mathbf{1 0}$ & $\mathrm{C}_{42} \mathrm{H}_{49} \mathrm{O}_{10} \mathrm{Cl}_{3}$ & 820.19 & -3741.0534 & -3741.0525 & -3741.5631 & 5.1168 \\
\hline
\end{tabular}

The results show that ester (10) is the most promising ligand $(-8.7 \mathrm{kcal} / \mathrm{mol})$, which is bound with SARS-CoV-2 $\mathrm{M}^{\text {pro }}$ via many hydrophobic bonding and hydrogen interactions. The binding site is mainly located in a hydrophobic cleft bordered by the amino acid residues CYS145, HIS41, HIS63, MET49, PHE294, GLY143, ARG298, and PRO252.

Table 8 Energy (eV) of HOMO, LUMO, Gap $(\Delta)$, hardness $(\eta)$ and softness $(S)$ of MGP esters

\begin{tabular}{llllll}
\hline Compounds & HOMO & LUMO & Gap $\left(\Delta_{\varepsilon}\right)$ & $\eta$ & $S$ \\
\hline $\mathbf{1}$ & -6.1918 & 1.3761 & 7.5679 & 3.7839 & 0.2643 \\
$\mathbf{2}$ & -9.0384 & -3.1165 & 5.9219 & 2.9609 & 0.3377 \\
$\mathbf{3}$ & -8.9195 & -3.1413 & 5.7782 & 2.8891 & 0.3461 \\
$\mathbf{4}$ & -8.8462 & -3.0529 & 5.7933 & 2.8966 & 0.3452 \\
$\mathbf{5}$ & -8.7679 & -3.3715 & 5.3964 & 2.6982 & 0.3706 \\
$\mathbf{6}$ & -8.0634 & -3.9527 & 4.1107 & 2.0553 & 0.4865 \\
$\mathbf{7}$ & -8.3964 & -3.0967 & 5.2997 & 2.6498 & 0.3773 \\
$\mathbf{8}$ & -8.7320 & -2.9792 & 5.7528 & 2.8790 & 0.3473 \\
$\mathbf{9}$ & -6.4538 & -2.2378 & 4.2160 & 2.1080 & 0.4743 \\
$\mathbf{1 0}$ & 8.7212 & -3.5957 & 5.1255 & 2.5627 & 0.3902 \\
\hline
\end{tabular}

There are four hydrogen bond contacts with four various amino acids, CYS145, ARG298, HIS41, and GLY143, at distances of $2.865,2.132,2.905$, and $2.320 \AA$, respectively. Compound (10) had an additional benzene ring in the MGP, providing a high density of electrons in the molecule indicated the highest binding score. These findings indicated that modifying the $-\mathrm{OH}$ group and a long carbon chain/aromatic ring molecule increased binding affinity, whereas adding hetero groups like $\mathrm{Br}$ caused some fluctuations in binding affinities; however, modifying with halogenated aromatic rings increased binding affinity. The docked pose clearly showed that the drugs molecules bind within the active site

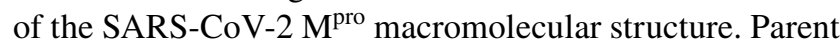
molecule MGP (1) exhibited interactions with the key residues of main protease CYS145 and HIS41 through hydrogen bonding within a closer bond distance $(2.087 \AA)$.

Additionally, GLY143 and THR111 interactions were found because of the unique interaction of the branched alkyl chain with the pyranose ring. Acyl chain substituted esters (5-6) revealed a binding score than (2-4) with the main protease indicating the ligand's burying in the receptor cavity. Despite having fluctuating binding affinity, they also 


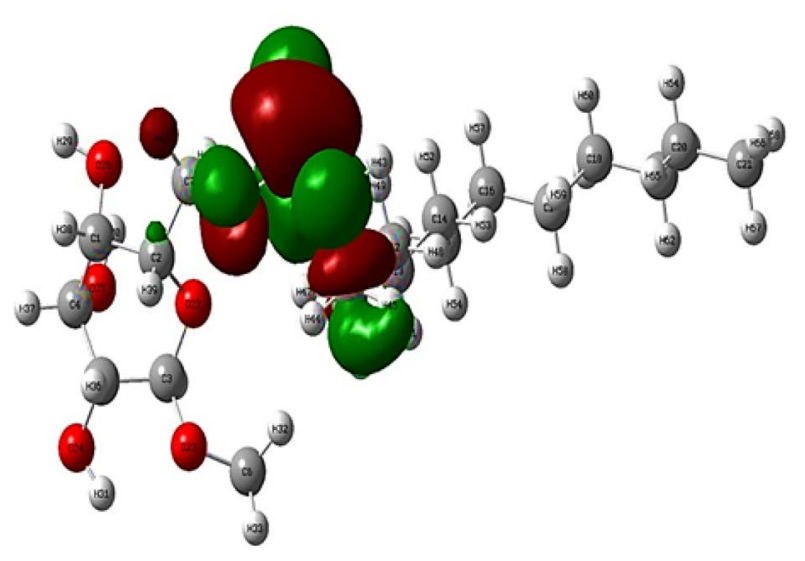

${ }^{\varepsilon} \mathrm{HOMO}=-9.0384 \mathrm{eV} \quad \Delta \dot{\mathrm{G}}=\mathbf{5 . 9 2 1 9} \mathrm{eV} \quad{ }^{\varepsilon} \mathrm{LUMO}=-3.1165 \mathrm{eV}$

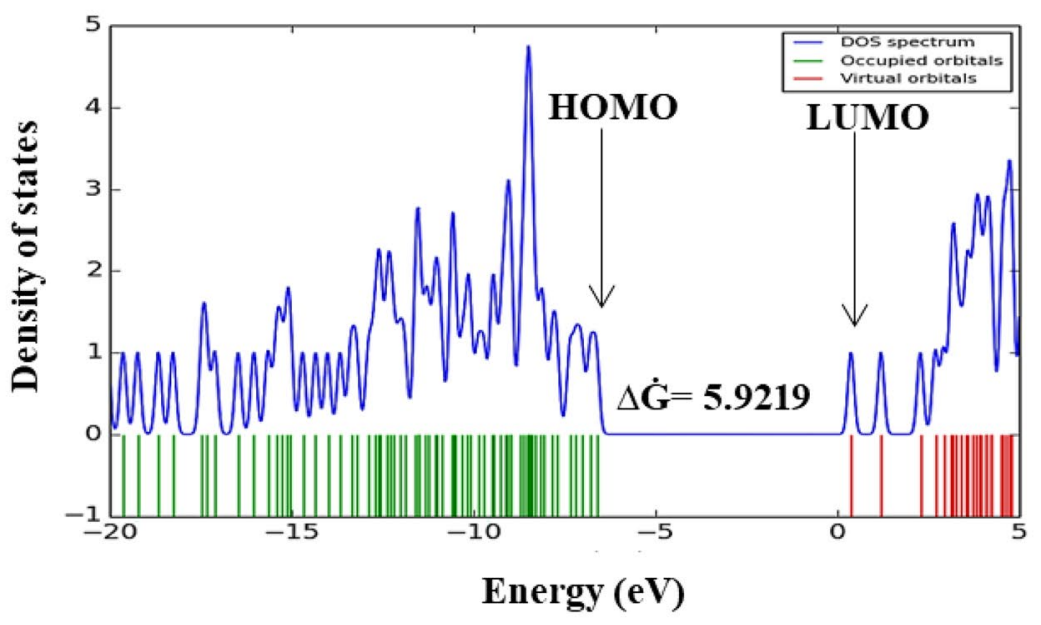

Fig. 12 Molecular orbital distribution plots of HOMO-LUMO including the density of states of MGP ester (2) at DFT/ B3LYP/3-21G

interact with the catalytic binding of the main protease such as CYS44, CYS145, HIS41, HIS246, PHE294, GLN110, GLN189, ARG298, GLU166, SER144, MET276, THR199, PRO293, ILE106, LEU187, and GLY143. In addition, these esters exhibited diverse non-bonding interactions such as conventional hydrogen bond, pi-alkyl, alkyl bond, pi-sigma with the active site of the main protease. Again, the aromatic substituents were increased the binding energy in the case of esters $(8-10 ;-8.3,-8.5$, and $-8.7 \mathrm{kcal} / \mathrm{mol})$.

Interestingly, these esters interacted with the similar binding site of main protease and CYS145, GLY143, HIS41, PHE294, THR26, THR199, and MET49 residues for all. THR199 and THR26 displayed the minimum bond distance of $1.868 \AA$ and $1.840 \AA$ amongst all the interactions. So, these outcomes clear that, due to having high electron density, aromatic substituents can easily increase the binding ability and the antiviral ability of the MGP esters. Along with PHE294, all the esters displayed

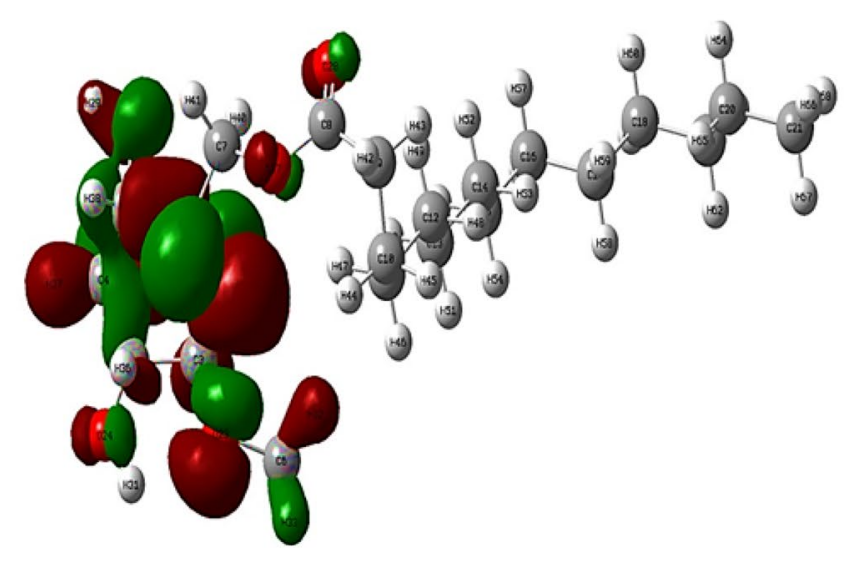

the maximum $\pi-\pi$ interactions with the GLN110 and MET276, denoting the tight binding with the active site. Reports suggest that PHE294 is considered as the principal component of the pi-alkyl, pi-sigma, pi-cation, and pianion responsible for the accessibility of small molecules to the active site. Binding energy and binding mode were improved in esters (2-4 and 8-10) because of significant hydrogen bonding. It was observed that the alterations of the $-\mathrm{OH}$ group in MGP exalted the $\pi-\pi$ interactions with the amino acid chain on the binding site. In contrast, their polarity improvement resulted in the formation of hydrogen bond interactions. The maximum numbers of H-bonds were observed for esters (2, 4, 6, 8, and 10), with CYS145, HIS41, GLY143, and GLU166 residues. Hydrogen bonds executed a vital function in shaping the specificity of ligand binding with the receptor, drug design in chemical and biological processes, and molecular recognition and biological activity [62]. It has already been 


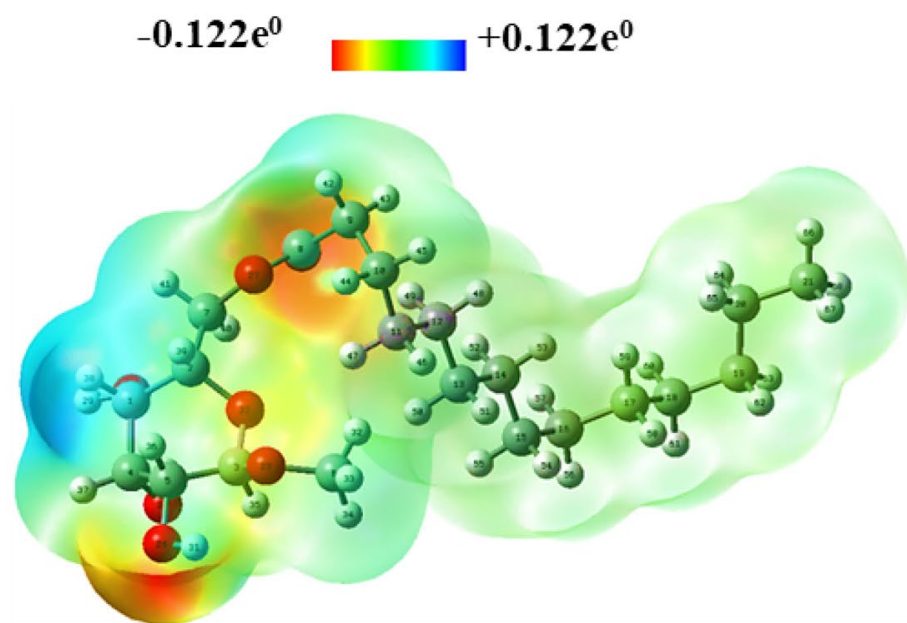

2

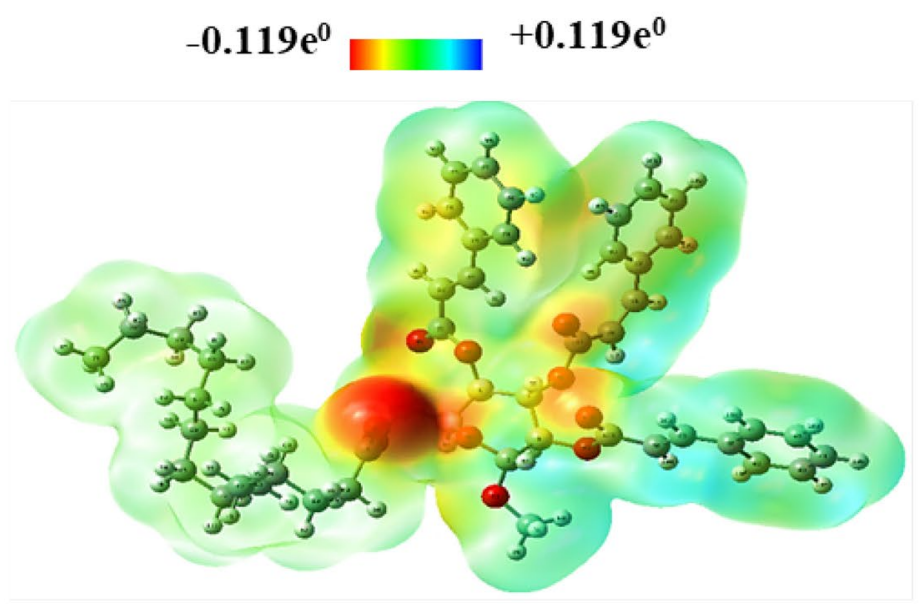

4

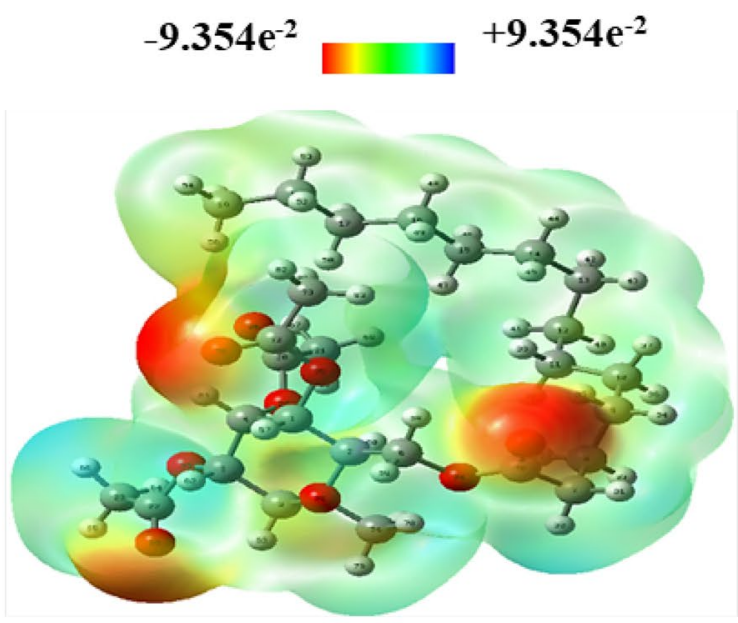

3
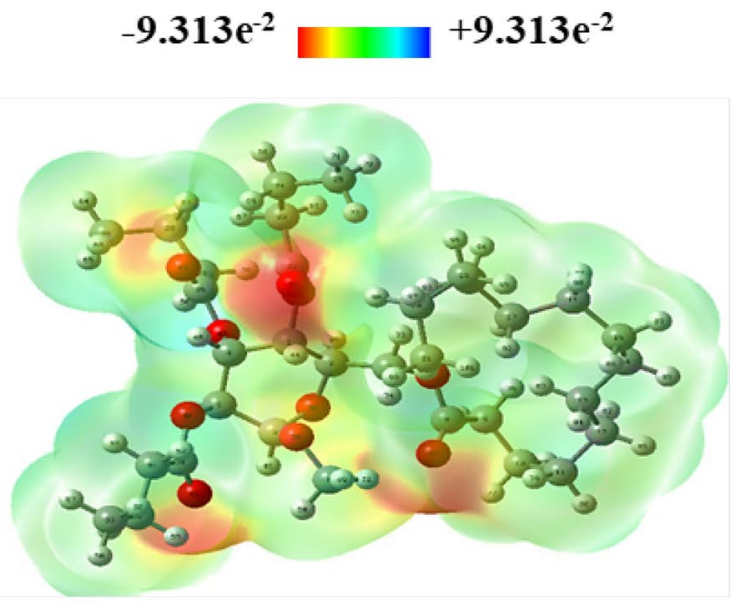

8

Fig. 13 Map of the molecular electrostatic potential of MGP esters (2, 3, 4, and 8)

reported that ten commercial medicines possibly form $\mathrm{H}$-bonds with key residues of 2019-nCoV main protease [63]. Hydrogen bond surface and hydrophobic surface of ester (10) with the protein were consequently represented in Fig. 16. We observed from the blind docking study of all MGP esters with the SARS-CoV-2 protease like the standard drug Remdesivir. The above-mentioned residues generally surround the molecules as the standard drug, suggesting that this molecule may prevent the viral replication of SARS-CoV-2.

The distance of the ligands and the change in accessible area of the two important catalytic residues (CYS145 and HIS41) within the protease's active site is shown in Table 9. Although the blind docking studies reveal that all the molecules can act as potential agents for COVID treatments, but from the estimated free energy of binding
Table 9 Binding energy of the MGP esters against $\mathrm{M}^{\text {pro }} 6 \mathrm{Y} 84$

\begin{tabular}{llllll}
\hline Compounds & Binding affinity & Interaction types & Compounds & Binding affinity & Interaction types \\
\hline $\mathbf{1}$ & -5.9 & H & $\mathbf{6}$ & -6.0 & H, C, PS, A, PA \\
$\mathbf{2}$ & -8.1 & H, C, PA & $\mathbf{8}$ & -8.3 & H, C, PAn, PCa, A, PA \\
$\mathbf{3}$ & -8.5 & H, C, A, PA & $\mathbf{9}$ & -8.5 & H, PAn, A, \\
$\mathbf{4}$ & -8.2 & H, A & $\mathbf{1 0}$ & -8.7 & H, A, PA \\
$\mathbf{5}$ & -6.5 & H, A, PA & Remdesivir & -10.5 & H, A, PA \\
\hline
\end{tabular}

HConventional Hydrogen Bond, CCarbon Hydrogen Bond, A Alkyl, PA Pi-Alkyl, PS Pi-sigma, PAn PiAnion, $P C a$ Pi-Cation, $P D H$ Pi-Donor Hydrogen Bond, PPSPi-Pi Stacked 
Table 10 Non-bonding interaction data of MGP esters against $\mathrm{M}^{\text {pro }} 6 \mathrm{Y} 84$

\begin{tabular}{|c|c|c|c|c|c|c|c|c|c|}
\hline \multicolumn{5}{|c|}{ Main protease $6 Y 84$} & \multicolumn{5}{|c|}{ Main protease $6 \mathrm{Y} 84$} \\
\hline \multicolumn{3}{|c|}{ Hydrogen bond } & \multicolumn{2}{|c|}{ Hydrophobic bond } & \multicolumn{3}{|c|}{ Hydrogen bond } & \multicolumn{2}{|c|}{ Hydrophobic bond } \\
\hline Compounds & Residues & $\begin{array}{l}\text { Distance } \\
(\AA)\end{array}$ & Residues & $\begin{array}{l}\text { Distance } \\
(\AA)\end{array}$ & Comp & Residues & $\begin{array}{l}\text { Distance } \\
(\AA)\end{array}$ & Residues & $\begin{array}{l}\text { Distance } \\
(\AA)\end{array}$ \\
\hline \multirow[t]{8}{*}{1} & THR111 & 3.085 & & & 6 & ARG298 & 2.214 & PHE294 & 3.578 \\
\hline & THR111 & 2.244 & & & & ASP295 & 3.435 & ILE249 & 5.149 \\
\hline & GLY143 & 3.363 & & & & CYS145 & 2.094 & VAL202 & 3.944 \\
\hline & HIS41 & 2.078 & & & & GLU166 & 1.254 & PRO293 & 4.099 \\
\hline & CYS145 & 2.990 & & & & & & VAL297 & 3.841 \\
\hline & CYS145 & 2.872 & & & & & & ARG298 & 4.337 \\
\hline & & & & & & & & VAL303 & 4.346 \\
\hline & & & & & & & & PHE294 & 4.895 \\
\hline \multirow[t]{4}{*}{2} & CYS145 & 2.618 & TYR237 & 4.895 & 8 & CYS145 & 2.722 & HIS41 & 4.351 \\
\hline & HIS41 & 3.637 & MET49 & 4.705 & & THR26 & 1.840 & ASP289 & 3.834 \\
\hline & GLU166 & 2.461 & & & & GLY143 & 3.537 & MET49 & 3.999 \\
\hline & ASP289 & 3.637 & & & & TYR237 & 3.570 & LEU287 & 4.984 \\
\hline \multirow[t]{3}{*}{3} & GLY143 & 1.803 & CYS145 & 5.452 & 9 & CYS145 & 2.997 & ASP289 & 4.047 \\
\hline & HIS41 & 3.596 & PRO168 & 4.081 & & ARG131 & 3.067 & GLN189 & 5.491 \\
\hline & CYS44 & 3.562 & HIS41 & 5.182 & & THR199 & 1.868 & & \\
\hline \multirow[t]{5}{*}{4} & THR199 & 2.844 & MET276 & 5.299 & 10 & CYS145 & 2.865 & PRO252 & 4.091 \\
\hline & CYS145 & 3.078 & LEU287 & 5.281 & & ARG298 & 2.132 & HIS41 & 3.881 \\
\hline & SER144 & 3.694 & HIS246 & 2.365 & & HIS41 & 2.905 & HIS63 & 3.655 \\
\hline & PHE294 & 4.251 & GLN110 & 3.710 & & GLY143 & 2.320 & MET49 & 4.993 \\
\hline & & & & & & & & PHE294 & 5.027 \\
\hline \multirow[t]{5}{*}{5} & ARG298 & 2.331 & ILE106 & 4.993 & Remdesivir & ASP295 & 2.334 & ASP295 & 4.223 \\
\hline & CYS145 & 2.3015 & PHE294 & 3.478 & & CYS145 & 2.698 & & \\
\hline & & & PHE294 & 4.459 & & GLN110 & 2.268 & & \\
\hline & & & & & & THR111 & 2.203 & & \\
\hline & & & & & & THR111 & 2.358 & & \\
\hline
\end{tabular}

values could infer that the ester (10) with the highest negative minimum binding energy value $-8.7 \mathrm{kcal} / \mathrm{mol}$ amongst all the studied esters could be the best possible SARS-CoV-2 inhibitor. In fine, it was resolved that most of the selected MGP esters showed promising activities and might develop effective antiviral drugs against the SARS-CoV-2.

\section{Molecular dynamics simulation}

The molecular dynamics simulation was conducted to understand the structural stability of the complexes. The root mean square deviations of the $\mathrm{C}$-alpha atoms of the complexes were analyzed to understand the flexible nature of the complexes. Figure 17(A) indicates that all complexes had an initial upper trend which might be responsible for the flexible nature of the complexes. However, the complexes were stabilized after $15 \mathrm{~ns}$ times and maintained integrity throughout the simulations times. Also, all complexes had RMSD less than $2.5 \AA$ for the whole simulations times, indicating the complexes' stable nature. The solvent-accessible surface area of the simulations systems was explored to understand the changes in the protein surface area where the higher SASA (solvent accessible surface area) defines the expansion of the surface area. In contrast, the lower SASA is related to the truncated nature of the complexes. Figure 17(B) indicates that all complexes had a similar SASA trend and did not fluctuate much. Compound 10 had a lower SASA than the other complexes, indicating the complexes' truncated nature. The radius of gyrations of the complexes defines the mobile nature of the complexes. Figure 17(C) indicates that the complexes all complexes had a similar Rg trend did not much fluctuate except for MGP ester 10. This trend defines the stable nature of the complexes. The hydrogen bond pattern of the systems was similar for all of the esters and did not deviate much in the simulation trajectories, which correlate with the complex's stability. The root mean square fluctuations defines the flexible nature of the complexes across the amino acid residues. Figure 17(D) 


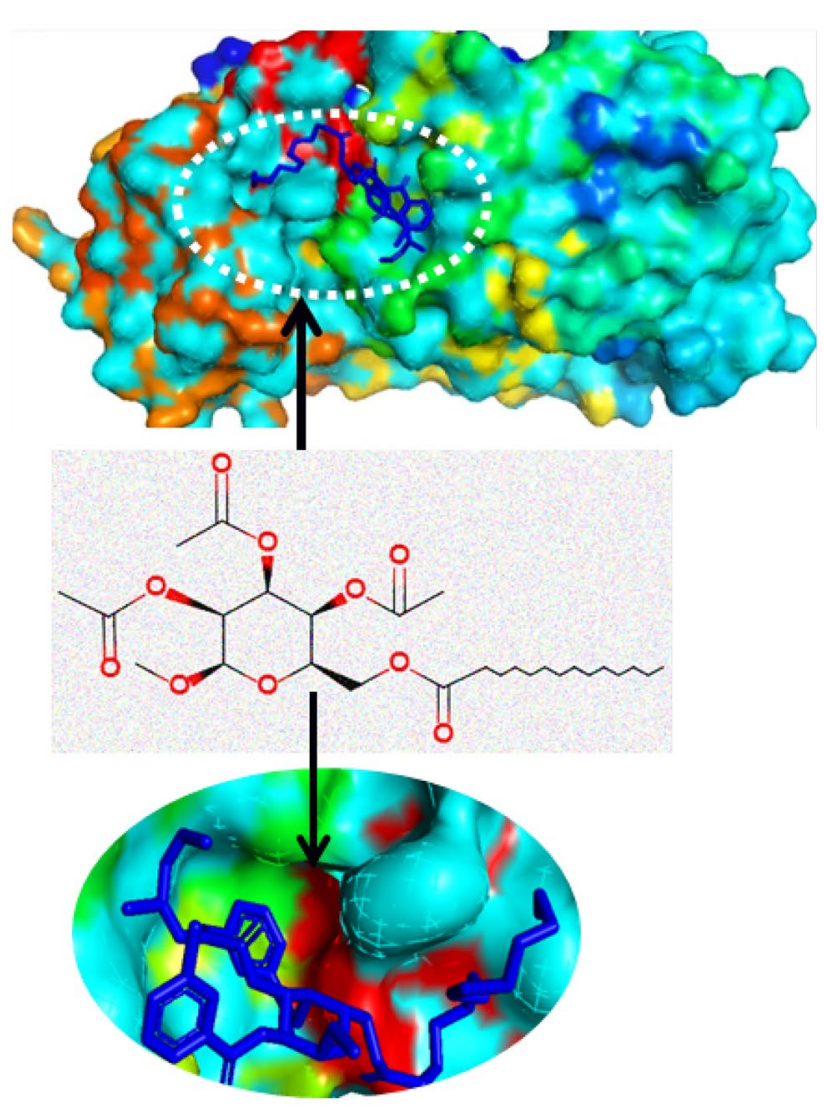

a

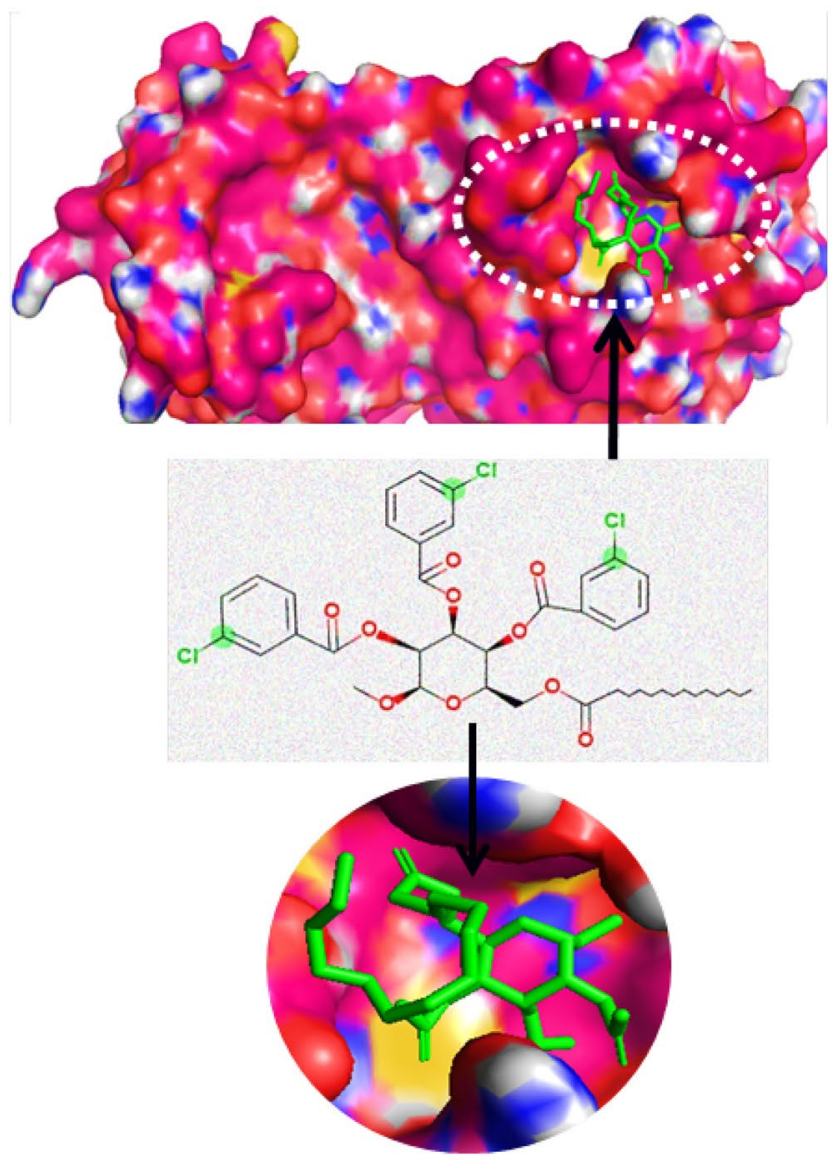

b

Fig. 14 Docked conformation of ester (3) at inhibition bounding site of 6 Y84 (a) and Docked conformation of ester (10) at inhibition bounding site of 6 Y84 (b)

indicates that the complexes' stable nature. The hydrogen bond of a biological system requires assessment to evaluate the bonding and structural change in the complex. They play a key role in giving the structural integrity of the systems. The five simulated complexes had a solid hydrogen bonding pattern as lesser aberrations were observed. The number of hydrogen bonds between solute and solvents was calculated in Fig. 17(E). The simulation time's initial and final phases also had the firm hydrogen bond as they did not fluctuate either.

\section{The pharmacokinetic profile and toxicity analysis}

The pkCSM ADMET descriptors algorithm protocol was used to predict the pharmacokinetic properties of the compounds, such as ADME, and toxicity. Membrane permeability [indicated by the colon cancer cell line (Caco-2)], intestinal absorption, skin permeability thresholds, and substrate or inhibitor of P-glycoprotein are all factors that influence drug absorption. A value of intestinal absorbance less than $30 \%$ indicates poor absorbance. Table 11 shows that all of the esters have excellent absorption with more than 30. Skin permeability is an important factor to consider when improving drug efficacy, and it is especially important in the development of transdermal drug delivery. A molecule will barely penetrate the skin if $\log \mathrm{Kp}$ is more than $-2.5 \mathrm{~cm} / \mathrm{h}$ [63]. From Table 10 it can be seen that the skin permeability (Kp of MGP esters is $-2.278 \mathrm{~cm} / \mathrm{h}(<-2.5)$. Therefore, it can be predicted that all esters have good skin penetrability. For the pkCSM predictive model, high Caco-2 permeability is translated into predicted $\log$ Papp values $>0.90 \mathrm{~cm} / \mathrm{s}$ [33]. As Table 10 shows, the value of Caco-2 permeability (log Papp) of the MGP esters ranged from -4.2 to $-2.3 \mathrm{~cm} / \mathrm{s}$, $\log$ Papp $<0.9 \mathrm{~cm} / \mathrm{s}$, so it is predicted that these have low Caco-2 permeability.

For the discovery of oral administrative drugs, solubility is one of the major descriptors. Highly water solubility was useful for delivering sufficient active ingredients in a small volume of such pharmaceutical dosage. These values water 

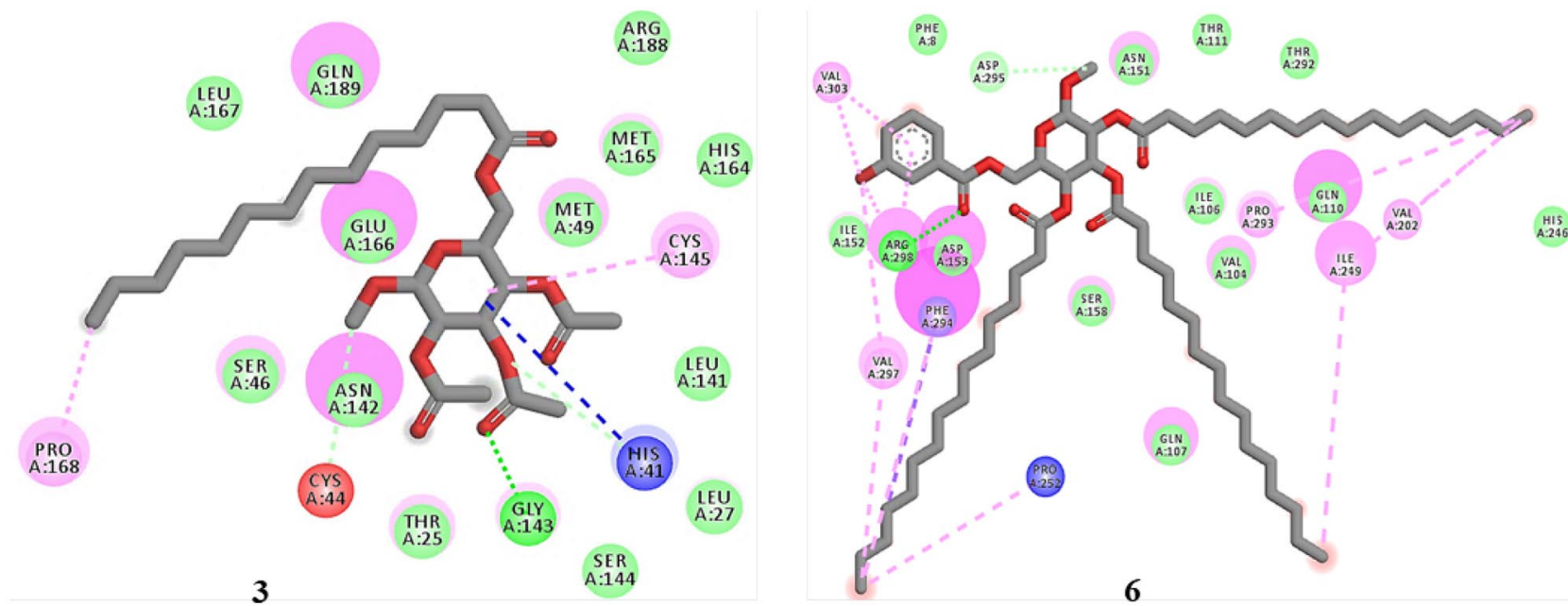

Interactions
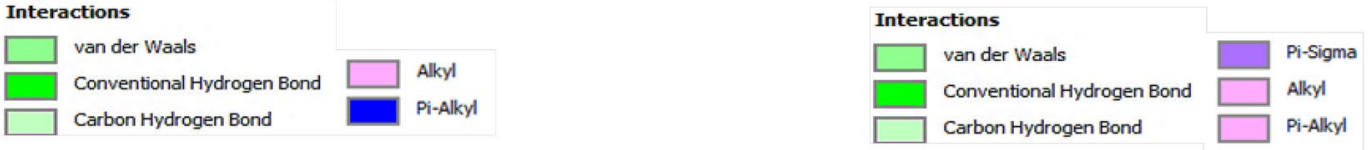

Fig. 15 Non-bonding interactions of compound (3 and 10) with the amino acid residues of 6Y84 generated by Discovery Studio

solubility is given in $\log (\mathrm{mol} / \mathrm{l})$ (Insoluble $\leq-10<$ poorly soluble $<-6<$ Moderately $<-4<$ soluble $<-2<$ very soluble $<0 \leq$ highly soluble). From the results that appear in Table 11, it was observed that the esters tested are soluble. Distribution volume $(\mathrm{Vd})$ is a pharmacokinetic parameter reflecting the tendency of an individual substance to either linger in the plasma or redistribute to another tissue compartment. According to Pires et al. [64] VDss is considered low if it is below $0.71 \mathrm{~L} / \mathrm{kg}(\log$ VDss $<-0.15)$ and high if it is above $2.81 \mathrm{~L} / \mathrm{kg}$ ( $\log$ VDss $>0.45$ It can be shown from Table 12 that the value of MGP esters VDss ranged from -1.249 to 0.035 , with only esters (3 and 9-10) having a VDss value of $<-0.15$. Blood-brain partitioning and brain distribution are critical properties for drugs targeting the CNS. The esters tested a $\log \mathrm{BB}<-1$ considered poorly distributed to the brain.
From Table 12 it can be seen that the logPS (the CNS permeability) value of MGP esters ranges from -1.42 to -4.20 , $\log \mathrm{PS}<-3$, so it can be predicted that esters (4-6 and 8) are unable to penetrate the CNS. Furthermore, it can be seen from Table 12 the $\log$ CLtot value of MGP esters ranges from 0.25 to $2.46 \mathrm{ml} / \mathrm{min} / \mathrm{kg}$, and from those values can be predicted the rate of excretion of the compound.

Metabolism is predicted based on the Cyp (cytochrome P450) models for substrate or inhibition (Cyp1A2, Cyp2C19, Cyp2D6, and Cyp3A4). Table 13 shows that all MGP esters have no effect on or inhibition of all enzymes except CYP3A4, implying that all esters in the body are metabolized by the P450 enzyme. The bioactivity radar charts of the MGP esters (Fig. 18) revealed that all candidates had promising pharmacokinetic profiles.
Fig. 16 Hydrogen bond surface (a) and hydrophobic surface (b) of 6 Y84 with ester (10)

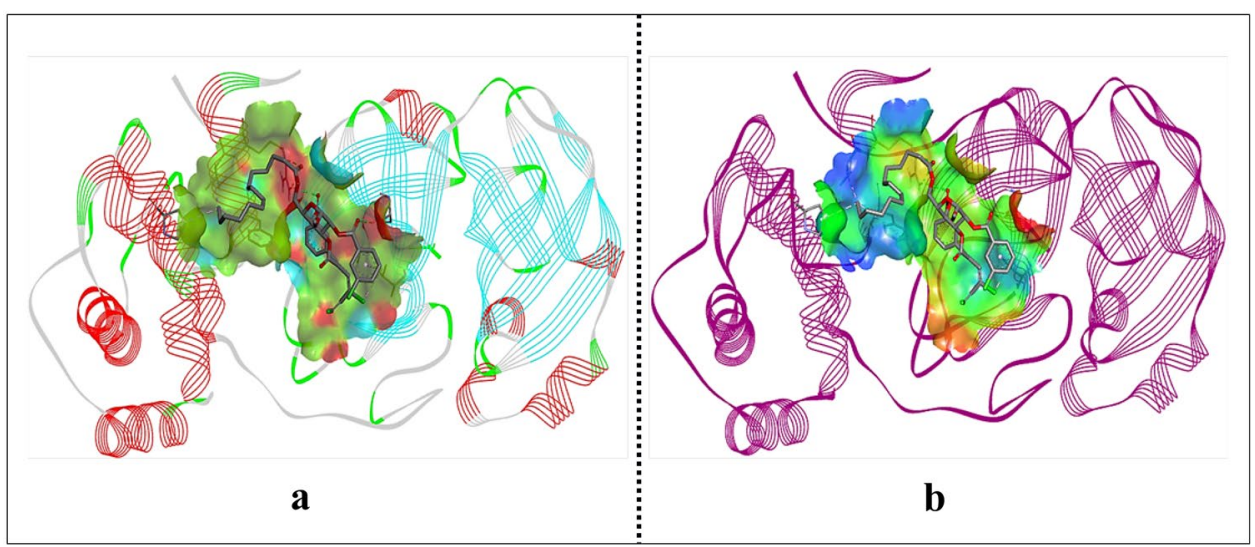



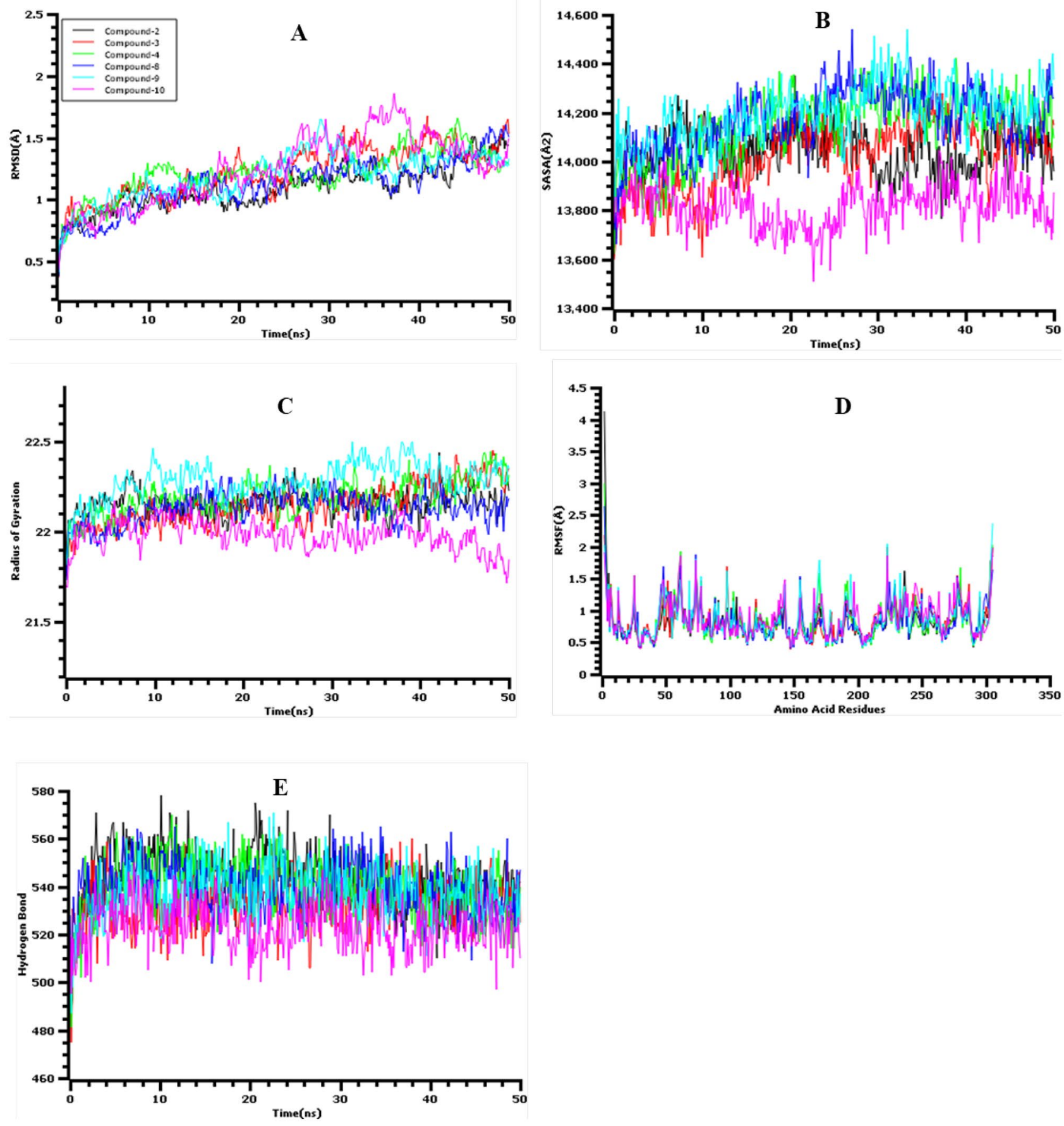

Fig. 17 The molecular dynamics simulation trajectories from 100-ns simulation time, here (A) root mean square deviation of the C-alpha atoms; (B) solvent-accessible surface area of the docked complex to understand the change in protein area; (C) Radius of the gyration of the complexes (D) root mean square fluctuation and (E) hydrogen bond of the complexes 
Table 11 Prediction of in silico absorption of MGP esters

\begin{tabular}{lllll}
\hline Compounds & $\begin{array}{l}\text { Water solubility } \\
(\text { log mol/L) }\end{array}$ & $\begin{array}{l}\text { Caco-2 } \\
\text { permeability }\end{array}$ & $\begin{array}{l}\text { Intestinal } \\
\text { absorption }\end{array}$ & $\begin{array}{l}\text { Skin } \\
\text { permeability }\end{array}$ \\
\hline $\mathbf{1}$ & 0.067 & -0.211 & 32.866 & -3.391 \\
$\mathbf{2}$ & -2.925 & 0.768 & 55.591 & -2.760 \\
$\mathbf{3}$ & -4.161 & 0.893 & 66.873 & -2.728 \\
$\mathbf{4}$ & -3.741 & 0.897 & 64.976 & -2.735 \\
$\mathbf{5}$ & -2.892 & 0.543 & 100 & -2.735 \\
$\mathbf{6}$ & -2.892 & 0.471 & 100 & -2.735 \\
$\mathbf{7}$ & -2.892 & 0.317 & 100 & -2.735 \\
$\mathbf{8}$ & -3.013 & 1.108 & 83.366 & -2.735 \\
$\mathbf{9}$ & -2.896 & 0.431 & 80.158 & -2.735 \\
$\mathbf{1 0}$ & -3.029 & 0.894 & 86.803 & -2.735 \\
\hline
\end{tabular}

Table 13 Prediction of in silico of metabolism of MGP esters

\begin{tabular}{lllll}
\hline Compounds & Cyp1A2 & Cyp2C19 & Cyp2D6 & Cyp3A4 \\
\hline $\mathbf{1}$ & No & No & No & No \\
$\mathbf{2}$ & No & No & No & No \\
$\mathbf{3}$ & No & No & No & Yes \\
$\mathbf{4}$ & No & No & No & Yes \\
$\mathbf{5}$ & No & No & No & Yes \\
$\mathbf{6}$ & No & No & No & Yes \\
$\mathbf{7}$ & No & No & No & Yes \\
$\mathbf{8}$ & No & No & No & Yes \\
$\mathbf{9}$ & No & No & No & Yes \\
$\mathbf{1 0}$ & No & No & No & Yes \\
\hline
\end{tabular}

Table 12 Prediction in silico of distribution and execration of MGP esters

\begin{tabular}{|c|c|c|c|c|c|}
\hline \multirow[t]{2}{*}{ Compounds } & \multicolumn{3}{|c|}{ Distribution } & \multicolumn{2}{|l|}{ Execration } \\
\hline & Vdss & BBB permeability & CNS permeability & Total Clearance & $\begin{array}{l}\text { Renal } \\
\text { OCT2 } \\
\text { substrate }\end{array}$ \\
\hline 1 & 0.035 & -0.881 & -4.670 & 0.686 & No \\
\hline 2 & -0.552 & -1.211 & -3.772 & 1.839 & No \\
\hline 3 & -0.039 & -1.789 & -3.486 & 1.561 & No \\
\hline 4 & 0.315 & -1.923 & -2.682 & 1.743 & No \\
\hline 5 & -1.249 & -2.699 & -1.498 & 2.366 & No \\
\hline 6 & -0.884 & -2.828 & -1.428 & 2.464 & No \\
\hline 7 & 0.009 & -1.541 & -3.234 & 0.252 & No \\
\hline 8 & -0.733 & -1.829 & -2.619 & 1.064 & No \\
\hline 9 & -0.102 & -3.062 & -4.201 & 0.588 & No \\
\hline 10 & -0.121 & -2.387 & -3.353 & 0.384 & No \\
\hline
\end{tabular}

The model provided by pkCSM pharmacokinetics predicts the total clearance $\log$ (CLtot) of a given compound in $\log (\mathrm{ml} / \mathrm{min} / \mathrm{kg})$. The larger the CLtot value of the compound, the faster the excretion processes. The results of the compounds are described in Table 14, and their high LD50 values (1.66 to 2.89) suggest that the compounds are lethal only at very high doses. The negative result in the AMES test suggests that the compound could not be mutagenic. The results also suggest that all esters tested may not inhibit the hERG channel and may not have skin sensitization. 


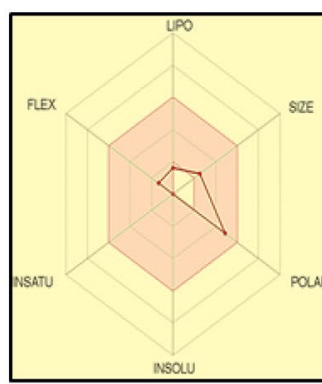

1

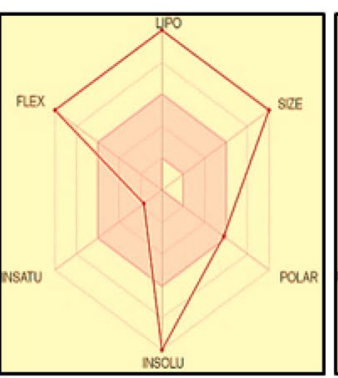

6

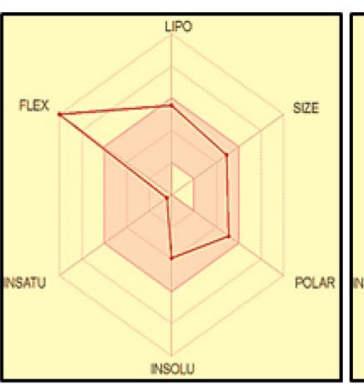

2

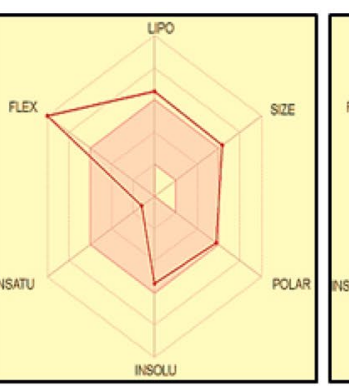

3

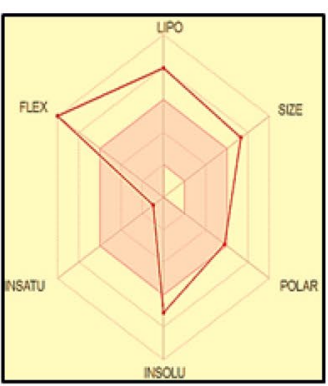

4

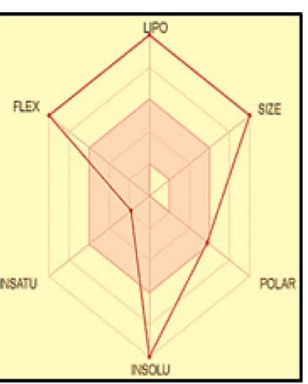

5

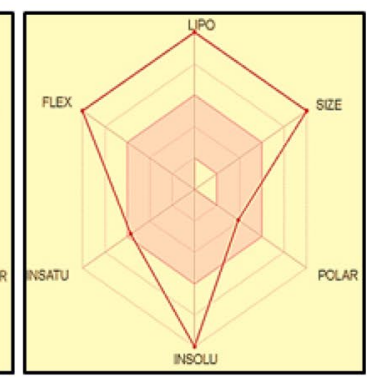

7

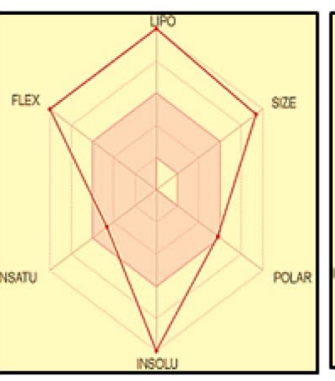

8

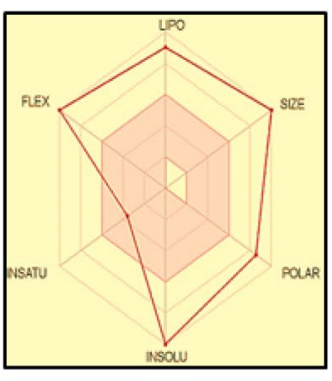

9

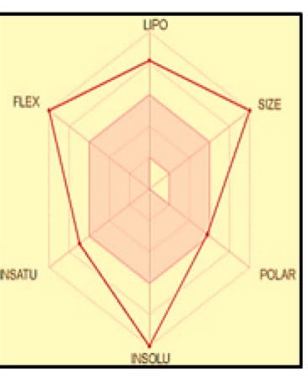

10

Fig. 18 Bioactivity radar Charts of the MGP esters where FLEX: Flexibility, LIPO: Lipophilicity, INSATU: Insaturation, and INSOLU: Insolubility

Table 14 Prediction in silico of toxicity of MGP esters

\begin{tabular}{lllll}
\hline Compounds & $\begin{array}{l}\text { AMES } \\
\text { toxicity }\end{array}$ & $\begin{array}{l}\text { Herg1 } \\
\text { inhibition }\end{array}$ & LD50 & $\begin{array}{l}\text { Skin } \\
\text { sensitization }\end{array}$ \\
\hline $\mathbf{1}$ & No & No & 1.533 & No \\
$\mathbf{2}$ & No & No & 1.895 & No \\
$\mathbf{3}$ & No & No & 2.092 & No \\
$\mathbf{4}$ & No & No & 1.666 & No \\
$\mathbf{5}$ & No & No & 2.486 & No \\
$\mathbf{6}$ & No & No & 2.485 & No \\
$\mathbf{7}$ & No & No & 2.482 & No \\
$\mathbf{8}$ & No & No & 2.600 & No \\
$\mathbf{9}$ & No & No & 2.521 & No \\
$\mathbf{1 0}$ & No & No & 2.899 & No \\
\hline
\end{tabular}

\section{Conclusions}

In this work, we have presented a computational study toward the identification of new inhibitors of SARS-CoV-2 where molecular docking studies have been performed on a series of monosaccharide (MGP) esters, a promising anti-SARS$\mathrm{CoV}-2$ agent. The most significant properties for biological chemistry, chemical reactivity and frontier orbital studies like PASS, HOMO, LUMO, gap and molecular electrostatic potential in molecules were optimized to be indicated as an excellent drug molecule. All the designed MGP esters have energy gaps lower than MGP and the modified esters were more reactive than the parent drug. Insertion of various aliphatic and aromatic groups in MGP structure can significantly improve their mode of biological behavior. PASS prediction of the MGP esters $2-10$ showed $0.36<\mathrm{Pa}<0.55$ for antibacterial, $0.38<\mathrm{Pa}<0.70$ for antifungal, $0.26<\mathrm{Pa}<0.54$ for antioxidant and $0.29<\mathrm{Pa}<0.76$ for anticancer activities expressing antimicrobial and antitumor potency of the modified esters. Molecular docking simulation exhibited that, many of these esters showed notable binding interactions and binding energy with SARS-CoV-2 $\mathrm{M}^{\text {pro }}$. Six MGP esters (2-4 and 8-10) showed in silico potent ability to fight SARS-CoV-2. Furthermore, molecular dynamics simulation study confirms the binding stability of docked complex in a trajectory analysis i.e., the protein-ligand complex is highly stable in any biological system. In fine, these esters were analyzed for their pharmacokinetic properties. The combination of toxicity prediction, in silico ADMET prediction, and druglikeness had promising results as most of the designed molecules possessed improved kinetic parameters, maintained all drug-likeness rules as well as showed an interesting result in terms of biological activity. Finally, this research will be useful to understand the chemical, thermal, physicochemical, biological and pharmacokinetic properties of MGP esters. Further studies should be performed in vitro and in vivo to assert these esters as drug candidates to treat SARS-CoV-2. 
Supplementary Information The online version contains supplementary material available at https://doi.org/10.1007/s10719-021-10039-3.

Acknowledgements The authors are very much thankful to the Ministry of Science and Technology (MOST), Government of Bangladesh [Ref: 39.00.0000.009.06.009.20-1331/Phy's-530, dated: 8-12-2020], and by JSPS KAKENHI under Grant No. JP19K06239 (to Y.O.) from Yokohama City University, Japan for providing the financial support. The authors are also indebted to the Director, Wazed Miah Science Research Centre, JU, and Dhaka, Bangladesh for recording of spectra. Authors are also thankful to criticical reading and English editing by Enago.

Author contributions MRA and FY synthetic and analysis. SD antimicrobiology. SM, MAS, and TBE performed computational and interpretation of results. IH anticancer and article edited. YF, SR, and YOg validation of results. MY and YO validation of article and improve the manuscript. SMAK conceptualization, methodology, article writing, and supervision. All authors reviewed and approved the manuscript.

\section{Compliance with ethical standards}

Ethical approval This article does not contain any studies with animals performed by any of the authors.

Conflicts of interest The authors declare that they have no conflicts of interest.

\section{References}

1. Bertozzi, C.R., Kiessling, L.L.: Chemical glycobiology. Science 291, 2357-2364 (2001). https://doi.org/10.1126/science.1059820

2. Chen, S., Fukuda, M.: Cell type-specific roles of carbohydrates in tumor metastasis. Meth. Enzymol. 416, 371-380 (2006). https:// doi.org/10.1016/S0076-6879(06)16024-3

3. Varki, A.: Glycobiology 3, 97-112 (1993). https://doi.org/10. 1093/glycob/3.2.97

4. Seeberger, P.H., Werz, D.B.: Synthesis and medical applications of oligosaccharides. Nature 446, 1046-1051 (2007). https://doi. org/10.1038/nature05819

5. Kawsar, S.M.A., Islam, M., Jesmin, S., Manchur, M.A., Hasan, I., Rajia, S.: Evaluation of the antimicrobial activity and cytotoxic effect of some uridine derivatives. Int. J. Biosci. 12, 211-219 (2018). https://doi.org/10.12692/ijb/12.6.211-219

6. Kawsar, S.M.A., Hamida, A.A., Sheikh, A.U., Hossain, M.K., Shagir, A.C., Sanaullah, A.F.M., Manchur, M.A., Imtiaj, H., Ogawa, Y., Fujii, Y., Koide, Y., Ozeki, Y.: Chemically modified uridine molecules incorporating acyl residues to enhance antibacterial and cytotoxic activities. Int. J. Org. Chem. 5, 232-245 (2015). https://doi.org/10.4236/ijoc.2015.54023

7. Shagir, A.C., Bhuiyan, M.M.R., Ozeki, Y., Kawsar, S.M.A.: Simple and rapid synthesis of some nucleoside derivatives: structural and spectral characterization. Curr. Chem. Lett. 5, 83-92 (2016). https://doi.org/10.5267/j.ccl.2015.12.001

8. Rana, K.M., Ferdous, J., Hosen, A., Kawsar, S.M.A. Ribose moieties acylation and characterization of some cytidine analogs. J. Sib. Fed. Univ. Chem. 13, 465-478 (2020). https://doi.org/10. 17516/1998-2836-0199

9. Bulbul, M.Z.H., Chowdhury, T.S., Misbah, M.M.H.,Ferdous, J., Dey, S., Hasan, I., Fujii, Y., Ozeki. Y., Kawsar, S.M.A.: Synthesis of new series of pyrimidine nucleoside derivatives bearing the acyl moieties as potential antimicrobial agents. Pharmacia. 68, 23-34 (2020). https://doi.org/10.3897/pharmacia.68.e56543
10. Arifuzzaman, M., Islam, M.M., Rahman, M.M., Mohammad, A.R., Kawsar, S.M.A." An efficient approach to the synthesis of thymidine derivatives containing various acyl groups: characterization and antibacterial activities. ACTA Pharm. Sci. 56, 7-22 (2018). https://doi.org/10.23893/1307-2080.APS.05622

11. Maowa, J., Alam, A., Rana, K.M., Hosen, A., Dey, S., Hasan, I., Fujii, Y., Ozeki. Y., Kawsar, S.M.A.: Synthesis, characterization, synergistic antimicrobial properties and molecular docking of sugar modified uridine derivatives. Ovidius. Univ. Ann. Chem. 32, 6-21 (2021). https://doi.org/10.2478/auoc-2021-0002

12. Alam, A., Hosen, M.A., Hosen. A., Fujii, Y., Ozeki. Y., Kawsar, S.M.A.: Synthesis, characterization, and molecular docking against a receptor protein FimH of Escherichia coli (4XO8) of thymidine derivatives. J. Mex. Chem. Soc. 65, 256-276 (2021). https://doi. org/10.29356/jmcs.v65i1.1464

13. Rana, K.M., Maowa, J., Alam, A., Hosen, A., Dey, S., Hasan, I., Fujii, Y., Ozeki. Y., Kawsar, S.M.A.: In silico DFT study, molecular docking, and ADMET predictions of cytidine analogs with antimicrobial and anticancer properties. In Silico Pharmacol. 9, 1-24 (2021). https://doi.org/10.1007/s40203-021-00102-0

14. Farhana, Y., Amin, M.R., Hosen, A., Kawsar, S.M.A.: Bromobenzoylation of methyl $\alpha$-D-mannopyranoside: synthesis and spectral characterization. J. Sib. Fed. Univ. Chem. 14, 171-1838 (2021). https://doi.org/10.17516/1998-2836-0226

15. Devi, S.R., Jesmin, S.; Rahman, M., Manchur, M.A., Fujii, Y., Kanaly, R.A., Ozeki, Y., Kawsar, S.M.A.: Microbial efficacy and two step synthesis of uridine derivatives with spectral characterization. ACTA Pharm. Sci. 57, 47-68 (2019). https://doi.org/10. 23893/1307-2080.APS.05704

16. Alam, A., Hosen, M.A., Islam M., Ferdous, J., Fujii, Y., Ozeki. Y., Kawsar, S.M.A.: Synthesis, Antibacterial and cytotoxicity assessment of modified uridine molecules. Curr. Adv. Chem. Biochem. 6, 114-129 (2021). https://doi.org/10.9734/bpi/cacb/v6/8670D

17. Kawsar, S.M.A., Kumar, A.: Computational investigation of methyl $\alpha$-D-glucopyranoside derivatives as inhibitor against bacteria, fungi and COVID-19 (SARS-2). J. Chil. Chem. Soci. 66, 5206-5214 (2021)

18. Mirajul, M.I., Arifuzzaman, M., Monjur, M.R., Rahman, A., Kawsar, S.M.A.: Novel methyl 4,6-O-benzylidene- $\alpha$-Dglucopyranoside derivatives: synthesis, structural characterization and evaluation of antibacterial activities. Hacettepe J. Biol. Chem. 47, 153-164 (2019). https://doi.org/10.15671/hjbc.622038

19. Kawsar, S.M.A., Faruk, M.O., Rahman, M.S., Fujii, Y., Ozeki, Y.: Regioselective synthesis, characterization and antimicrobial activities of some new monosaccharide derivatives. Sci. Pharm. 82, 1-20 (2014). https://doi.org/10.3797/scipharm.1308-03

20. Agamennone, V., Le, N.G., Straalen, N.M., Brouwer, A., Roelofs, D. Antimicrobial activity and carbohydrate metabolism in the bacterial metagenome of the soil-living invertebrate Folsomia candida. Sci. Rep. 9, 7308 (2019). https://doi.org/10.1038/s41598-019-43828-w

21. Grzywacz, D., Liberek, B., Myszka, H.: Synthesis, modification and biological activity of diosgenyl $\beta$-d-glycosaminosides: An overview. Molecules 25, 5433 (2020). https://doi.org/10.3390/ molecules 25225433

22. Lu, H.: Drug treatment options for the 2019-new coronavirus (2019-nCoV). Biosci. Trends. 14, 69-71 (2020). https://doi.org/ 10.5582/bst.2020.01020

23. Kawsar, S.M.A., Hosen, M.A., Fujii, Y., Ozeki, Y.: Thermochemical, DFT, molecular docking and pharmacokinetic studies of methyl $\beta$-D-galactopyranoside esters. J. Comput. Chem. Mol. Model. 4, 452-462 (2020). https://doi.org/10.25177/JCCMM.4.4.RA.10663

24. Maowa, J., Hosen, M.A., Alam, A., Rana, K.M., Fujii, Y., Ozeki. Y., Kawsar, S.M.A.: Pharmacokinetics and molecular docking studies of uridine derivatives as SARS- COV-2 $\mathrm{M}^{\text {pro }}$ inhibitors. Phys. Chem. Res. 9, 385-412 (2021). https://doi.org/10.22036/ pcr.2021.264541.1869 
25. Farhana, Y., Amin, M.R., Hosen, M.A.; Bulbul, M.Z.H.; Dey, S., Kawsarm S.M.A.: Monosaccharide derivatives: Synthesis, antimicrobial, PASS, antiviral, and molecular docking studies against sarscov- $2 \mathrm{~m}^{\text {pro }}$ inhibitors. J. Cellul. Chem. Technol. 55, 477-499 (2021). https://doi.org/10.35812/CelluloseChemTechnol.2021.55.44

26. Bulbul, M.Z.H., Hosen, M.A., Ferdous, J., Misbah, M.M.H., Chowdhury, T.S., Kawsar, S.M.A.: Thermochemical, DFT study, physicochemical, molecular docking and ADMET predictions of some modified uridine derivatives. Int. J. New Chem. 8, 88-110 (2021). https://doi.org/10.22034/ijnc.2020.131337.1124

27. Kawsar, S.M.A., Hosen, M.A.: An optimization and pharmacokinetic studies of some thymidine derivatives. Turkish Comp. Theo. Chem. (TC\&TC). 4, 59-66 (2020). https://doi.org/10.33435/tcandtc.718807

28. Kawsar, S.M.A., Kabir, A.K.M.S., Manik, M.M., Hossain, M.K., Anwar, M.N.: Antibacterial and mycelial growth inhibition of some acylated derivatives of D-glucopyranoside. Int. J. Biosci. 2, 66-73 (2012)

29. Kabir, A.K.M.S., Matin, M.M., Kawsar, S.M.A.: Synthesis and antibacterial activities of some uridine derivatives. Chittagong Univ. J. Sci. 22, 13-18 (1998)

30. Clinical and Laboratory Standards Institute (CLSI). Performance Standards for Antimicrobial Disk Susceptibility Tests. 23rd informational supplement M100-S23, Wayne, USA, (2013)

31. Grover, R.K., Moore, J.D.: In-vitro efficacy of certain essential oils and plant extracts against three major pathogens of Jatropha curcas L. Phytopathology 52, 876-879 (1962)

32. Bauer, A.W., Kirby, W.M.M., Sherris, J.C., Truck, M.D.: Antibiotic susceptibility testing by a standardized single disk method. Am. J. Clin. Pathol. 45, 493-496 (1966). https://doi.org/10.1093/ ajcp/45.4_ts.493

33. Gaussian, R.A., Frisch, M.J., Trucks, G.W., Schlegel, H.B., Scuseria, G.E., Robb, M.A., Cheeseman, J.R., Scalmani, G., Barone, V., Mennucci, B., Petersson, G.A.: Gaussian, Inc, Wallingford CT. (2009)

34. Density-functional exchange-energy approximation with correct asymptotic behaviour: Becke, A.D. Phys. Rev. A. 38, 3098-3100 (1998). https://doi.org/10.1103/PhysRevA.38.3098

35. Lee, C., Yang, W., Parr, R.G.: Development of the colle-Salvetti correlation-energy formula into a functional of the electron density. Phys. Rev. B. 37, 785-789 (1988). https://doi.org/10.1103/ PhysRevB.37.785

36. Pearson, R.G.: Absolute electronegativity and hardness correlated with molecular orbital theory. Proc. Nat. Acad. Sci. 83, 84408441 (1986). https://doi.org/10.1103/PhysRevB.37.785

37. Kumaresan, S., Senthilkumar, V., Stephen, A.; Balakumar, B.S. GC-MS analysis and pass-assisted prediction of biological activity spectra of extract of Phomopsis sp. isolated from Andrographis paniculata. World J. Pharm. Res. 4, 1035-1053 (2015)

38. Berman, H.M., Westbrook, J., Feng, Z., Gilliland, G., Bhat, T.N, Weissig, H., Shindyalov, I.N., Bourne P.E.: The protein data bank. Nucleic Acids Res. 28, 235-242 (2000)

39. Delano, W.L.: The PyMOL molecular graphics system. de-lano scientific, San Carlos, CA, USA, 2002. http://www.pymolorg

40. Guex, N., Peitsch, M.C.: SWISS-MODEL and the Swiss-Pdb Viewer: An environment for comparative protein modeling. Electrophoresis 18, 2714-2723 (1997). https://doi.org/10.1002/elps. 1150181505

41. Dallakyan, S., Olson, A.J.: Small-molecule library screening by docking with PyRx. In: Hempel, J.E.; Williams, C.H.; Hong, C.C.; (eds.) Chemical biology: methods and protocols. Springer, New York, NY, 2015, 243-250. https://doi.org/10.1007/ 978-1-4939-2269-7

42. Version ADS 4.0, Accelrys, San Diego, USA, (2017)

43. Land, H., Humble, M.S.: YASARA: A tool to obtain structural guidance in biocatalytic investigations. Methods Mol. Biol. 1685, 43-67 (2018). https://doi.org/10.1007/978-1-4939-7366-8_4
44. Wang, J., Wolf, R.M., Caldwell, J.W., Kollman, P.A., Case, D.A.: Development and testing of a general Amber force field. J. Comput. Chem. 25, 1157-1174 (2004). https://doi.org/10.1002/jcc. 20035

45. Harrach, M.F., Drossel, B.: Structure and dynamics of TIP3P, TIP4P, and TIP5P water near smooth and atomistic walls of different hydroaffinity. J. Chem. Phys. 140, 174501 (2014). https:// doi.org/10.1063/1.4872239

46. Essmann, U., Perera, L., Berkowitz, M.L., Darden, T., Lee, H., Pedersen, L.G.: A smooth particle mesh Ewald method. J. Chem. Phys. 103, 8577-8593 (1995). https://doi.org/10.1063/1.470117

47. Harvey, M.J., De Fabritiis, G.: An implementation of the smooth particle mesh Ewald method on GPU hardware. J. Chem. Theory Comput. 5, 2371-2377 (2009). https://doi.org/10.1021/ct900275y

48. Krieger, E., Nielsen, J.E., Spronk, C.A.E.M., Vriend, G.: Fast empirical pKa prediction by Ewald summation. J. Mol. Graph. Model. 25, 481-486 (2006). https://doi.org/10.1016/j.jmgm.2006. 02.009

49. Krieger, E., Vriend, G.: New ways to boost molecular dynamics simulations. J. Comput. Chem. 36, 996-1007 (2015). https://doi. org/10.1002/jcc.23899

50. Mahmud, S., Biswas, S., Paul, G.K., Mita, M.A., Promi, M.M., Afrose, S., Hasan, R., Zaman, S., Uddin, S., Dhama, K.: Plantbased phytochemical screening by targeting main protease of SARS-CoV-2 to design effective potent inhibitors. Biology. 10, 589 (2021). https://doi.org/10.3390/biology10070589

51. Mahmud, S., Mita, M.A., Biswas, S., Paul, G.K., Promi, M.M., Afrose, S., Hasan, R., Shimu, S.S., Zaman, S., Uddin, S., Tallei, T.E., Emran, T.B., Saleh, A.: Molecular docking and dynamics study to explore phytochemical ligand molecules against the main protease of SARS-CoV-2 from extensive phytochemical datasets. Expert Rev. Clin. Pharmacol. 00, 1-11 (2021). https://doi.org/10. 1080/17512433.2021.1959318

52. Mahmud, S., Paul, G.K., Biswas, S., Afrose, S., Mita, M.A., Hasan, M.R., Shimu, M.S.S., Hossain, A., Promi, M.M., Ema, F.K., Chidambaram, K., Chandrasekaran, B., Alqahtani, A.M., Emran, T.B., Saleh, M.A.: Prospective role of peptide-based antiviral therapy against the main protease of SARS-CoV-2. Front. Mol. Biosci. 8, 628585 (2021). https://doi.org/10.3389/fmolb. 2021.628585

53. Cheng, F., Li, W., Zhou, Y., Shen, J., Wu, Z., Liu, G.: admetSAR: A comprehensive source and free tool for assessment of chemical ADMET properties. J. Chem. Inf. Mod. 52, 3099-3105 (2012). https://doi.org/10.1021/ci300367a

54. Lipinski, C.A., Lombardo, F., Dominy, B.W., Feeney, P.J.: Experimental and computational approaches to estimate solubility and permeability in drug discovery and development. Adv. Drug Deliv. Rev. 46, 3-25 (2021). https://doi.org/10.1016/s0169409x(00)00129-0

55. Hunt, W.A.: The effects of aliphatic alcohols on the biophysical and biochemical correlates of membrane function. Adv. Exp. Med. Biol. 56, 195-210 (1975). https://doi.org/10.1007/ 978-1-4684-7529-6_9

56. Cohen, N., Benson, S.W.: Estimation of heats of formation of organic compounds by additivity methods. Chem. Rev. 93, 24192438 (1993). https://doi.org/10.1021/cr00023a005

57. Lien, E.J., Guo, Z.R., Li, R.L., Su, C.T.: Use of dipole moment as a parameter in drug-receptor interaction and quantitative structure-activity relationship studies. J. Pharm. Sci. 71, 641-655 (1982). https://doi.org/10.1002/jps.2600710611

58. Saravanan, S., Balachandran, V.: Quantum chemical studies, natural bond orbital analysis and thermodynamic function of 2,5-dichlorophenylisocyanate. Spectrochimica Acta Part A: Mol. Biomol. Spectrosc. 120, 351-364 (2014). https://doi.org/10.1016/j. saa.2013.10.042 
59. Amin, M.L.: P-glycoprotein inhibition for optimal drug delivery. Drug Target Insight. 7, 27-34 (2013). https://doi.org/10.4137/ DTI.S12519

60. Politzer, P., Murray, J.S.: Molecular electrostatic potentials and chemical reactivity. Rev. Comput. Chem. 2, 273-312 (1991)

61. Politzer, P., Truhlar, D.G.: Chemical applications of atomic and molecular electrostatic potentials: reactivity, structure, scattering, and energetics of organic, inorganic, and biological systems. Springer Science \& Business Media, New York, (2013)

62. Perlstein, J.: The weak hydrogen bond in structural chemistry and biology. J. American Chem. Soc. 123, 191-192 (2001). https:// doi.org/10.1021/ja0047368
63. Liu, X., Wang, X.J.: Potential inhibitors against 2019-nCoV coronavirus $\mathrm{M}$ protease from clinically approved medicines. J. Genet. Genom. 7, 119-121 (2020). https://doi.org/10.1016/j.jgg.2020.02. 001

64. Pires, D.E.V., Blundell, T.L., Ascher, B.D.: pkCSM: Predicting small-molecule pharmacokinetic and toxicity properties using graph-based signatures. J. Med. Chem. 58, 4066-4072 (2015). https://doi.org/10.1021/acs.jmedchem.5b00104

Publisher's Note Springer Nature remains neutral with regard to jurisdictional claims in published maps and institutional affiliations.

\section{Authors and Affiliations}

\section{Md R. Amin ${ }^{1} \cdot$ Farhana Yasmin $^{1} \cdot$ Sujan Dey ${ }^{2} \cdot$ Shafi Mahmud $^{3} \cdot$ Md A. Saleh $^{3} \cdot$ Talha B. Emran $^{4} \cdot$ Imtiaj Hasan $^{5}$. Sultana Rajia ${ }^{6} \cdot$ Yukiko Ogawa $^{7} \cdot$ Yuki Fujii $^{7} \cdot$ Masao Yamada $^{8} \cdot$ Yasuhiro Ozeki $^{8} \odot$ - Sarkar M. A. Kawsar ${ }^{1}$}

1 Laboratory of Carbohydrate and Nucleoside Chemistry, Department of Chemistry, Faculty of Science, University of Chittagong, Chittagong-4331, Bangladesh

2 Department of Microbiology, Faculty of Biological Science, University of Chittagong, Chittagong 4331, Bangladesh

3 Microbiology Laboratory, Department of Genetic Engineering and Biotechnology, University of Rajshahi, Rajshahi 6205, Bangladesh

4 Department of Pharmacy, BGC Trust University Bangladesh, Chittagong-4381, Bangladesh
5 Department of Biochemistry and Molecular Biology, Faculty of Science, University of Rajshahi, Rajshahi-6205, Bangladesh

6 Center for Interdisciplinary Research, Varendra University, Rajshahi-6204, Bangladesh

7 School of Pharmaceutical Sciences, Nagasaki International University, Huis Ten Bosch-cho, Sasebo, Nagasaki 2825-7859-3298, Japan

8 School of Science, Yokohama City University, Kanazawa-ku, Yokohama, Seto 22-2236-0027, Japan 